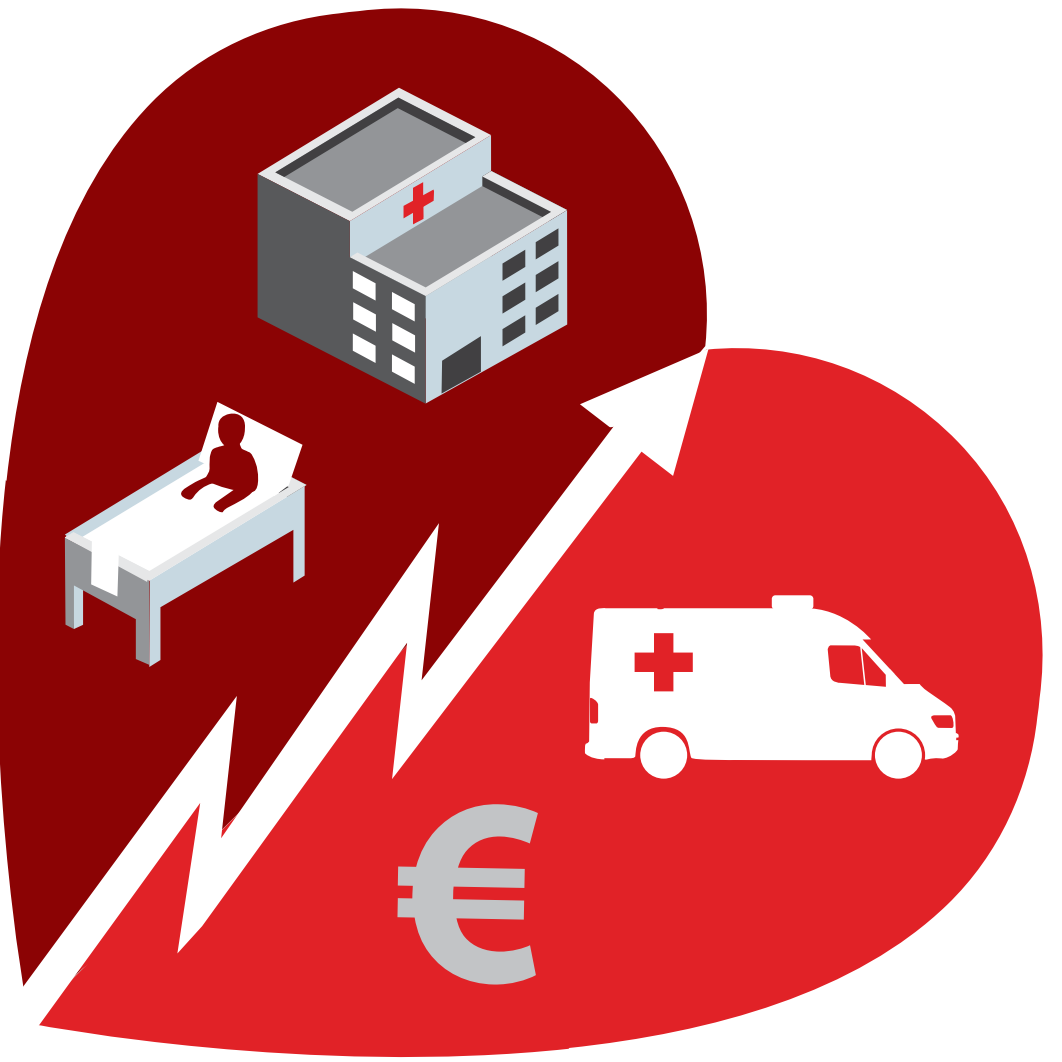

\title{
The Cost of Heart Failure in Ireland
}

The social, economic and health implications of Heart Failure in Ireland 


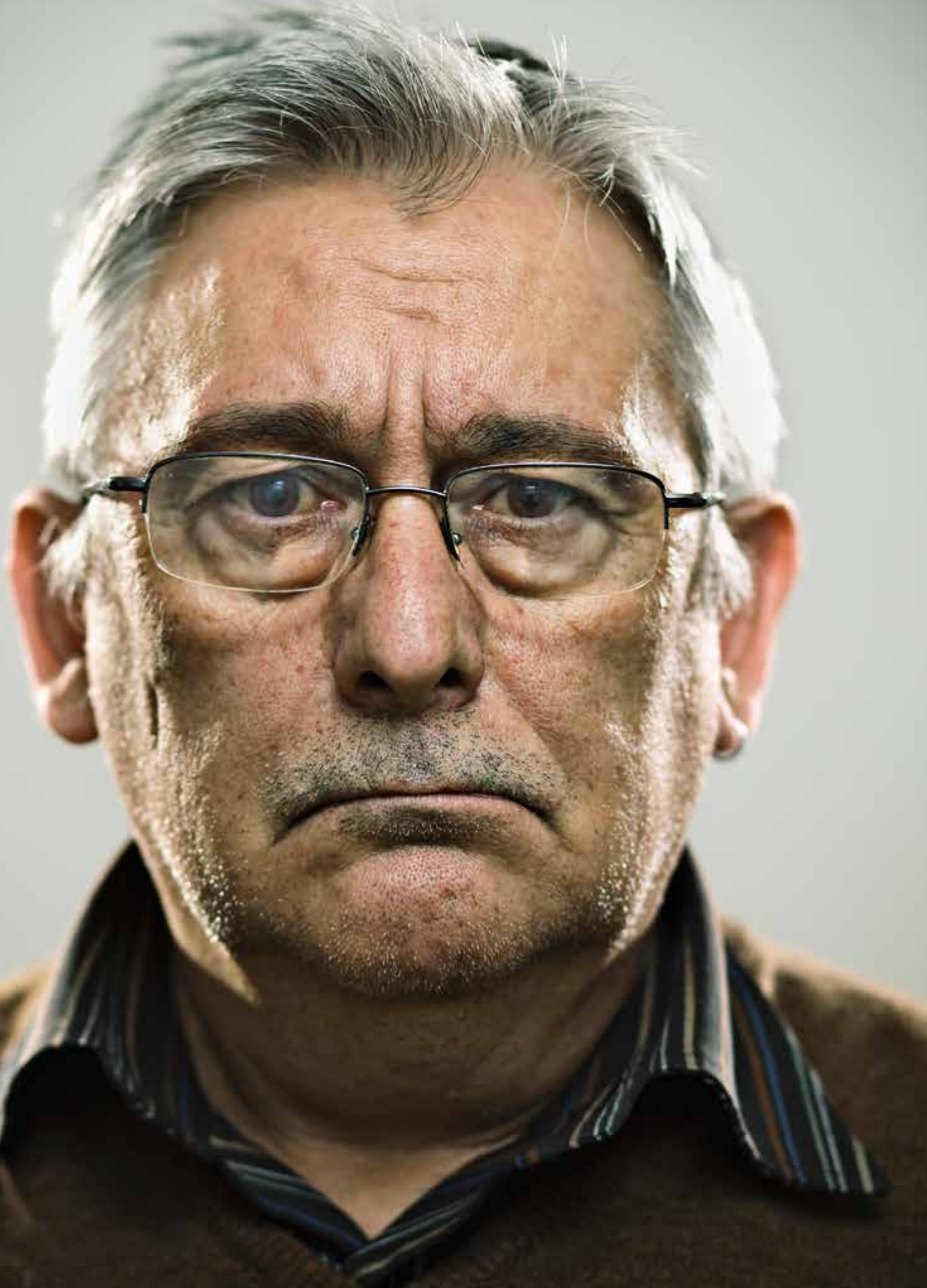




\section{The Cost of Heart Failure in Ireland}

The social, economic and health implications of Heart Failure in Ireland 


\section{Foreword}

We are delighted to introduce the Cost of Heart Failure Report; the first report to provide analysis on the cost of heart failure to the patient, healthcare system, and society in Ireland.

The data outlined in this report is significant and clearly states the impact this chronic disease has throughout primary and secondary care, and to Irish society.

The report found that the cost of heart failure amounts to $€ 660$ million each year. Currently there are 90,000 people in Ireland suffering with heart failure and another 160,000 people are living with impending heart failure. Feeding this epidemic of heart failure is the ageing population; better survival from myocardial infarction; continued suboptimal management of hypertension and improved prognosis for those with established heart failure. Heart failure will continue to produce significant morbidity and place an ever-increasing strain on healthcare resources.

According to the report, hospital-related costs are $47 \%$ of the total direct cost of heart failure. Heart failure takes a significant toll on hospital bed days, adding to the bed shortage crisis. Seven per cent of all HSE inpatient bed days are heart failure related. The total annual bed day for heart failure comes to 231,042 and the average length of stay is 11 days. Significantly, heart failure hospitalisations have increased three-fold and are expected to rise by more than $50 \%$ over the next 25 years.

The majority of the day-to-day care for heart failure takes place in general practice, particularly as this involves a predominantly older group of people with multiple illnesses.

According to the report primary care-related costs are $25 \%$ of the total direct cost of heart failure. The findings of the report demonstrate a profound regional disparity in heart failure patient services, data and outcomes nationwide. There is a need to provide and develop structured care for patients which links primary care and secondary care to manage this growing problem.

Approaches to heart failure have improved over the last few years in Ireland. The National Heart Failure Clinical Programme has carried out a significant amount of important work for patients living with heart failure, but there remains a lot more to be done. Focusing on heart failure prevention, the Heartbeat Trust has developed an effective screening and early intervention strategy to prevent heart failure and allied cardiovascular presentations in a cost effective manner. Notwithstanding these successes much more is required to manage this societal challenge.

We recommend this report is used to help identify problem areas in heart failure prevention and treatment within the community as well as areas where spending can be increased to better serve the patient and healthcare professionals. The healthcare system needs to develop and implement strategies to cope with the associated cost of increased incidence, and do what it can now to prevent and manage heart failure incidence in the future.

We ask that the findings of this report are carefully considered and used to improve heart failure care and services for patients, in order to improve the healthcare system and result in reduced costs and efficiencies.

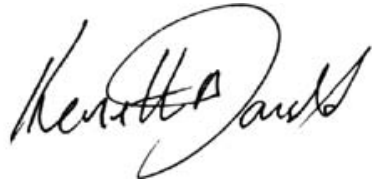

Professor Kenneth McDonald

Consultant Cardiologist, St. Vincent's Hospital, Dublin, Clinical Lead for the National Heart Failure Clinical Care Programme and President of the Irish Cardiac Society

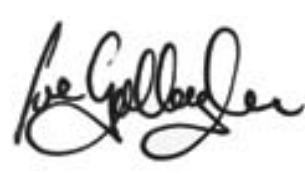

\author{
Dr Joe Gallagher \\ General Practitioner, \\ Gorey, Co. Wexford
}




\section{Foreword}

We in the Irish Heart Foundation welcome this report on the Cost of Heart Failure. We would like to thank all the other organisations involved including the Heartbeat Trust, National University of Ireland Galway and Novartis Ireland.

We know first-hand from patients of the harsh impact that heart failure has on quality of life and the report presents hard facts in support of this. Some 80 per cent of heart failure patients suffer from physical symptoms such as severe breathlessness and fatigue. Patients with heart failure are also less able to work, or to participate in social activities. They are also likely to suffer from depression and social isolation. Worryingly only seven per cent of people can identify the common signs of heart failure, with people often mistaking them for the signs of aging.

The incidence of heart failure is set to increase in the coming years due in part to an aging population so it is important to plan now for the future. This report highlights the considerable strain that heart failure puts on the Irish health service and the regional disparities in terms of care.

One of the recommendations of the report is to ensure patients with potential symptoms of heart failure are diagnosed without delay, no matter where they live in the country. The report highlights the need for equitable and rapid access to community and, if appropriate, hospital diagnostic services.

Ultimately, we would like to ensure optimum methods of care for heart failure patients and to allow patients to be cared for in their own communities where possible, away from the acute hospital setting.

Awareness levels are low. We need to inform, encourage and educate specific groups on making healthier lifestyle choices in the hope of reducing heart failure prevalence and improving quality of life.

The Irish Heart Foundation hopes this research will help ensure provision of resources for optimum care and management of heart failure patients throughout Ireland.

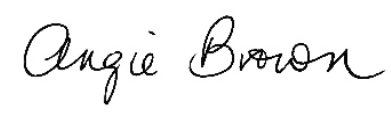

Dr Angie Brown, Consultant Cardiologist, Medical Director, Irish Heart Foundation 


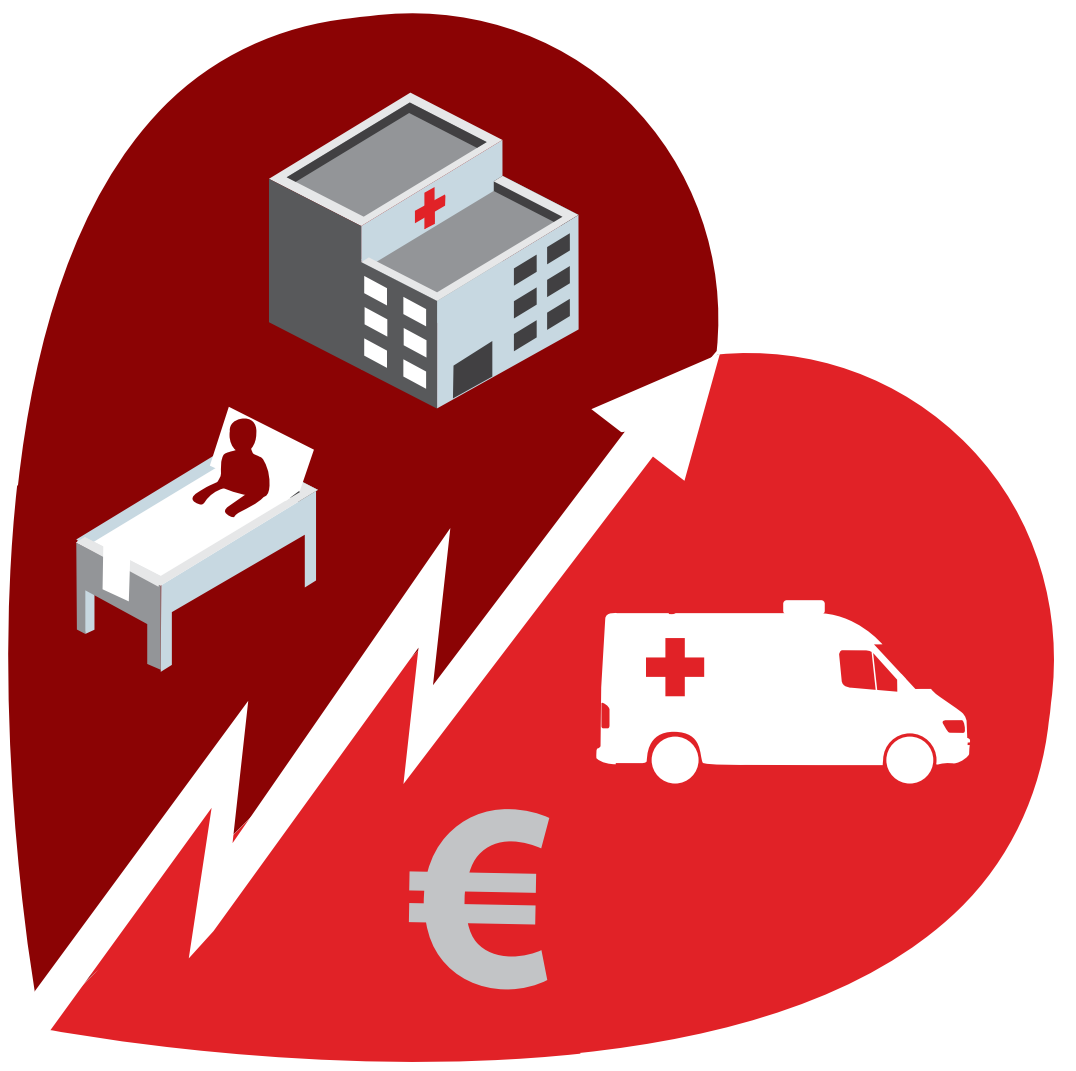




\section{Table of Contents}

Infographic

Key findings

Introduction

1.1 Aims and objectives

2 Disease overview

2.1 Defining the disease

2.2 Risk Factors

3 Current guidelines for the management of CHF

4 Epidemiology

4.1 Prevalence

4.2 Incidence

5 Human burden of HF

5.1 Morbidity

5.2 Mortality

5.3 Inpatient mortality

5.4 Mortalities in the Community

6 Global Economic Burden

6.1 Ireland 
7.2 Healthcare expenditure: Primary Care

7.3 Hospital Expenditure; Secondary care

7.3.1 Hospital inpatient activity

7.4 Out Patient Department visit

7.5 Incidence Population (suspected HF)

8 Drug Treatment/prescriptions

8.1 Non Healthcare expenditure: Methodology

8.1.1 Informal care

8.1.2 Life years lost

9.1 Direct Costs

9.2 Indirect expenditure: Non healthcare

10 Sensitivity analysis

11 Limitations

12 Discussion 
14.1 Appendix A: Disease overview

14.2 Appendix B: Chronic and Acute heart failure treatment guidelines

14.3 Appendix C: International prevalence and incidence

14.4 Appendix D: Co-morbidity Variation in the EU \& US registries

14.5 Appendix E: Primary and All case HF diagnoses

14.6 Appendix F: Global economic Burden of HF

14.7 Appendix G: IMS analysis

14.8 Appendix H: Professional Curiosity (2013)

14.9 Appendix I: Estimated prevalence of HF in Ireland (2007)

14.10 Appendix J: Cost of Illness Review

14.11 Appendix k: Treatment pathways

Acknowledgments: We are grateful to Professor Kenneth McDonald (Clinical Lead for Heart Failure; Cardiologist, St Vincent's University Hospital), Dr. Joe Gallagher, (G.P., Gorey, Co. Wexford), Brendan Kennelly (Programme Director M. Sc. (Health Economics) at NUI Galway), Dr. Caroline Daly (Consultant Cardiologist, St. James's Hospital) and Dr. Roisin Morgan, (Cardiology SpR, St. James's Hospital), David Farrell (Heart Failure Nurse, Beaumont Hospital), Dr. Claire Collins (Director ICGP Research Group), Karen Cradock (Allied Health Professionals Rep, Physiotherapy, on the National Heart Failure Clinical Programme), The Central Statistics Office, Dublin, The Irish Heart Foundation (IHF), and Heartbeat Trust.

Declaration of Interest: The funding for this report was provided by Novartis Ireland Ltd. 


\section{The Cost of \\ Heart Failure in Ireland}

Hospital related costs are

$47 \%$ of total direct cost

7\% of all HSE inpatient bed days
are Heart Failure related $^{\mathrm{a}}$

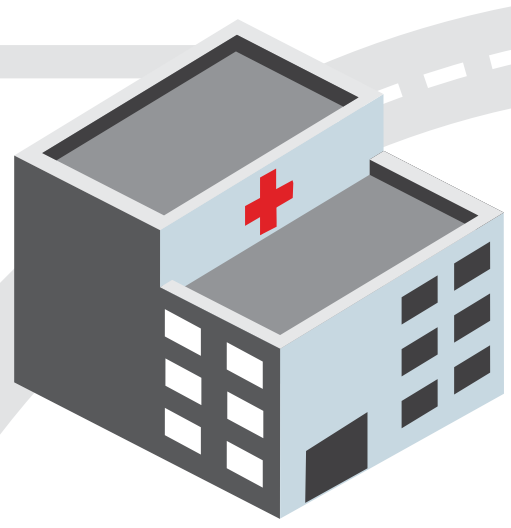

231,042 Total hospital

11 days $\begin{gathered}\text { The average length } \\ \text { of hopital say }\end{gathered}$

\section{High re-admission rates}
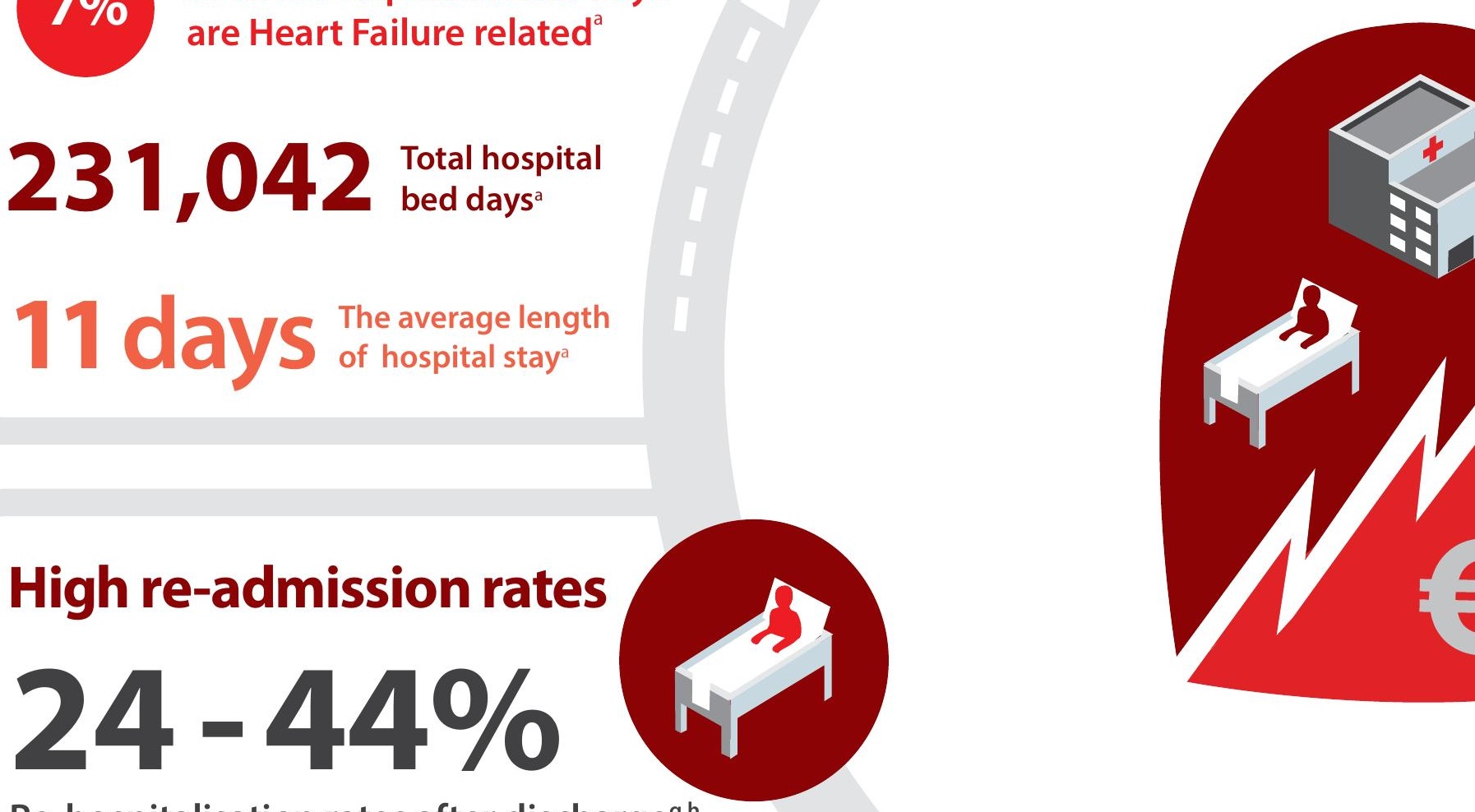

Re-hospitalisation rates after discharge ${ }^{g, h}$

Heart Failure hospitalisations:

- have increased 3 fold $^{f}$ expected to rise by more than $50 \%$ over the next 25 years $^{\mathrm{e}}$ 


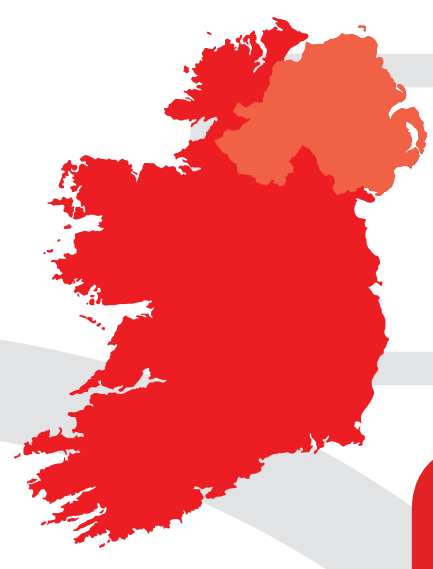

\section{The total cost of Heart Failure} is estimated at $=6000$

"... it felt like I was drowning"

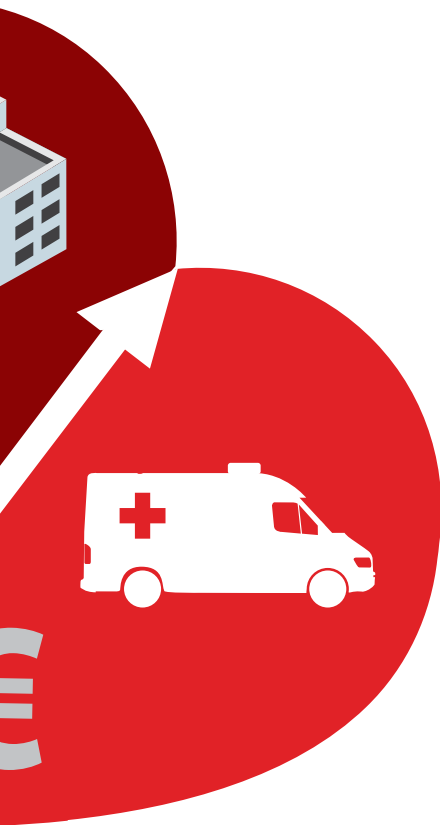

Quality of Life

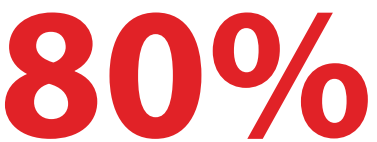

suffer from symptoms such as severe breathlessness and fatigue ${ }^{b}$

Patients are less able to work/participate in social activities, and are likely to suffer from depression and social isolationc

\section{Primary care}

related costs* account for

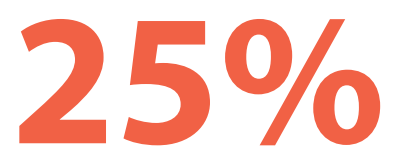

of total direct cost ${ }^{* *}$ of Heart Failure ${ }^{a}$

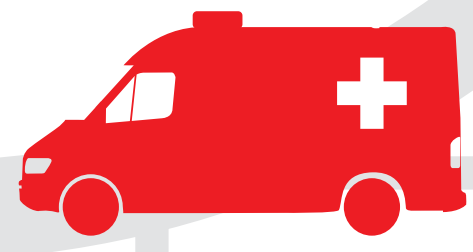

Findings of the report demonstrate "a profound regional disparity in Heart Failure patient data, services and outcomes nationwide" a

\section{Medication}

Drug costs account for

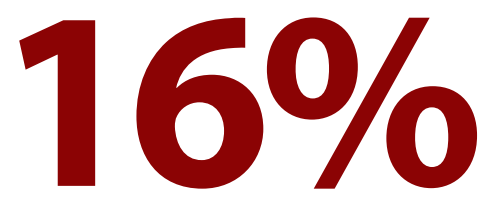

of total direct cost of Heart Failure ${ }^{a}$ 


\section{0,000}

people in Ireland suffer with Heart Failure

160,000 people with impending (asymptomatic) Heart Failure

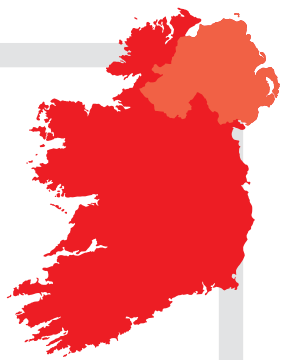

The prevalance of Heart Failure is set to increase ${ }^{k}$

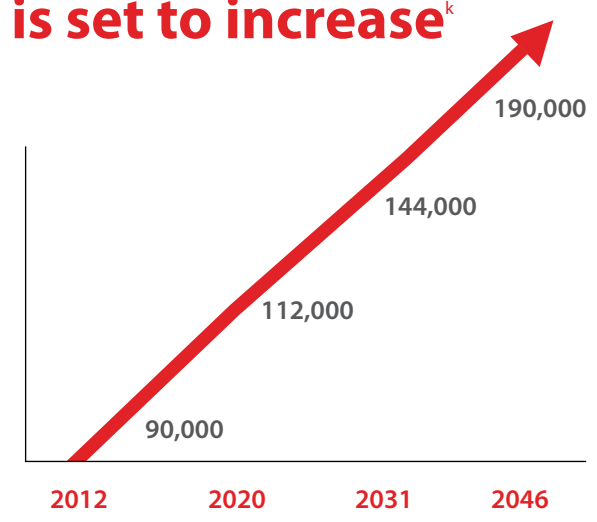

new cases of Heart Failure each year

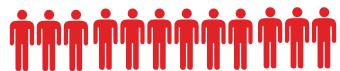

\section{Lack of awareness of signs and symptoms}

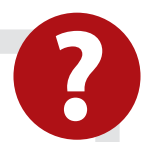

The prevalence and cost of Heart Failure is set to increase due to:

- an ageing population

- 62\% increase in diabetes

- 50\% increase in Coronary Artery Disease (CAD) ${ }^{1}$

- $\mathbf{7 \%}$ people can identify the common symptoms of Heart Failure. ${ }^{j}$

- 1 in 4 people with symptoms would wait a week or more to seek medical advice, or not seek medical advice at all. ${ }^{j}$

- $\mathbf{8 4 \%}$ of people incorrectly thought patients with heart failure live longer than those with cancer, heart attack or stroke. ${ }^{j}$

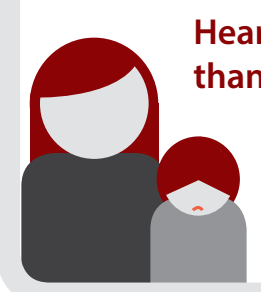

Heart Failure causes more deaths than Breast and Bowel cancer

Patients report greater physical impairment than patients with arthritis and chronic lung disease $\mathrm{m}^{\mathrm{m}}$

\section{Recommendations:}

1. Include Heart Failure within existing chronic disease policies and ensure there are sufficient resources to implement the National Clinical Programme for Heart Failure (HSE) on a national level

2. Ensure patients with potential symptoms of Heart Failure are diagnosed without delay, with equitable and rapid access to community and if appropriate, hospital diagnostic services

3. Patients with diagnosed Heart Failure should have access to appropriate treatment and follow up

4. Implement a Heart Failure prevention and early detection strategy (i.e. screening to prevent Heart Failure for high risk people)."

H Attributed to Prof. Ken Mc Donald, Consultant Cardiologist \& Clinical Lead for the HSE Heart Failure Clinical Care programme and Dr. Angie Brown, Consultant Cardiologist \& Medical Director of the Irish Heart Foundation 


\section{Key findings}

The total cost of Heart Failure (HF) in the Republic of Ireland in the year 2012, from a societal perspective, is estimated at approximately $€ 660 \mathrm{~m}$.

- The direct cost of HF to the Health Service Executive (HSE) was $€ 158 \mathrm{~m}$. This represented $1.2 \%$ of the healthcare budget in 2012. The gross current estimate for the HSE was $€ 13,317 \mathrm{~m}$ as set out in the published estimates of receipts and expenditure (1).

- Direct costs can be further categorised as the monetary and percentage value of the total direct costs. These include hospitalisations $€ 42,943,087$ (27.2\%), General Practitioner (GP) appointments $€ 40,093,486$ (25.4\%), drug cost $€ 26,137,255$ (16.5\%), nursing home care $€ 17,925,376$ (11.3\%), diagnostic investigation $€ 11,161,663$ (7.1\%), Out-Patient Department (OPD) appointments $€ 12,638,660$ (8\%), heart transplant procedures $€ 2,925,583$ (1.9\%), clinical specialist assessment $€ 3,275,023(2.1 \%)$, ambulance $€ 876,817$ (0.6\%), cardiac rehabilitation $€ 29,722(0.02 \%)$.

- HF is one of the most common causes of admission to a medical facility in Ireland for patients aged 65 years and older (2), accounting for $30 \%$ of a cardiologist's workload (3).

Less than $1 \%$ of patients are referred for cardiac rehabilitative services.

$\Rightarrow \quad$ HF related admissions account for 4\% of inpatient admissions and for 7\% of all HSE inpatient bed days in the year 2012.

Current spending on cardiovascular health accounts for only $6 \%$ of the healthcare budget- this is lower than the EU27 average of $10 \%$ (4).

$\Rightarrow \quad$ HF was responsible for 537 deaths in Ireland in 2012; this equates to 3,683 of potential life years lost, and 46 full lifetimes lost per annum - the economic value of these premature deaths is estimated to be over $€ 134 \mathrm{~m}$.

26,783 disability-adjusted life years (DALYs) are lost annually due to HF in Ireland.

$\Rightarrow$ Current policy favours a shift of care from hospitals to primary care for chronic disease such as HF. The demand on the HSE budget is such that limited additional resources are available for such a transition, with an estimated 3.6\% of the healthcare budget in 2012 allocated to primary care $(1,5)$.

- Ireland's national HF programme stipulates that every patient with symptoms of heart failure is diagnosed correctly and without delay, but this is aspirational at present and mainly dependent on the availability of resources.

$\Rightarrow \quad$ The cost of HF in Ireland over coming decades is very likely to expand, as the main precipitating factors of $\mathrm{HF}$ are predicted to increase. The Institute of Public Health (IPH) has predicted a $40 \%$ increase in blood pressure (i.e. hypertension), $62 \%$ increase in diabetes, $48 \%$ increase in stroke and a $50 \%$ increase in Coronary Artery Disease (CAD) (6). All these play an important role in the incidence of HF.

- Cardiovascular conditions are one of the leading health concerns of older people and have a dramatic consequence on Quality of Life (QoL) as a result of the pain and loss of independence involved.

Informal care is estimated at $€ 364.2 \mathrm{~m}$ and represents the largest component of the cost of HF.

- The geographic distribution of expenditure is evident in post discharge clinics and rehabilitative centres nationwide. In some areas, catchment boundaries have remained unchanged for decades, with little recognition of demographic transformation. The result is wide variability in the provision of services. This variability is confirmed by an analysis which assessed patient outcomes and service capacity in public and private hospitals. 


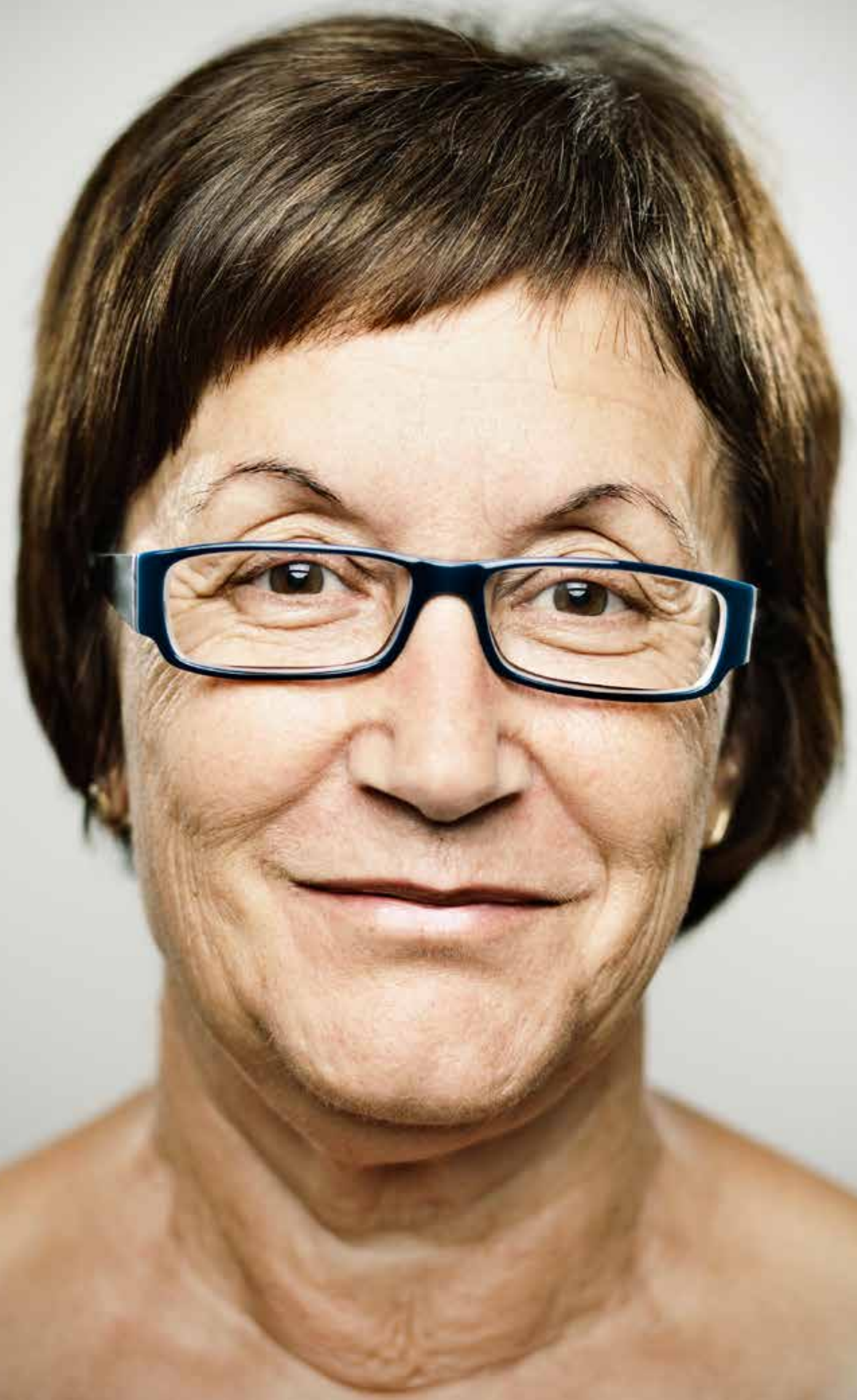




\section{Introduction}

Numerous cost-of-illness studies have been conducted in Ireland in a wide variety of chronic conditions over the past 30 years. Although there are many Irish scientific publications detailing the risk factors, symptoms, course and outcomes of Heart failure (HF) as well as numerous personal accounts, there has only been one health economics publication assessing the cost of inpatient HF care in 2000 (7). No estimate of the national cost of heart failure in primary or community care settings has been assessed to date. It is the aim of this report to address this information requirement so as to advise future policy and resource decisions.

According to the World Health Organisation (WHO), 'the cost to the world of the current and projected epidemic of chronic disease ... dwarfs all other health costs' (8), and will be the leading cause of disability by 2020 unless successfully managed (9). In 2011, chronic disease accounted for $86 \%$ of all deaths in Ireland - chiefly cardiovascular diseases, cancers, chronic respiratory diseases and diabetes (10). Moreover, chronic diseases are having an effect throughout the age distribution and already one-quarter of all chronic disease related deaths are among people below the age of 60 (11). Current adverse health trends in Ireland are similar to those causing concern in other developed countries. These include significant increases in the levels of chronic disease, exposure to health risks, and in particular, those recognised in the genesis of Heart Failure (HF) $(4,6)$. If these patterns continue, they threaten to reverse the declining trend in cardiovascular disease mortality of recent decades (4).

$\mathrm{HF}$ is one such chronic cardiovascular condition. It is described as an abnormality of cardiac structure or function leading to failure of the heart to deliver oxygen at a rate commensurate with the requirements of the metabolising tissues, despite normal filling pressures (or only at the expense of increased filling pressures) (12). Many patients experience episodes of Acute Heart Failure (AHF) which are life-threatening events requiring urgent medical attention and can mark a transition to a more debilitating phase of the disease. Over time, most patients experience multiple episodes of AHF, which typically become more frequent and separated by shorter intervals as the ability of the heart to recover declinesi. These episodes place increased demand on healthcare resources.

One in five men and women will develop HF over their lifetime (13), with a markedly higher incidence in older age groups despite a shorter remaining lifespan (14). HF affects between 1 and $2 \%$ of the population in developed countries, with similar or higher proportions reported in single-centre studies (15-21). The prevalence rises steeply with increasing age, particularly from 50 years and onwards (22), affecting approximately $10 \%$ of those aged 75 years or older (23). In Ireland, it is estimated that HF affects approximately 90,000 people, with as many having significant impairment of heart function without symptoms of heart failure, but at high risk of future development of this syndrome $(2,24)$.

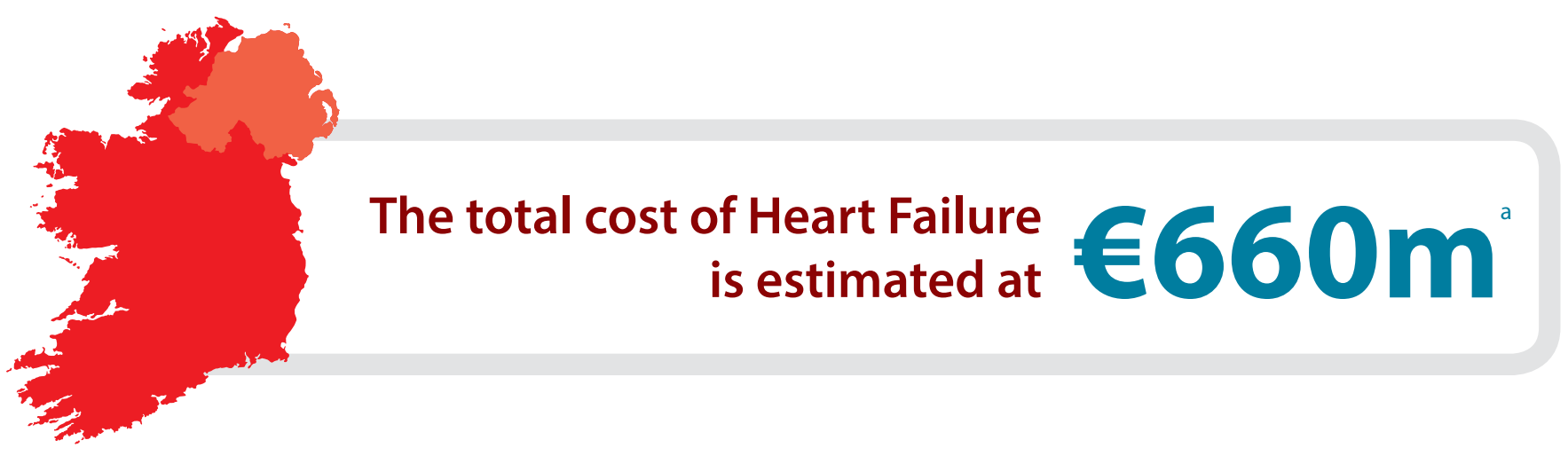


The incidence of HF is expected to increase substantially over the next 30 years (25), and despite this, Ireland's public awareness is strikingly low (see Discussion for further detail). The Department of Health (DoH) warns of "a potential epidemic of heart failure in Ireland over the next 10 years" (4), arising from increasingly successful therapies, improved survival rates from Myocardial Infarction (MI) and prevention of sudden cardiac death, and a rise in the number of older people during this time. $\mathrm{HF}$ is one of the most rapidly growing cardiovascular diseases (26) and is now the only major cardiovascular disease on the increase in Europe (27).

HF is estimated to cost between 1 and $2.5 \%$ of healthcare expenditure (28-30). In Ireland, HF accounted for between $1.2 \%$ and $2.1 \%$ of healthcare expenditure in $2012^{i i}$, and accounts for approximately $30 \%$ of a cardiologist's workload (3). A significant part of this cost is due to high hospital admission rates. $\mathrm{HF}$ is the most common cause of admission to a medical facility in patients aged 65 years and older $(2,31,32)$. While hospitalisations for most other cardiovascular conditions have remained static or decreased over the past number of decades (33), hospitalisations attributable to HF have increased three fold (34), and are expected to rise by more than $50 \%$ over the next 25 years (30).

The DoH found that HF and stroke accounted for the greatest bed use from 1998-2008 among all cardiovascular conditions in the Irish hospital setting. HF accounted for $42.6 \%$ of all cardiovascular disease bed days, and $35 \%$ of in-patient stays (the rest were attributable to Coronary Heart Disease (CHD), stroke and Transient Ischemic Attack (TIA), peripheral arterial disease) $(4,33)$. Bed days required by HF patients rose by $7.1 \%$ over a 10 year period despite changing practices, such as day cases increasing by $67 \%$ in 2006 (33). A more recent analysis of the Hospital In-Patient Enquiry (HIPE) system (35) suggests HF related admissions $s^{\text {iii account }}$ for approximately $4 \%$ of all inpatient hospital admissions, and $7.3 \%$ iv of all HSE bed days in $2012^{v}$.

Despite improvements in care over the past 20 years, the outlook for patients with $\mathrm{HF}$ remains grim, and survival rates remain poor. Mortality and survival rates differ between chronic and acute phases of this debilitating condition. In the first year of diagnosis, 30 to $40 \%$ of patients will die from this condition and thereafter the mortality rate decreases to $10 \%$ per year (36, 37). Patients in the AHF phase of the disease have a high risk of mortality, with European Union (EU) and the United States (US) outcome data confirming an in-hospital mortality rate between 4 and 11\% (38-41). In Ireland, among all cardiovascular diseases in 2008, patients admitted with HF had the second highest mortality rate (11.8\%) following stroke (14.1\%) (4). Today, 1 in 13 admissions will die from HF during their inpatient admission (35). However, James et al. (42) established that, with access to timely diagnosis with appropriate medical management and follow up services, the mortality rate can be reduced significantly in the first year following diagnosis.

Yet, as the disease progresses over time, the human burden becomes evident. Fear, anxiety, and depression are common (43), as the negative consequences of HF extend to activities such as sleep (44), sexual function (45) and mental health (46). Between 21 to $55 \%$ of patients develop severe and prolonged depression $(43,47)$, and between 50 and $70 \%$ of HF patients report anxiety levels $60 \%$ higher than those without cardiac disease $(48,49)$. Consequently, this can increase the management and monitoring complexity for both patients and physicians, with patients reporting high levels of psychological distress and difficulties adhering to treatment regimens.

Work, travel and day-to-day social and leisure activities are difficult for those with breathlessness and extreme fatigue (50), as over $80 \%$ of HF patients suffer from physical symptoms such as dyspnoea, fatigue, oedema, sleeping difficulties, and chest pain $(51,52)$. Patients report, on average, greater physical impairment than that incurred by patients with arthritis and chronic lung disease (53). Symptom burden adversely affects Quality of Life (QOL) (54-57), although the emotional, physical and financial costs are also high for caregivers (58).

In spite of the human and economic burden associated with HF, the OECD (2012) estimated that only $3 \%$ of total healthcare expenditure goes towards population wide prevention and public health programmes. Although cardiovascular mortality has reduced significantly during the past two decades in Ireland, HF remains the 'Cinderella' of cardiovascular diseases, receiving

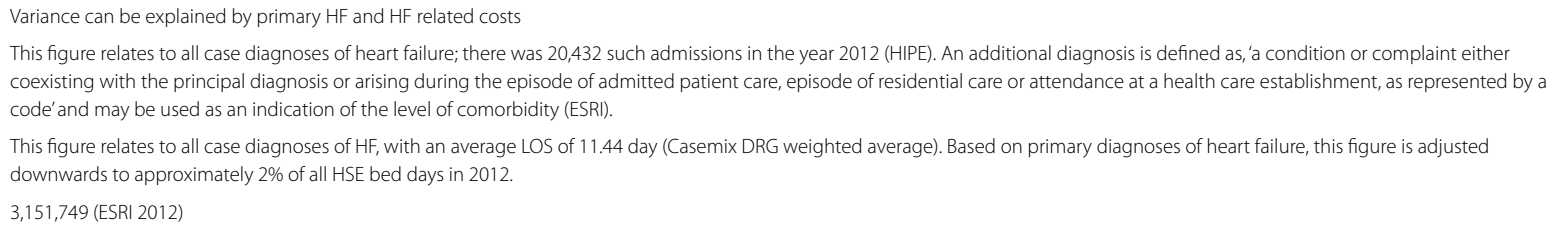


proportionally less consideration than the management of acute coronary syndromes and arrhythmia (59). The first National Cardiovascular Health Strategy, Building Healthier Hearts, was launched in 1999. The revised policy document covers the period 2010 to 2019 (4). It addresses the full spectrum of cardiovascular disease and stroke, including the prevention and management of these conditions. A requisite for a partnership approach in all of the actions set out by recent policy in this area is evidenced in Changing Cardiovascular Health, as it stipulates, "A policy that can improve cardiovascular health and cardiovascular disease management will have beneficial effects for the whole healthcare system and population" (4).

Generally speaking, Cost-of-Illness (Col) studies are not considered full economic evaluations because they do not assess actions to address a problem (60). However, Col studies can highlight the importance of health issues in society, and in some cases, estimates are broken down to show the distribution of disease costs across healthcare services and payers, which can help demonstrate the burden borne by specific stakeholders (61). In light of the seriousness of this disease, both in human and financial terms, the aim of this report is to estimate the overall economic cost of HF in Ireland, and thereby contribute to improved resource allocation in this area. In doing so, this report examines the overall course of disease, current treatment interventions, national and international epidemiology, and the burden of disease (both in human and economic terms), before introducing the methods and results of this report, followed by a discussion, report limitations and conclusion.

\subsection{Aims and objectives}

Using a prevalence based methodology, it is the aim of this report to;

1. Estimate the extent of the HF burden in primary and secondary health care settings in Ireland.

2. Describe the complex healthcare trajectories followed by patients with suspected (incidence) or diagnosed (prevalence) $\mathrm{HF}$ in Ireland. Prevalence treatment trajectories are assessed both in the acute and chronic stages of the disease.

3. Describe the financial and social impact of acute and chronic HF on patients, their families, caregivers, and society.

\section{0,000} people in Ireland suffer with Heart Failure
160,000 people with impending (asymptomatic) Heart Failure ${ }^{\mathrm{i}}$

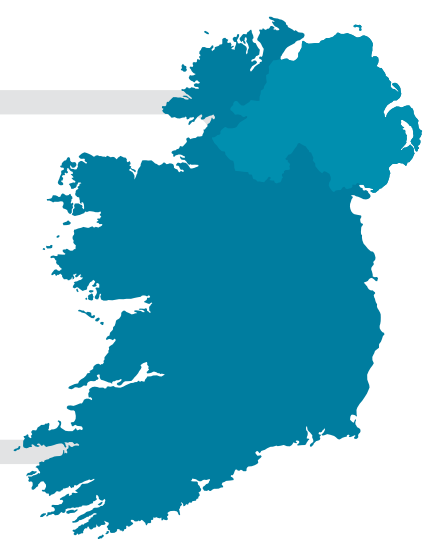




\section{Disease overview}

\subsection{Defining the disease}

$\mathrm{HF}$ is an abnormality of cardiac function and structure (with a progressive weakening of the heart muscle), characterised by its inability to pump adequate amounts of blood needed to perfuse organs and other tissues. HF can be classified as acute or chronic, with chronic being the most common form (62). Chronic Heart Failure (CHF) involves persistent signs and symptoms of HF that may be stable, worsen or become decompensated over time $(62,63)$. Alternatively, HF may present acutely, and is defined as the rapid onset or change in the signs and symptoms of $\mathrm{HF}$, resulting in the need for urgent therapy (63). The progression to acute HF results in the need for hospitalisation (77) (64). Unlike CHF, AHF does not allow time for the heart to adapt through cardiac remodelling and hypertrophy.

Table 1. European Society of Cardiology (ESC) definition of Heart Failure

\begin{tabular}{|l|l|}
\hline Symptoms typical of HF & Fatigue, tiredness, ankle swelling, and/or breathlessness at rest or on exercise \\
\hline Signs typical of HF & $\begin{array}{l}\text { Tachycardia, tachypnoea, pulmonary rales, pleural effusion, raised jugular venous } \\
\text { pressure, peripheral oedema, hepatomegaly, third heart sound, cardiac murmurs. }\end{array}$ \\
\hline $\begin{array}{l}\text { Objective evidence of a structural or } \\
\text { functional abnormality of the heart at rest }\end{array}$ & $\begin{array}{l}\text { Cardiomegaly, abnormality on echocardiogram, raised natriuretic peptide (NP) } \\
\text { concentrations }\end{array}$ \\
\hline
\end{tabular}

Source: Dickstein et al., 2008 (63) McMurray et al.,2012 (23) Swedberg, K., et al., 2005 (65) McDonald 2013 (12), Yancy et al., (77).

Current treatment options address symptoms such as fluid retention and breathlessness and offer an improvement in heart function, however survival rates remain poor. Once established, the deterioration in the heart's condition can often be managed, but typically cannot be reversed. Therefore, preventing HF is of paramount importance.

CHF can be classified based on Left Ventricular Ejection Fraction (LVEF), which is either reduced (HF-rEF) or preserved (HF-pEF). HF patients may have HF-pEF (diastolic HF; the heart muscle cannot relax adequately during ventricular filling) or HF-rEF (systolic $\mathrm{HF}$; the heart muscle cannot contract properly and less oxygen-rich blood is pumped out to the body).

Approximately half of patients presenting with symptoms of HF have preserved LVEF $(>50 \%)^{v i}$, which is referred to as HF-pEF (63). Approximately $20 \%$ of patients with HF have definite HF-pEFvii and $30 \%$ uncertain HF-pEF, leaving approximately $50 \%$ with definite HF with reduced ejection fraction (HF-rEF). HF-pEF is most prevalent among older women, with hypertension and/or diabetes mellitus and often coronary artery disease or atrial fibrillation $(77,23)(64)$. The prevalence of HF-pEF is increasing (66).

It is important to note that no single diagnostic test for HF exists; diagnosis relies on clinical judgment based on patient history, physical examination and selected investigations $(30,62,63,67,68)$. Inherent difficulties exist when making an accurate diagnosis of HF-pEF due to the lack of standardisation and inconsistency in the application of diagnostic criteria and, in particular, the LVEF cut off point (69). Similarly, the potential for misdiagnosis in elderly and overweight patients can limit the precision of these estimates (70). Consequently, the proportion of HF-pEF to HF-rEF varies greatly between studies.

The importance of this distinction is most relevant when choosing treatment options ${ }^{\text {viii, }}$, and the probability of a patient's subsequent response ${ }^{i x}$. For example, Angiotensin II Receptor Blockers (ARBs) have been reported to provide benefit in patients with HF-rEF $(71,72)$, but not in patients with $\operatorname{HF}-p E F(73,74)$. Over the last decade, advances in pharmacotherapy have led to a significant reduction in death from HF-rEF, whereas the mortality rate from HF-pEF remained unchanged over the same period $(69,75)$.

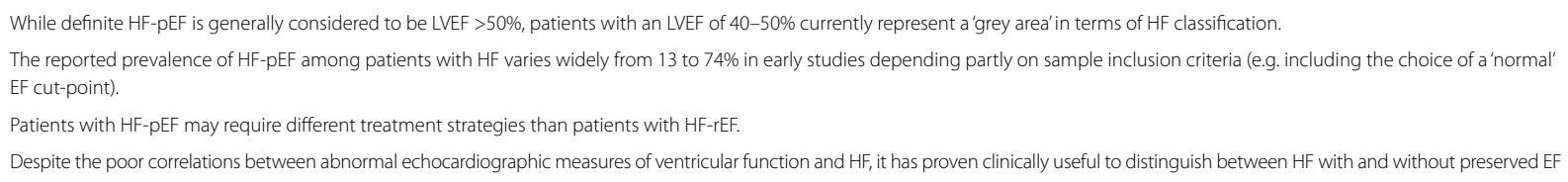




\subsection{Risk Factors}

Several issues have been identified that increase the risk of individuals developing HF, although the exact rank order of these factors and whether they differ in importance between sexes and races is still uncertain (12). They include

1) Age

2) Hypertension (high blood pressure)

3) Coronary Artery Disease (CAD)

4) Valvular Heart Disease

5) Atherosclerosis (build-up of fats, cholesterol, and other substances in and on your artery walls, plaques)

6) Diabetes

7) Obesity

8) Hyperlipidaemia (high levels of fat in the blood)

9) Physical Inactivity

10) Kidney Disease

11) Exessive Alcohol Intake

12) Smoking 


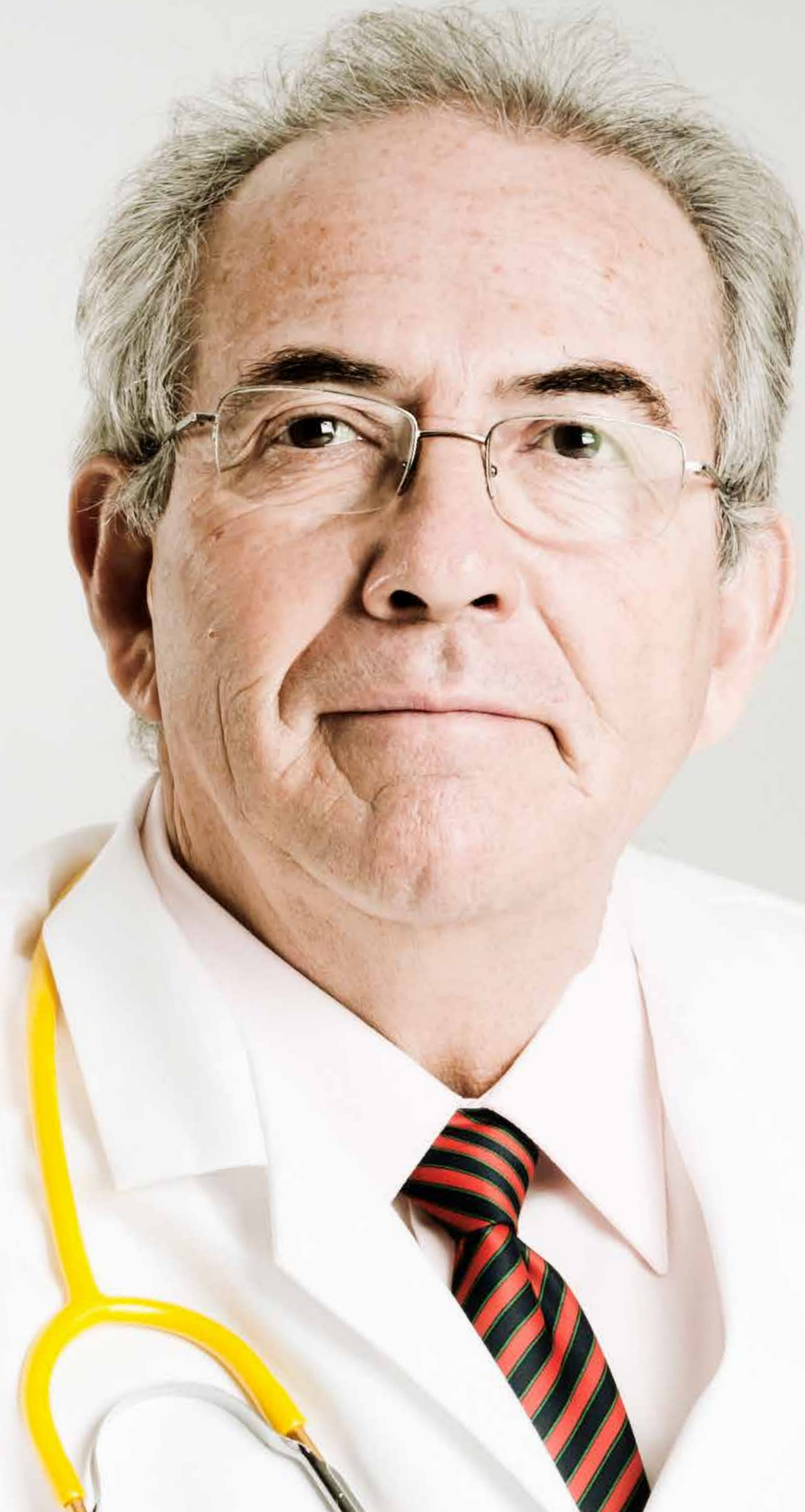




\section{Current guidelines for the management of HF}

Compliance with clinical practice guidelines is associated with improved outcomes for patients with HF. However in many countries, including Ireland, there is a considerable variation in how closely guideline recommendations are followed.

The general recommended aims of treatment for AHF are to:

Provide symptom relief as quickly as possible after admission to hospital

$\rightarrow$ Optimise treatment

Minimise side effects

Minimise hospital Length of Stay (LoS)

Plan longer term care after discharge from hospital (76)

The European Society of Cardiology (ESC) and American College of Cardiology (ACC) /American Heart Association (AHA) guidelines recommend careful monitoring for the effects of treatment, and to avoid hypotension and Worsening Renal Function ${ }^{\times}$ (WRF). For intermediate (i.e. on discharge) and long-term care, all guidelines recommend that oral therapy with ACE Inhibitors Inhibitors (ACEI), ARBs, or beta-blockers (BB) is initiated before discharge from hospital for HF-rEF patients, where appropriate, and that these agents are used for long-term therapy ${ }^{\mathrm{xi}}(23,77)$.

The National Institute for Clinical Excellence (NICE) CHF guidelines make recommendations surrounding all the key areas of managing HF, including diagnosis, drug and non-drug treatments, and management of depression and anxiety related to HF. The latest NICE guidelines for first and second line CHF are presented below (68).

\section{First line treatment}

- ACEls and diuretics are recommended for all patients with HF-rEF.

- Beta-blockers licensed for HF are recommended for all patients with HF-rEF including older adults and patients with peripheral vascular disease, erectile dysfunction, diabetes mellitus, interstitial pulmonary disease and chronic obstructive pulmonary disease (COPD) without reversibility.

Stable patients who are already taking a beta-blocker for co-morbidity, and who develop HF-rEF, should be switched to a beta-blocker licensed for HF. 


\section{Second line treatment}

Seek specialist advice before offering second-line treatment to patients with HF-rEF. One of the following should be considered if a patient remains symptomatic despite optimal therapy with an ACEI and a beta-blocker, or is intolerant to ACEl therapy:

An aldosterone antagonist licensed for HF (especially if the patient has moderate-to-severe HF [New York Heart Association (NYHA) class III-IV], or has had an MI within the past month) or

An ARB ${ }^{\mathrm{xi}}$ licensed for HF (especially if the patient has mild-to-moderate HF [NYHA class II-III])

The evidence base for the treatment of HF-rEF is more firmly established than for HF-pEF, with ACEls and beta blockers being considered the standard treatments. Additional agents are also available to treat HF-rEF, including ARBs, aldosterone antagonists and ivabradine in some cases. A summary of existing pharmacological treatments used in HF in Ireland is detailed in a later section of the report. For further treatment interventions, please see the Appendix $B$. 


\section{Epidemiology}

\subsection{Prevalence}

In 2002 the Irish Heart Foundation (IHF) predicted an evolving HF crisis in Ireland, which at the time affected up to 80,000 people, with nearly double the number $(160,000)$ estimated to have impaired left ventricular dysfunction or impending HF (24). It estimated that over 300,000 people in Ireland would be directly affected by HF in 2010 (see Appendix I) (24). More recently (2011), the HSE published the "Heart Failure Quality \& Clinical Care Programme" which estimated that 120,000 patients in Ireland were suffering from $\mathrm{HF}$ (78).

The availability of accurate data regarding the prevalence and incidence of HF in Ireland remains limited. Prevalence estimates are derived from European and American epidemiological studies. Using this methodology, a national prevalence rate of $2 \%$ in the adult population (25-69 years), increasing to $10 \%$ in those aged 70 years and older was applied (23). Conservatively, this resulted in an estimated patient population of 90,071. The latter estimate is applied in this report.

\subsection{Incidence}

Applying age and gender specific incidence rates from over four decades of data from the Framingham Heart Study ${ }^{\text {xiii }}$ (79), an estimated 9,327 patients aged 45 years and older are diagnosed with HF in Ireland annually. Given current deteriorating lifestyle choices, and the increase in physical inactivity, a younger risk profile of people suffering from cardiovascular conditions is becoming evident, including those under the age of 65 years (4). According to the DoH, the annual incidence of $\mathrm{HF}$ in Ireland exceeds 10,000 (4) and may be more reflective of current demographic trends, and thus applied.

The New York Heart Association (NYHA) functional classification system for HF can be used to determine the severity of disease, based on patient symptoms and/or structural changes to the heart. The percentage of patients in NYHA class I, II, III and IV was $33 \%, 44 \%, 21 \%$ and $2 \%$, respectively. The $1 \%$ reported 'unknown' was evenly dispersed among each classification I-IV (0.25\%) and presented below. Estimates were derived from IMPROVE-HF registry (80), the largest US outpatient HF patient registry ${ }^{\mathrm{xi}}$. To see how this compares internationally, please see Appendix A).

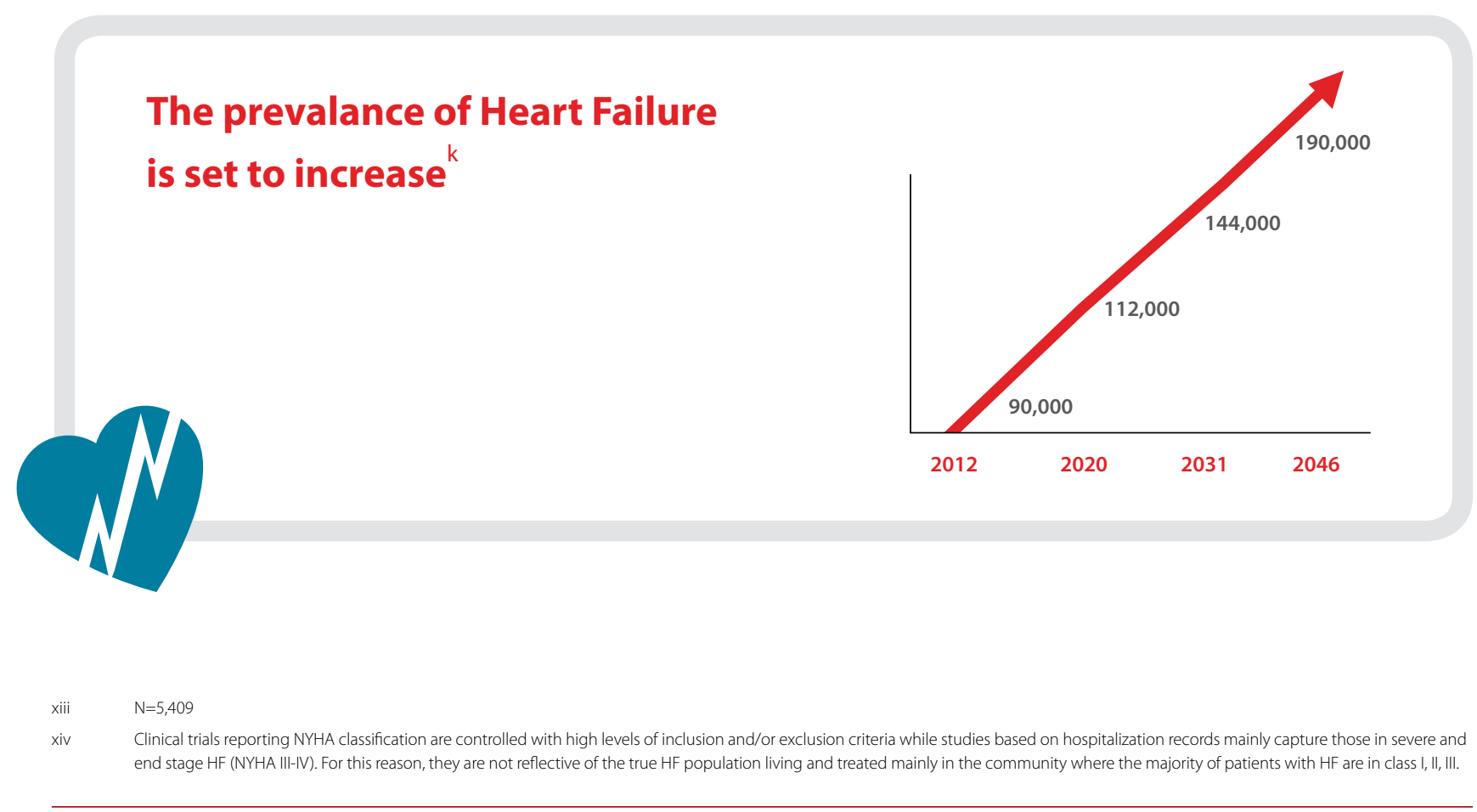


Figure 1. NYHA functional classification adapted for Ireland (80)

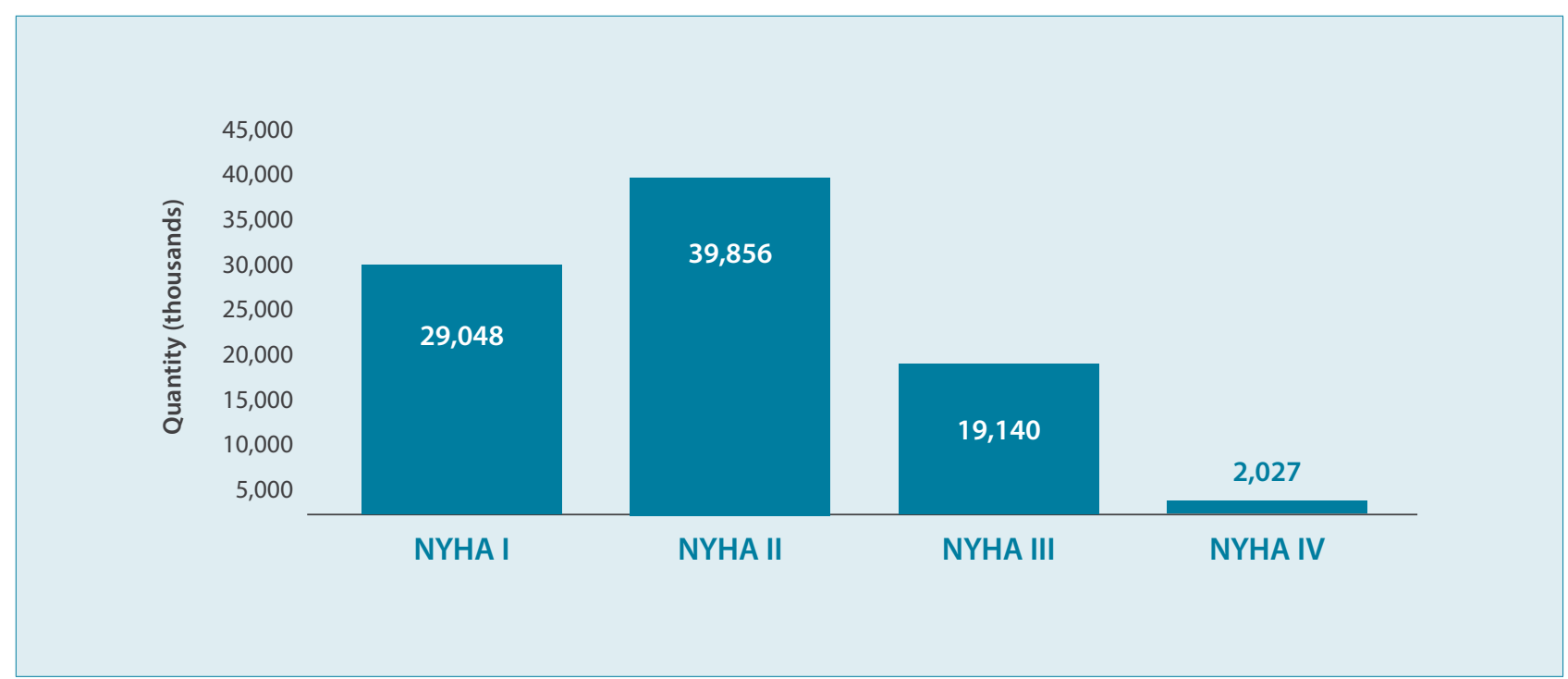




\section{Human burden of HF}

\subsection{Morbidity}

The uncertain disease trajectory and possibility of sudden death accentuates the burden of HF (81), as well as other co-morbidities that frequently occur in tandem with HF. HF patients report a diminished QoL, resultant of the burdening morbidity and high levels of psychological distress associated with the chronic condition. Studies have shown that Health-Related QoL (HRQoL) is more severely impaired in HF than it is in several other common chronic conditions including diabetes, chronic lung disease, depression, and atrial fibrillation $(53,82-86)$. QoL decreases sharply with the severity of HF symptoms (83).

The symptoms of HF, such as dyspnoea and fatigue, have a significant and detrimental impact on the functional capacity and QoL of HF patients (53). Physical limitations appear to be the most salient aspects of CHF to patients and include walking difficulty, difficulty performing day-to-day tasks, being slowed down, needing to rest before completing an activity and difficulty coping with leisure activities (87). One patient describes, 'It's a life but it's not much of a life' (88) (p. 931).

The negative consequences on functional status after an acute episode of decompensated HF are often not temporary, so a continual decline is not uncommon in the first year following the diagnosis. In the final phase of HF (NYHA functional class IV), the psychological and physical symptom burden of a dying HF patient has been compared to that of the dying cancer patient. The main reported symptoms are weakness/fatigue (80\%), pain (78\%), dyspnoea (61\%), depression (59\%), insomnia (45\%), anorexia (43\%), anxiety (43\%) constipation (37\%) and nausea/vomiting (32\%) $(89,90)$. It is therefore unsurprising that, in the concluding months of life, the experience is characterised by distressing and poorly controlled symptoms in addition to other unmet needs such as information about their disease, loss of autonomy, lack of self-esteem, and social isolation (81). Tully et al. found levels of 'probable/definite' depression and anxiety present in $18 \%$ and $16 \%$ of Irish HF patients respectively (33).

Worsening of the disease does not only impact the patient but also their caregivers. Studies have identified relatively high levels of deteriorating mental health and quality of life among partners of patients with HF $(58,91-93)$. The QoL of carers is lower in those individuals caring for patients with higher NYHA class (93).

In Ireland, the number of comorbidities in patients hospitalised with HF and other cardiovascular diseases is captured by the Hospital Inpatient Enquiry (HIPE) system and depicted below.

\section{Quality of Life}

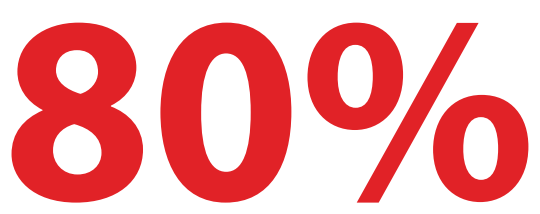

suffer from symptoms such as severe breathlessness and fatigue ${ }^{b}$

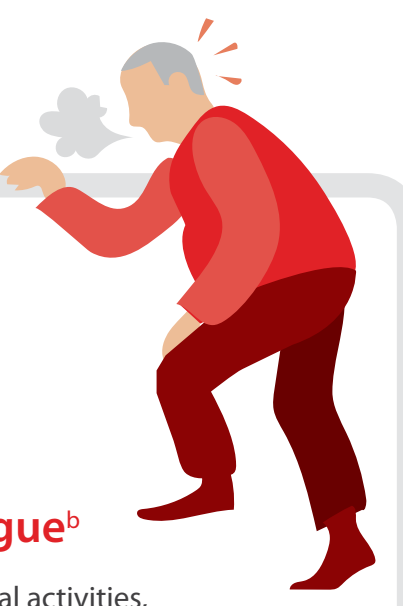

Patients are less able to work/participate in social activities, and are likely to suffer from depression and social isolation ${ }^{c}$ 
Figure 2. Number of diagnoses associated with cardiovascular hospital admissions in Ireland (2012) (35)

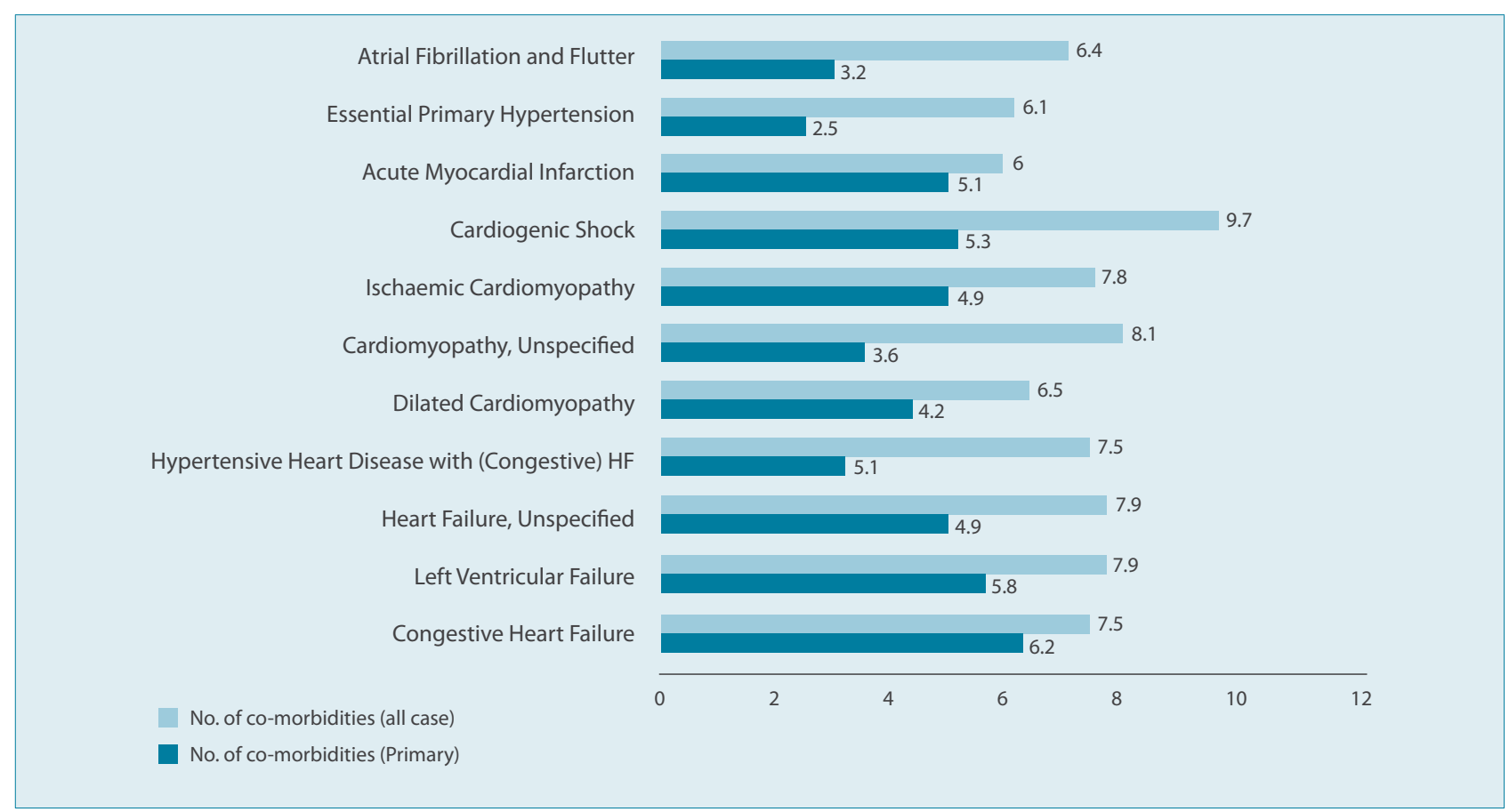

\subsection{Mortality}

\section{AHF}

Historically, HF has had poor prognosis. Following an index hospitalisation for $\mathrm{HF}, 8 \%$ of patients will die within one month (94), with more than a third of patients dying within 12 months of diagnosis and a 50\% rate of readmission at 6 months (36, 64). Survival rates among patients hospitalised for HF is worse than that of many common cancers (95) and whilst in-hospital mortality rates are declining in Ireland $(4,35)$, the quality of life and prognostic outlook for HF patients who survive an acute hospitalisation remains poor.

\section{CHF}

Community-based surveys show that within 5 years, 60 to $70 \%$ of patients die as a consequence of HF (most from worsening heart failure or sudden cardiac deaths -probably because of a ventricular arrhythmia) $(96,97)$. The outlook for patients diagnosed in a timely manner and optimally managed is more optimistic. In Ireland, James et al., (42) described the survival rates of incident HF patients in a community dwelling population presenting in the outpatient setting and managed in a disease management programme. It demonstrated that the current prognosis of patients with HF presenting in the community is better than previously reported, with a $63.8 \%$ five year survival for a population with an average age of 79.4 years at diagnosis. Furthermore, analysis shows that this represents a calculated loss of 6 months of life over a five year period as a result of this diagnosis compared to an age-matched simulated cohort from the Irish population. In an adjusted hazard model, the risk of death for both HF-rEF and HF-pEF is similar. 


\subsection{Inpatient mortality}

The number of deaths directly attributed to HF is likely to be an underestimate of the actual number of deaths it causes. There is a discrepancy between the severity and high prevalence of HF and the 'share' of deaths attributed to HF in cause-of-death statistics. This raises the question of whether HF might be underreported in mortality statistics (98). In fact, a priori, underestimation of HF as a cause of death is to be expected. It is well known that what initiates the path immediately leading to death can be a variety of possible events, such as MI, and arrhythmia or stroke which can also be chosen as the underlying cause of death. Listing HF as the underlying cause of death is advised against in WHO guidelines. The underlying cause of death is defined by WHO as 'the disease or injury which initiated the train of morbid events leading directly to death' (99). In this view, HF is considered as a 'mode of dying', which should not be listed as the underlying cause of death if another plausible cause is mentioned on death certificates. Possibly, this guidance was to refer to AHF only, however the extension of this guidance is now interpreted to HF in general.

HF deaths may be assigned to ill-defined cardiovascular codes because of insufficient clinical information at the time of death, local medical diagnostic practices or simply by error. This means that precipitating causes of HF such as coronary heart disease, are more commonly given as the cause of death, whilst the disaggregation of under diagnosis and underreporting factors are unclear. Furthermore, HF deaths that occur in the Emergency Department (ED) setting prior to inpatient referral are not captured by HIPE. Inevitably, therefore, the overall economic burden of HF is seriously underestimated. For this reason, International Classification of Disease (ICD ${ }^{\mathrm{xv}}$ Codes pertaining to HF discharges in Hospital In-patient Enquiry (HIPE) analyses have increased over time, whilst other cardiovascular conditions remain constant, or reduced over time. This portrays the complexity and ambiguity surrounding HF diagnoses in Ireland, and internationally (see Table 5).

To negate this coding limitation, and possible under coding of the condition, it was advised through HSE communication to extend Diagnosis Related Group (DRG) coding beyond pure HF codes (I50.0, 150.1, I50.9) to include 4 additional DRG codes ${ }^{\mathrm{xui}}$ $(I 11.0,142.0,142.9$, and I25.5) $(100,101)$. This ensured the majority of all possible HF admissions in 2012 were captured. Based on an analysis of HIPE data pertaining to these codes, mortalities are presented according to the disease code, age, and gender, totalling 437 in 2012. It is a policy within the HIPE unit not to disclose data relating to 5 or fewer discharges. Where this is the case, these data have been replaced by the symbol $\sim$. Where additional observations were denoted by $\sim$ (i.e. $<5$ admissions), a midpoint of 2.5 was applied. The total number of missing observations is estimated at 7.5 admissions. This estimates an overall inpatient mortality of 445 (rounded).

Table 2. Ireland inpatient mortality rates (35)

\begin{tabular}{|c|c|c|c|c|c|c|}
\hline Codes & Description & Total & $\begin{array}{l}\% \text { of total } \\
\text { mortalities }\end{array}$ & Male deaths & $\begin{array}{l}\text { Female } \\
\text { deaths }\end{array}$ & $\begin{array}{c}\text { Missing observations } \\
\text { (derived) }\end{array}$ \\
\hline 150 & Congestive HF & 368 & $83 \%$ & 206 & 162 & \\
\hline 150.1 & Left Ventricular Failure & 36 & $8 \%$ & 15 & 21 & \\
\hline 150.9 & Heart Failure Unspecified & 17 & $4 \%$ & 9 & 8 & \\
\hline I11.0 & $\begin{array}{l}\text { Hypertensive Heart Disease } \\
\text { with (Congestive) HF }\end{array}$ & 2.5 & $1 \%$ & $\sim$ & $\sim$ & 2.5 \\
\hline R57.0 & Cardiogenic Shock & 2.5 & $1 \%$ & $\sim$ & $\sim$ & 2.5 \\
\hline 125.5 & Ischaemic Cardiomyopathy & 16 & $4 \%$ & 7 & 9 & \\
\hline 142.9 & Cardiomyopathy, Unspecified & 2.5 & $1 \%$ & $\sim$ & $\sim$ & 2.5 \\
\hline
\end{tabular}

\footnotetext{
xV ICD-10-AM is used for coding diagnosis and conditions and it is the International Classification of Disease, $10^{\text {th }}$ Revision produced by the WHO with the Australian Modification. It consists of a tabular list of disease and applied to all activity coded in HIPE in Ireland.

150.0 Congestive heart failure; 150.1 Left Ventricular failure; 150.9 Heart Failure Unspecified; 111.0 Hypertensive heart disease with (congestive) heart failure ; 142.0 Dilated Cardiomyopathy 142.9 Cardiomyopathy Unspecified; 125.5 Ischaemic Cardiomyopathy; R57.0 Cardiogenic Shock
} 
Source: HIPE database; all percentage estimates are rounded to the nearest whole number.

From the inpatient mortality rates, $54 \%$ were attributable to male patients, while a lower rate of $46 \%$ of deaths were female patients. The highest inpatient mortality rates were observed among HF specific ICD codes (I50, I50.1, and I50.9), totalling approximately $95 \%$ of all mortalities, with extended coding accounting for less than $5 \%$ in 2012 (I11.0, R57.0, I25.5, and 142.9).

Overall, inpatient mortality for HF reduced from $16.7 \%$ to $11.8 \%$ in the years 1998 and 2008 (4). Based on a more recent HIPE analysis in 2012, HF mortality has continued to reduce, and is estimated at approximately $8 \%$ of primary HF admissions (35). However, caution should be taken when interpreting reported mortality rates, and more specifically, the variation in ICD Code versions (i.e. ICD-9 and ICD-10) and volumes (the number of codes applied) used to derive these mortality rates. For example, when estimating the rate of mortality amongst HF related admissions, as per the methodology employed for the years 1998 and 2008 (above), this mortality rate increases to $12 \%$.

\subsection{Mortalities in the Community}

$\mathrm{HF}$ related mortalities do not occur exclusively in the hospital setting, and can also occur in the community. According to the Central Statistics Office (CSO), there were approximately 500 deaths attributed to HF in 2012. However, mortality rates captured in 2012 were "subject to update"xvii at the time of analysis. To account for this, mortality data capturing the total number of HF deaths over the years 2003-2012 are used to estimate an overall robust average annual mortality rate in 2012. An additional 37 deaths were identified and dispersed in age and gender specific bands, dependent on the prevalence trends reported in previous years (2003-2012). Thus, an estimated 537 mortalities were attributable to HF in 2012.

Figure 3. One decade of HF mortalities in Ireland (2003-2012)

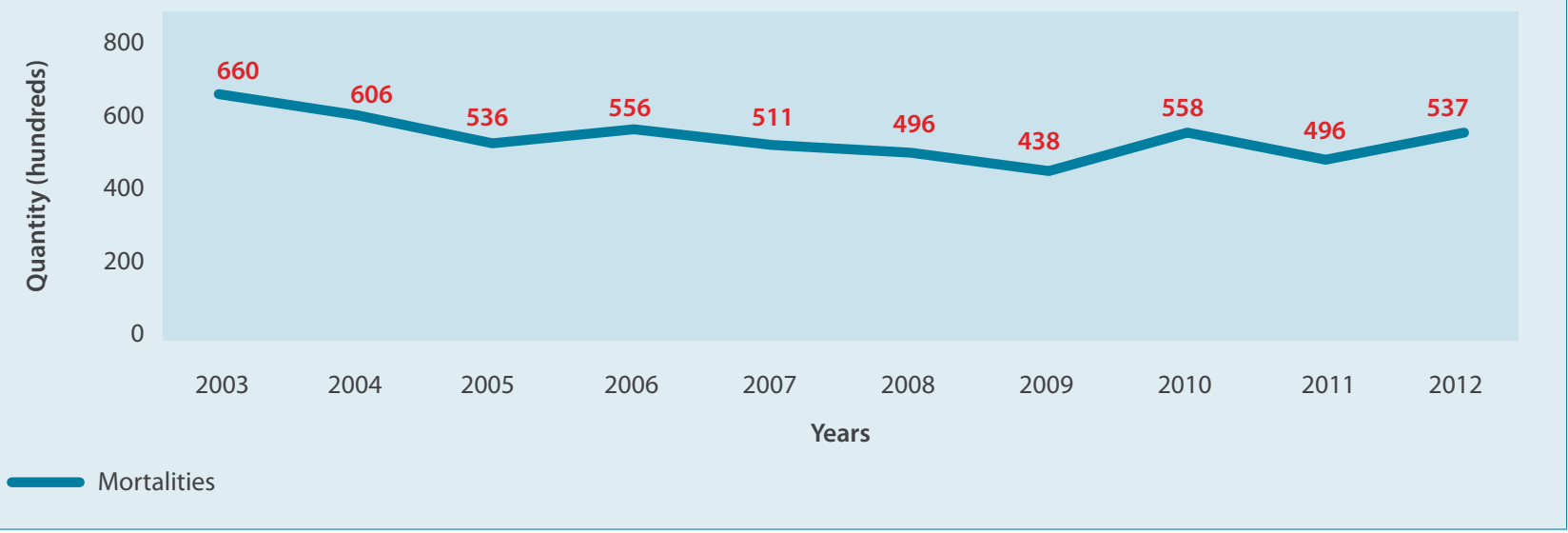

\section{Heart Failure causes more deaths than Breast and Bowel cancer}

Patients report greater physical impairment than patients with

arthritis and chronic lung disease ${ }^{\mathrm{m}}$

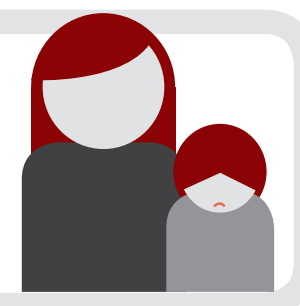


Source: CSO (2012) (102)

Unlike the latter inpatient mortality trends, the prevalence of HF related mortalities in the community (estimated at 537) was higher among female than male patients, at 58\% and 42\% respectively (102). Age and gender specific rates in 2012 are presented below. As expected, HF mortality increases with age, and is highest among females aged 85 years and over, estimated at 234 mortalities.

\section{Figure 4. Age and Gender specific HF mortalities in Ireland (2012)}

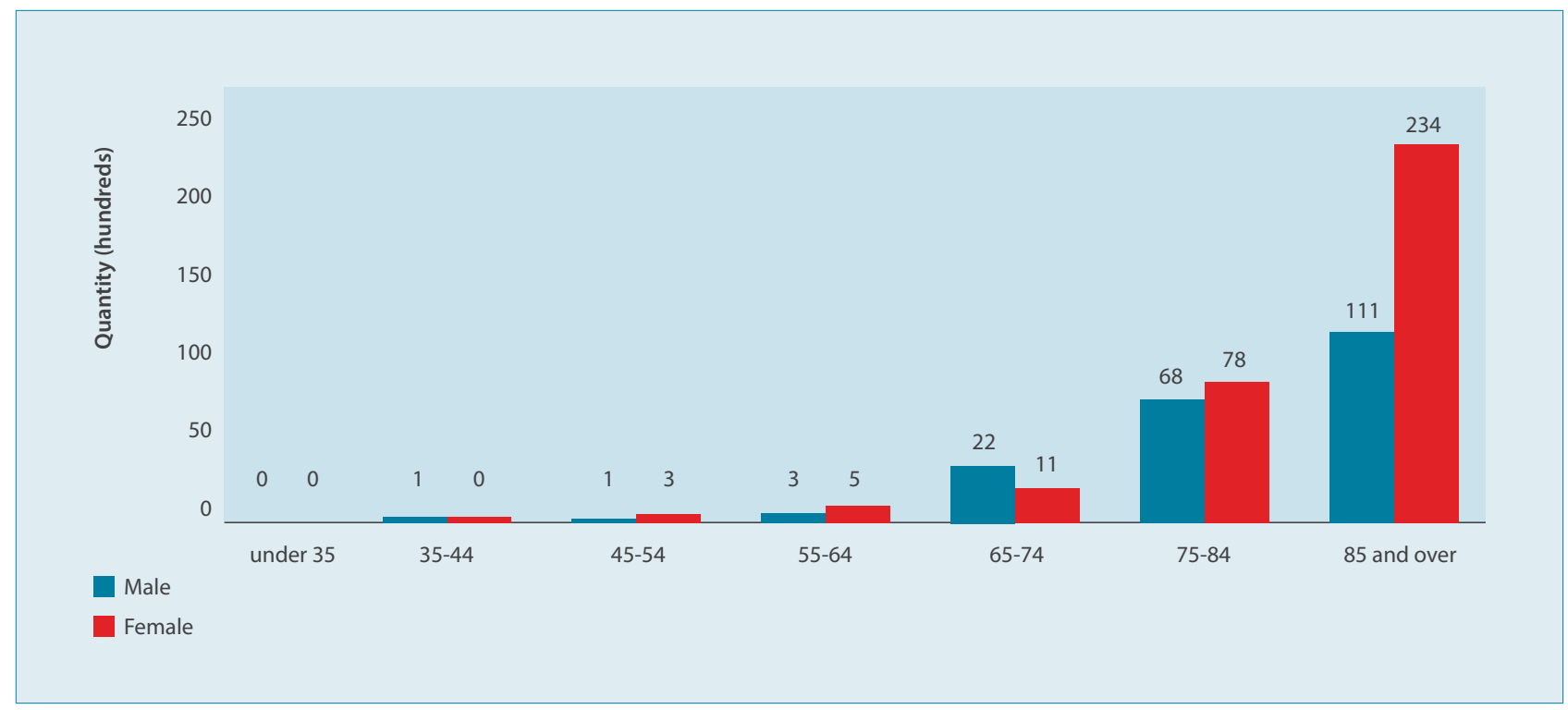

\section{Source: CSO (2012) (102)}

Using the same methodology to capture all HF related admissions (extending the volume of ICD codes to capture possible community HF mortalities), it is estimated that $775 \mathrm{HF}$ related mortalities occurred in the year 2012 (103). The range of definite and probable HF mortalities in Ireland in 2012 was estimated to range between 537 and 775, respectively.

While more than half of Irish hospitals now have dedicated inpatient and outpatient HF services, these services are patchy and distributed unevenly throughout the country (4). This dramatically impacts on survival trends and readmission rates nationally (see Appendix G) (104). Recent Irish findings (33) were a "a source of concern" at one year follow-up uviii, where $25 \%$ of HF patients had died prematurely. In a community based study, 10 year survival was found to be $75 \%$ for participants without HF compared to $26.7 \%$ for those with HF (105). After its onset, life expectancy can be as short as 1.7 years in men and 3.2 years in women (79). Stewart et al., $(84,95)$ describes the diminished HF survival rate when compared to cancer and other cardiovascular conditions, such as myocardial infarction. 


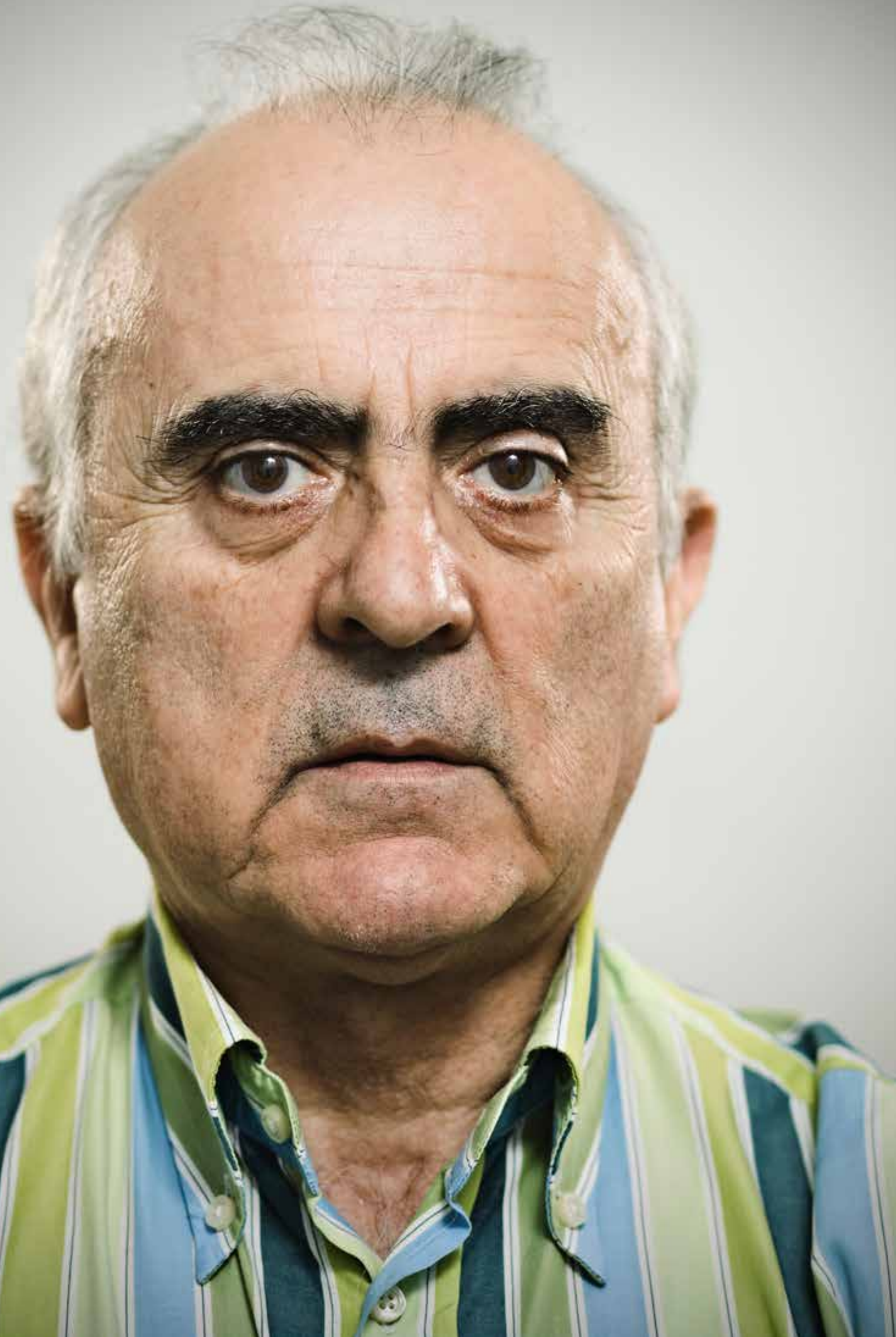




\section{Global Economic Burden}

The pattern of costs due to $\mathrm{HF}$ is similar in all industrialised countries, approximated at $1-2.5 \%$ of the total healthcare budget $(28,106)$. In 2013 , the reported global cost of HF was estimated at $\$ 108$ billion (29). Studies highlighting the burden of HF are described in Table 3. International cost of HF below.

Table 3. International cost of HF

\begin{tabular}{|c|c|c|c|c|}
\hline $\begin{array}{l}\text { Country } \\
\text { (year of costing) }\end{array}$ & Total direct cost & $\begin{array}{l}\text { Percentage } \\
\text { of total health- } \\
\text { care spending }\end{array}$ & $\begin{array}{l}\text { Percentage of costs } \\
\text { attributable to } \\
\text { hospitalisation or } \\
\text { nursing home care }\end{array}$ & Reference \\
\hline France (1990)a & FF 11.4 billion & 1.9 & 64 & (Berry et al., 2001) (106) \\
\hline Germany (2006) & $€ 2.9$ billion & 1.1 & - & (Neumann et al., 2009) (31) \\
\hline $\begin{array}{l}\text { New Zealand } \\
\text { (1990)a }\end{array}$ & NZ\$73 million & 1.4 & 67 & (Berry et al., 2001) (106) \\
\hline Spain (1993) & $\begin{array}{l}64,028-110,240 \\
\text { million pesetas }\end{array}$ & $1.8-3.1$ & - & (Antoñanzas Villar et al., 1997) (107) \\
\hline Sweden (2000)a & SEK5.0-6.7 billion & NA & 47 & (Agvall et al., 2005) (108) \\
\hline $\begin{array}{l}\text { The Netherlands } \\
\text { (1994)a }\end{array}$ & NLG654 million & 1.1 & 68 & (Berry et al., 2001) (106) \\
\hline UK (2000)a & $£ 905$ million & 1.9 & 69 & (Stewart et al., 2002) (28) \\
\hline USA (2007) & US\$30.2 billion & 1.3 & 58 & (Rosamond et al., 2007) (109) \\
\hline
\end{tabular}

a Exchange rates (1999 Feb): US\$1 = £0.61, NZ\$0.55, FF5.78, NLG6.56 and SEK13.5.

FF, French franc; NA, not available; NLG, Netherland guilder; SEK, Swedish kronor; NZ\$, New Zealand dollars; US\$, US dollars; E, UK pounds sterling.

The cost of treatment increases with both the extent of Left Ventricular Systolic Dysfunction (LVSD) and the severity of disease $(106,110)$. The cost of disease increases by up to 30 times for severe cases of HF compared with mild CHF, with healthcare costs for patients with NYHA class IV are between 8-30 times greater than patients with mild disease (NYHA class II) (106).

The latter statistics relate to direct and indirect costs of HF in 2010, and is likely to be underestimated as it is based on data for $\mathrm{HF}$ as the primary diagnosis or underlying cause of death. The precise magnitude of HF-related healthcare costs is difficult

The prevalence and cost of Heart Failure is set to increase due to:

- an ageing population

- $\sim 62 \%$ increase in diabetes

- $\sim 50 \%$ increase in Coronary Artery Disease (CAD)' 
to quantify as most patients with HF suffer from a variety of cardiovascular conditions, and separating the contribution of HF to overall healthcare costs is difficult. Moreover, comparisons across studies are somewhat problematic, as different study populations, observation periods, and/or measures of healthcare cost (i.e., provider expenses, payments for services, charges for services) have been utilised. Further discussion on the economic burden of HF internationally can be found in Appendix F.

\subsection{Ireland}

In an analysis published in 2009, on behalf of the HSE, the Royal College of Surgeons in Ireland evaluated the Hospital In-Patient Enquiry (HIPE) system. Data prepared for the cardiovascular health report highlighted the substantial increase in bed days utilised by HF admissions, increasing from 261,499 in 1998 with a median length of stay (LoS) of 8 days, to 291,988 in 2008 with a median LOS of 9 - a rise of $7.1 \%$ from 1998. The increase in bed days from 1998 to 2008 was despite a reduction in episodes of care, estimated at 20,825 and 19,400 in 1998 and 2008, respectively. Similarly, an increase in day cases over the same period was witnessed (from 1998 to 2008), estimated at 1,248 and 1,472, respectively. That is, day cases increased by approximately $18 \%$ over the study period, and episodes of care (inpatient admissions) reduced by approximately $7 \%$.

More crucially, this accounted for $35 \%$ of in-patient stays, and $41 \%$ of all cardiovascular disease bed days (the rest were attributable to coronary heart disease, stroke, TIA, and peripheral arterial disease). In 2008, HF was one of the most common causes of hospitalisation in patients over 65 years of age, with more than 20,000 patients admitted to hospital, $90 \%$ of which were emergency admissions (2). Although the argument of changing demographics and ageing populations has been put forth by EU and US counterparts, the same cannot be said for Ireland currently ${ }^{\mathrm{xix}}$.

Combining these reported figures for the years 1998 and 2008 with the analysis carried out in 2012, the overall bed days in admission (episodes of care) and bed days are presented below. Using the 2012'ready reckoner' (Casemix DRG reporting 2010 cost and case volume), the LoS for severe and non-severe HF patients estimated a weighted average LoS of 11.44 days per admission. This is a further increase of $27 \%$ in LoS from the most recent reported year 2008.

Figure 5. Ireland's cardiovascular trends (HF and stroke) $(4,35)$

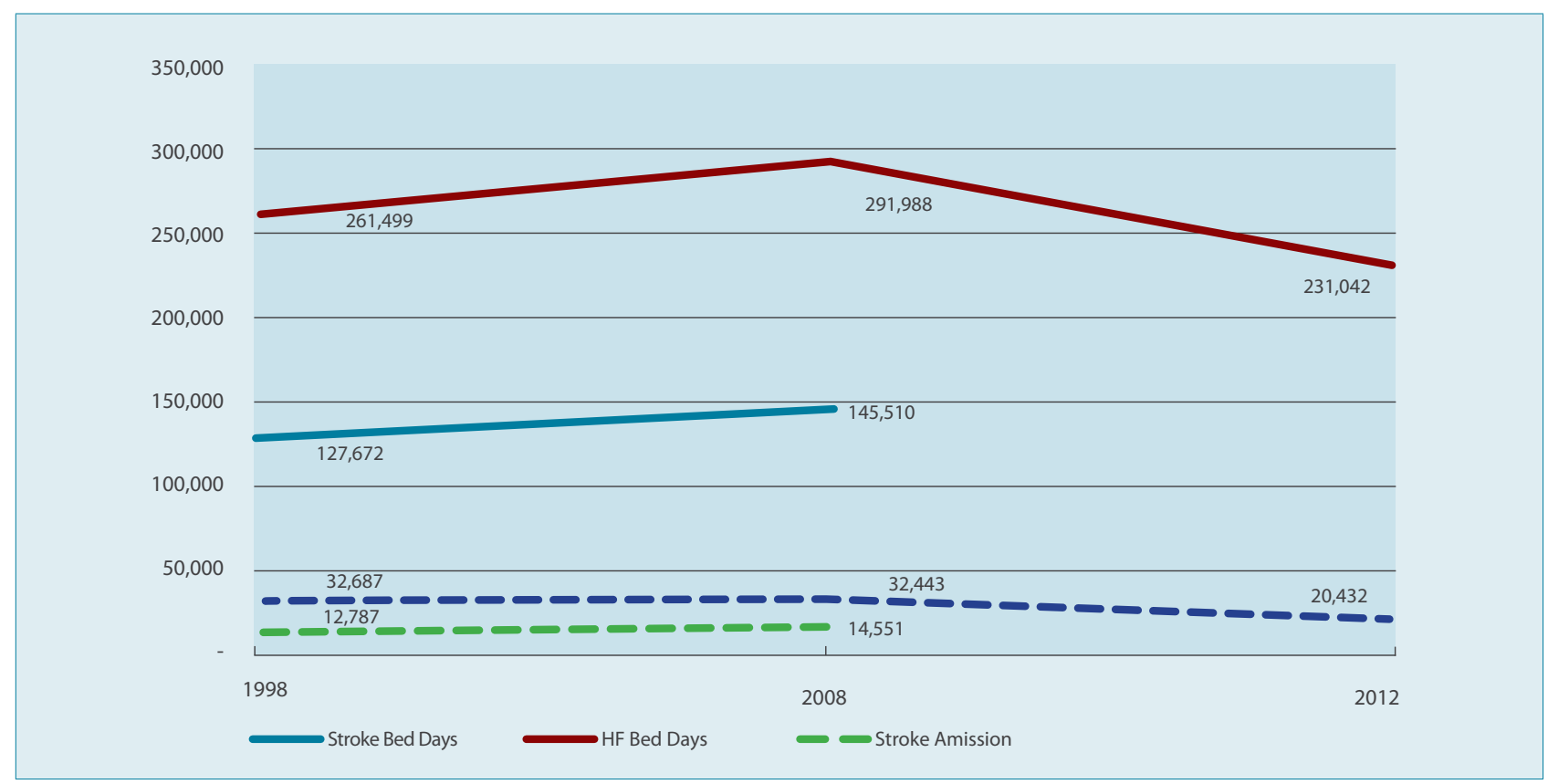


Comparing the numbers of admissions relating to pure HF codes $(150.0,150.1,150.9)$ and the extended HF codes (I11.0, 142.0, 142.9, and $125.5^{\times x}$ ) increases the number of primary admission from 5,294 to 5,642; an increase of 348 (7\%) HF related admissions.

All case admissions increase from 18,358 to 20,432 applying the same methodology, an additional 1,838 (10\%) HF related admissions.

Resource use based on primary diagnoses only estimates 64,544 bed-days attributable to HF admission in 2012. Extending this methodology to all case HF diagnoses, an estimated 231,042 bed days were attributable to HF admissions in the year 2012. The HSE resource utilisation of primary and all case HF admissions is illustrated in Table 4. HSE resource use.

\section{Table 4. HSE resource use}

\begin{tabular}{|l|l|c|c|c|c|}
\hline Diagnosis & Description & Admissions & $\begin{array}{c}\% \text { of Inpatients } \\
2012\end{array}$ & $\begin{array}{c}\text { \% of Emergency } \\
\text { admission 2012 }\end{array}$ & $\begin{array}{c}90 \% \text { HF admission } \\
\text { through ED }\end{array}$ \\
\hline Primary & HSE communication & 5,642 & $1.2 \%$ & $1.4 \%$ & $1.3 \%$ \\
\hline & Pure Heart Failure & & 5,293 & $1.1 \%$ & $1.4 \%$ \\
\hline All case & HSE communication & 20,432 & $4.1 \%$ & $5.2 \%$ & $4.2 \%$ \\
\hline & Pure Heart Failure & 18,358 & $3.7 \%$ & $4.7 \%$ & $4.2 \%$ \\
\hline
\end{tabular}

Source: HIPE (2012) \& Changing Cardiovascular Health National Cardiovascular Health Policy $2010-2019(4,35)$

Primary diagnoses account for approximately 25\% of HF related admissions in Ireland (see Figure 6. ICD-10 AM HF diagnoses 2012 (primary \& all case)). Approximately one-quarter of HF hospitalisations internationally have AHF listed as the primary diagnosis (111-114) (see Appendix D), in tandem with the findings of this report (35). Although primary HF hospitalisation rates have declined during the last decade, reduction in the rates of hospitalisations due to a secondary diagnosis of AHF has not been achieved.

These diagnoses can include ventricular dysrhythmias, generalised and ill-defined descriptions of cardiovascular disease, and complications of heart disease. Intuitively, LoS varies between patient types. According to Casemix (2012), those presenting with "heart failure +CCC" ${ }^{\prime \prime x i}$ (1,306 admissions) have a median LoS of 20.8 days. HF patients presenting without -CCC $(4,020)$ have a median LOS of 8.6 days. Based on these estimates, a national weighted average LoS of 11.44 days per HF admission in Ireland was estimated and applied (see Methodology).

The lower and higher estimated number of bed days in this report, compared to that of previous reports, is mainly due to the variation in the number of primary and all case HF diagnoses, and the number of ICD-10 codes used to identify HF related admission, which was substantially lower than previously applied (Table 5. Past and present cardiovascular ICD codes).

\section{Findings of the report demonstrate "a profound regional disparity in Heart Failure patient data, services and outcomes nationwide" a}

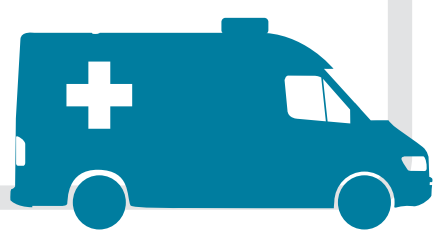


Figure 6. ICD-10 AM HF diagnoses 2012 (primary \& all case)

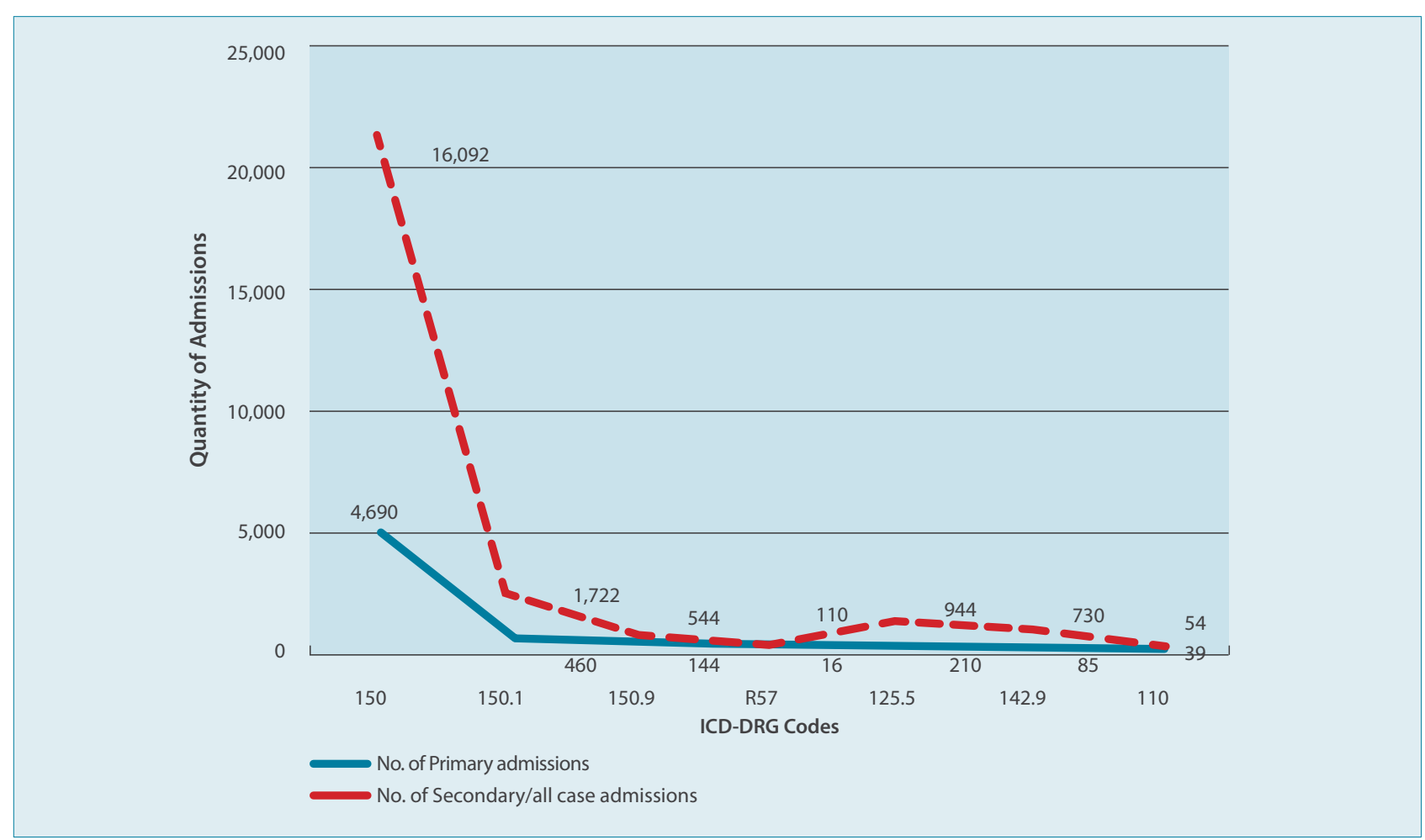

Source: HIPE (2012) (35)

Table 5. Past and present cardiovascular ICD codes

\begin{tabular}{|l|l|l|}
\hline Cardiovascular description & ICD-9-CM Codes (1998) & ICD-10 AM Codes (2006) \\
\hline CHD & $410-414$ & $120-125$ \\
\hline Stroke & $430-434,436-438$ & $160-169$ \\
\hline TIA & 435 & G45 \\
\hline PVD/PAD & $440,441,442,443.1,443.9,444$ & $170,171,172,173.1,173.9,174$ \\
\hline Heart Failure & $402,425.4,435.5,435.9,428$ & $\begin{array}{l}111.0,111.9,142.0,142.2, \\
142.5,142.6,142.7,142.8, \\
142.9,150\end{array}$ \\
\hline
\end{tabular}

Source: Changing Cardiovascular Health 2010-2019 (DoH \& Children) (4)

The majority of readmissions are related to cardiovascular disease (115-118) with recurrence of HF as the most common single reason, accounting for about $30 \%$ of all cases (119-123). In European studies, reported rehospitalisation rates range from $24 \%$ at 12 weeks (124) to $44 \%$ at 1 year after discharge (119). In the USA, 30-day readmission rates were about 20-25\% (115, 122, $123)$, however readmission rates of $60-67 \%$ have been reported with longer follow-up $(115,118,120)$. Worsening $H F$ on the background of CHF (decompensation) is the most common form of HF leading to hospitalisation (63).

Approximately 1 in 5 of patients with HF is admitted to hospital in any one year and many will be readmitted (4). Given that admissions are estimated at 1.29 per patient per annum (see Methodology), 5,642 admissions are estimated as 4,374 $\mathrm{HF}$ patients. This approximates 1 in $21 \mathrm{HF}$ patients, identifying a potential underestimation and overestimation of HF admissions and prevalence in the year 2012, respectively. 


\section{Methodology \\ 7.1 Search strategies used}

This is a prevalence based study, aggregating HF-related costs over a one year period for all those who develop (incidence population) or already suffer from the condition (prevalence/ community based population). Direct and indirect costs have been collected from a combination of primary and secondary sources. In the presence of data ambiguity or deficiency, national clinical leads for HF (at the primary, secondary, and community care levels) and other health care professionals (involved in the treatment of HF patients) have been consulted.

The lack of data in the private sector of the hospital system is addressed through the use of market research ${ }^{\mathrm{xxi}}$ (104).

Direct HF hospital related costs (secondary care) are obtained through Health Services Executive (HSE), Casemix DRG data, and the HIPE system.

Other direct costs, such as GP care, cardiac rehabilitation, and nursing home care were collected from the iPCRN database, St Vincent's University Hospital (SVUH), and HIPE respectively.

\section{$\Rightarrow$ Optimise treatment}

Indirect cost such as productivity loss were explored, but assumed negligible given the elderly HF population. Nevertheless, this was included to reflect the productivity loss of informal carers through application of the human capital approach. The number of informal care hours required by CHF patients is calculated in accordance with the International Classification of Functioning, Disability and Health \{Mji, 2001 \#525\}(ICF) (125) using the Activities of Daily Living (ADL), and the Instrumental Activities of Daily Living (IADLs). Further indirect costs include the monetisation of premature life years lost due to the condition. The methodology employs the CSO and Irish Life tables to estimate the number of life years lost; the costs were informed through national Health Information and Quality Authority (HIQA) registries and literature, and are detailed in further sections. The following categories of healthcare expenditure and costs are included.

Other types of activity relating to the prevention of HF, (such as Multi-Disciplinary Care (MDC)), and health education in community based settings were not included due to the varying levels of provision and activity across Ireland (104). Similarly, the contribution from the voluntary sector, social welfare, private spending (such as transport costs) and out of pocket payments was not addressed in this report. The methods used to estimate HF-related service utilisation and cost are described subsequently. 


\begin{tabular}{|c|c|c|}
\hline Cost Category & Description & Source \\
\hline & Community care & Applied sources and costs \\
\hline \multirow[t]{11}{*}{ Direct Cost } & $G P$ & $\begin{array}{l}\text { Quantity: iPCRN database (126); Stewart et al., (2002) (28) } \\
\text { Cost: Laya Healthcare (2012) (127) }\end{array}$ \\
\hline & \multicolumn{2}{|l|}{ Hospital Costs } \\
\hline & Hospitalisations & $\begin{array}{l}\text { Quantity: the Hospital Inpatient Enquiry (HIPE) System (35) } \\
\text { Cost: Ready Reckoner Casemix DRG } 2013 \text { (128) }\end{array}$ \\
\hline & Ambulance & $\begin{array}{l}\text { Quantity: McGowan et al., (2000) (7) } \\
\text { Cost: } 2012 \text { Naas General Hospital; A guide to patient charges (129) }\end{array}$ \\
\hline & $O P D$ & $\begin{array}{l}\text { Quantity: Stewart et al., } 2002 \text { (28); Biermann et al., } 2012 \text { (130); McDonald } 2013 \\
\text { HSE communication (12) } \\
\text { Cost: HSE communication with Morgan, R. } 2013 \text { (131) and Gallagher, J. } 2013 \text { (132) }\end{array}$ \\
\hline & Heart Transplant & $\begin{array}{l}\text { Quantity: HSE communication Mc Donald, K. } 2013 \text { (12) } \\
\text { Cost: Ready Reckoner Casemix DRG } 2013 \text { (128) }\end{array}$ \\
\hline & Specialist Assessment & $\begin{array}{l}\text { Quantity: NICE cost of Chronic Heart failure } 2010 \text { (30) } \\
\text { Cost: Payment by Results mandatory tariff 2010/11, 320 Cardiology }\end{array}$ \\
\hline & Cardiac Rehab & $\begin{array}{l}\text { Quantity: St Vincent's University Hospital; HSE communication (2013) (133); National } \\
\text { Audit of Cardiac Rehabilitation Report } 2008 \text { (134) } \\
\text { Cost: NICE Cardiac rehabilitation Commissioning Guide (135) }\end{array}$ \\
\hline & Diagnostics & Listed under Diagnostic section (extensive) \\
\hline & Nursing home care & $\begin{array}{l}\text { Quantity: HIPE (2012) (35); Mehta \& Dubrey (2006) (136); } \\
\text { Cost: HSE (2009) (137) ; EPS consultancy (2013) (138) }\end{array}$ \\
\hline & Pharmacotherapy & $\begin{array}{l}\text { Quantity \& Cost: St James's CHF report } 2010 \text { (139); IMS database analysis 2014; MIMS } \\
\text { 2012; Scientific engagement }\end{array}$ \\
\hline Indirect cost & Informal Care & Quantity \& Cost: CSO (2012) (140); Gure et al., (2007) (141); O'Brien (2009) (142) \\
\hline Economic Cost & Life Years Lost (LYL) & Quantity \& Cost: HIQA 2014 (143); CSO HF mortalities 2012 (102); CSO life tables (144) \\
\hline
\end{tabular}

\subsection{Healthcare expenditure: Primary Care}

\subsubsection{GP visits}

HF patients have frequent contact with primary care and are mainly cared for by their GP or internist (145) and It is known that patients with HF visit their GP often with HF as the most common reason for consultation (146). The same is true for Ireland, whereby $80 \%$ of GP visitations are related to chronic disease (147), including HF.

The average GP cost per eligible person in the GMS scheme was $€ 243.40$ in 2012, a reduction of 5.6\% from 2011 (148). There is substantial variation in the average GP cost per person by HSE region and local health office, from a low of €88.83 per person in 
Dublin West to a high of $€ 384.75$ in Dublin South. This reflects different age structures of the respective populations (capitation payments are weighted by age) and differences in GP numbers. This rate is intended to cover an unrestricted number of physician clinic appointments and house calls during that year. Data on GP fees are not routinely collected.

An online survey of 501 parents (with private health insurance) by Laya Healthcare in 2012 found that the national average cost of going to see the doctor was $€ 46.26$, rising to $€ 53.29$ in Dublin (127). For the purpose of this report, the lower estimate is applied (€46.26). Alternatively, based on the annual GMS fee (including allowances) of $€ 243.40$ per patient (5) and the number of GP visits for a HF patients per annum (8.8 visits), this would not equate to $€ 46.26$ per visitxiii. However, it is difficult to determine that all visits were primarily HF related, particularly among older patients with multiple co-morbidities. In addition, the societal perspective of this study necessitates the application of opportunity cost to GPs, as opposed to actual economic cost to the HSE.

\section{Clinic appointment}

According to the IPCRN database ${ }^{\text {xxiv }}$, HF patients make, on average, $8.8 \mathrm{GP}$ visits annually (132). The unit cost was applied to the HF population $(90,071)$ minus mortalities $(537)$ assumed to occur proportionally throughout the year $(0.5$ in the beginning of the year and 0.5 in the second half of the year). The total is multiplied by 8.8 visits to give total cost of GP visitation resulting from $\mathrm{HF}$ related illnesses.

$(90,071-537) \times 8.8 \times € 46.26$ (opportunity cost) $=$ total cost of GP care

\section{Home Visits}

In Ireland, physician house calls are provided by GP, although there is no available data pertaining to the frequency of these visitations (149). An estimated one in ten HF related GP consultations occur at home (28) and is considered a conservative estimate (132). There is no available data on the unit cost of a home visit in Ireland; hence a constant cost of $€ 46.26$ is similarly applied to the total number of home visits, accounting for mortality.

$79,686 \times 46.26$ (opportunity cost) $=$ total cost of GP home visits

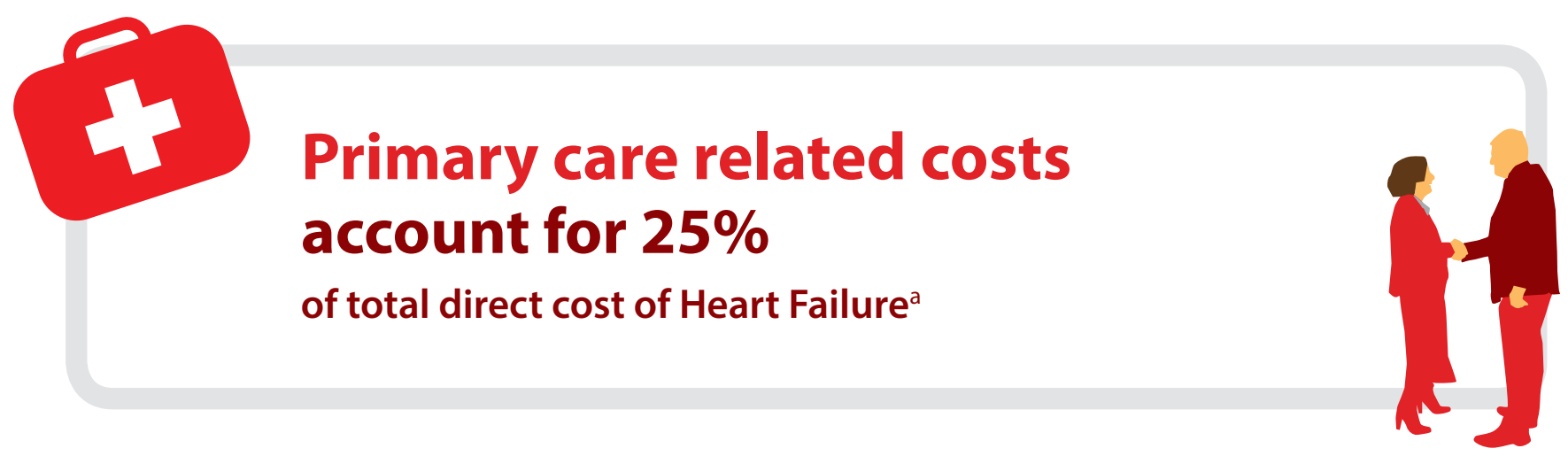




\subsection{Hospital Expenditure; Secondary care}

\subsubsection{Hospital inpatient activity}

\section{Quantity of Care}

$\mathrm{HF}$ is the cause of $5 \%$ of acute hospital admissions (63), whilst WHF is the second most common heart-related reason for admission to hospital via the emergency department (150).

The number of hospital cases for HF in Ireland in 2012, and their associated resource use were obtained from the Hospital Inpatient Enquiry (HIPE) system. HIPE collects demographic, clinical and administrative data on discharges from, and deaths in, acute public hospitals nationally. Therefore, HIPE data can provide an assessment of HF resource utilisation in secondary care settings using DRG model. In defining the conditions for the analysis of burden in this report, 'heart failure' as the principal diagnosis is applied, that is, 5,642 admissions.

The Irish context is of particular interest, giving an example of a health-care system where there is a complex mix of public and private provision, with implications for the composition of the cost burden. Qualitative market research identified an additional 921 acute HF admissions in the private hospital setting with a primary diagnosis of HF (104). The cost of an admission is kept constant between both settings.

\section{Cost of Care}

The cost of a hospital admission can be calculated using two approaches:

1. Cost per bed (top-down method which allocates total hospital costs across all hospital discharges on the basis of the LoS)

2. Casemix based costs (also a top down approach): Allocates total hospital costs cross all discharges on the basis of Casemix units rather than LoS- each discharge is assigned to a DRG (DRGs group cases which share common clinical attributes). A CMU (Casemix unit) measures the complexity (in terms of resource use) of the DRG:

Casemix Index:

( $\Sigma$ (Total number of cases per DRG $\times$ RV of the DRG)

(Total number of discharge equivalents)

Applying the first methodological approach poses issues relating to treatment and management of admissions. During hospitalisation, patients may be treated in multiple hospital departments (Intensive Care Unit (ICU), Coronary Care Unit (CCU), Acute Medical Unit (AMU) or be managed in a single department (general ward) depending upon hospital protocols and resource availability (e.g. bed and staff availability).

"National HF programme dictates that patients should see a cardiovascular (CV) team - but this is aspirational at present. So in many cases CV teams do not see the patient at all. This is mainly resource driven" (104).

Similarly, the average HF LoS varies nationally depending on the complexity/aetiology of the patient treatment received, and indeed, the demographics. Therefore HF patients are a heterogeneous ${ }^{\mathrm{xx}}$ group in terms of severity and treatments received, and such methods cannot be applied. Hence, different types of HF vary in LoS; this is evidenced in the table below. 
Class of AHF $\quad$ Median LOS (Interquartile Range; IQR), days

\begin{tabular}{|l|c|}
\hline ALL & $9(6-14)$ \\
\hline Acute Decompensated Chronic HF (ADCHF) & $9(6-14)$ \\
\hline De Novo AHF & $9(5-15)$ \\
\hline Decompensated Heart Failure* & $9(6-15)$ \\
\hline Hypertensive Heart Failure & $8(6-12)$ \\
\hline Right Heart Failure & $11(7-17)$ \\
\hline
\end{tabular}

Due to the uncertainties discussed, a Casemix weighted average is estimated for both cost and LoS and applied to the number of HF admissions captured in the year 2012, obtained through HIPE.

\section{Cost}

A weighted average cost was calculated from 2012 Casemix DRG costs (reporting in 2010 cost and units), considering both long $(1,306$ admissions for a duration of 20.32 days, at an average cost of $€ 10,839$ per admission) and short stay $(4,020$ admissions for a duration of 8.6 days, at an average cost of $€ 4,762$ per admission) non-elective HF patients, with and without Catastrophic Complication or Comorbidity (+/- CCC), inpatient admissions. Taking into account both patient types and inflating to 2012 costs (using the CPI growth for health services), an average cost of $€ 572$ per day was estimated.

\section{LoS}

The length of stay similarly varies between both patient types, from 20.8 days for those presenting with + CCC complications $(1,306$ admissions) and 8.6 days for those without -CCC complications $(4,020)$ in the year 2010 . Based on these estimates, a national mean LoS of 11.44 days per HF admission in Ireland was estimated.

Applying the inpatient weighted average LoS to the DRG daily cost and, a total hospital cost of $€ 6,543^{x \times v i i}$ is estimated per admission in 2012. Finally, applying this cost to the number of HF admission in 2012 results in a total cost for HF hospitalisations in the year 2012.

\section{5,642 (public admissions) +921 (private admissions) $\times € 6,543=$ total cost of hospitalisations}

The total cost of hospital admissions is estimated as follows for both public (1) and private (2) settings;

\section{2,642 $\times € 6,543=$ Annaul cost of inpatient admissions to public setting (HSE cost) \\ P $921 \times € 6,543=$ Annaul cost of inpatients admissions to private setting (Insurer cost)}

\footnotetext{
xxvi Average LOS is ICU/CCU in Irish hospitals is estimated at 10\% of HF admissions with an ALOS of 1.5 days (HSE communication, McDonald 2013; Stewart et al 2001). International studies estimate an LOS in the CCU or ICU for patients with AHF between 2-4 days: In a US study of hospital billing records for 82,808 patients with AHF, mean LOS was 2.3 days in ICU and 0.4 days in the CCU (Gradman AH, 2013) Analysis of data from the US ADHERE registry reported a mean LOS in the ICU/CCU of 3.6-4.2 days, depending on renal function staging (Heywood JT, et al 1997) A European study (the HF Pilot survey) reported a median LOS of 4 days in the ICU (Maggioni A,P. et al 2010)

xxvii Weighted average cost for HF admission reported by Veli-Pekka Harjola (2009) - €6,743

The HSE reports the average weekly cost to keep a patient in an acute setting at $€ 6,125-6,300$ (HSE 2012).
} 


\section{Heart Transplant}

Heart transplants offer people with severe HF a chance of long term survival. It is estimated that approximately $0.1 \%$ to $16.7 \%$ of patients hospitalised for AHF require a surgical procedure $(152,153)$. The importance and high cost burden associated with this procedure has been highlighted in previous HF costing studies (106), and is similarly recognised as such in this report.

In general, inpatient pharmacotherapy and procedural costs are not calculated as separate components of hospital expenditure due the inclusion of these costs in the DRG Casemix model. Given the severity and high cost of heart transplants, it has been estimated that 15 procedures ( $0.3 \%$ of hospital admissions) were carried out in 2012 for HF related issues (12).

The cost of a heart transplant was retrieved from the ready reckoner (2013) which reports the Casemix cost and quantity of procedural in \& outpatient services in 2011. It is estimated to cost $€ 194,844$ per procedure. This has been inflated ${ }^{x \times v i i}$ using the CPI index to reflect 2012 prices, estimated at $€ 195,039$.

\section{$15 \times € 195,039=$ total cost of HF transplants}

\section{Ambulance Cost}

Although the number of emergency/acute visits attributable to HF per annum is well documented $(63,150,154)$, the number of patients travelling via ambulance is not. Moreover, there is limited data on the cost of ambulance services in Ireland.

According to McGowan (7), Cost of Treating Heart Failure in an Irish Teaching Hospital, the cost of ambulance services are approximately $2.2 \%$ of the hospitalisation costs. Alternatively, the number of HF related hospital admission is captured through the HIPE database analysis. Approximately $90 \%$ of admissions first present at the Emergency Department (2), and it is assumed that $80 \%$ of these admissions travel via ambulance.

According to 2012 Naas General Hospital; "A Guide To Patient Charges", the average cost of an ambulance 'call out' is $€ 167$ (129). Multiplying the number of HF related admissions travelling via ambulance to the ED ${ }^{\text {xxix }}$, by the average cost of ambulance travel, estimates the total annual cost of ambulance services.

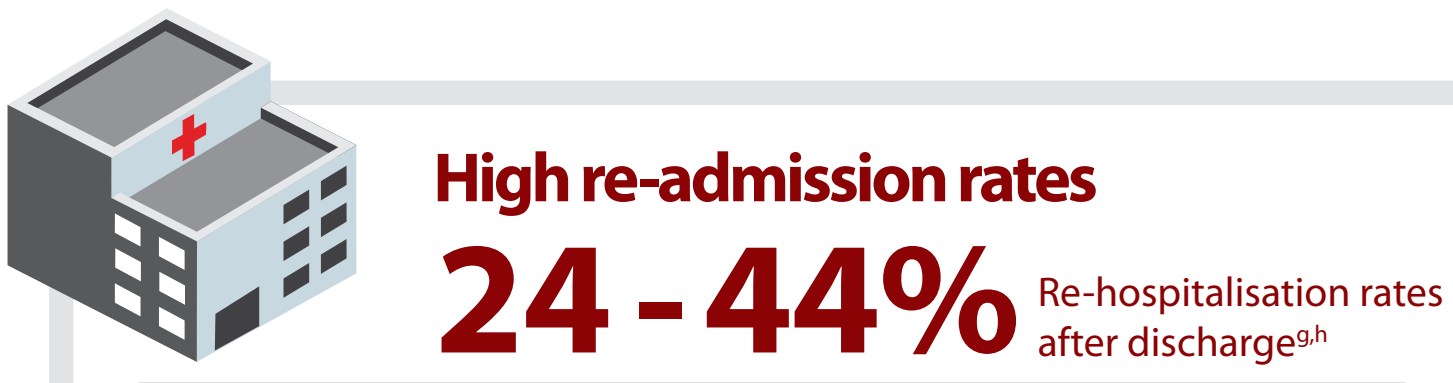

Heart Failure hospitalisations:

- have increased 3 fold

- expected to rise by more than

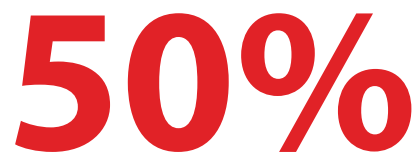

over the next 25 years ${ }^{\mathrm{e}}$

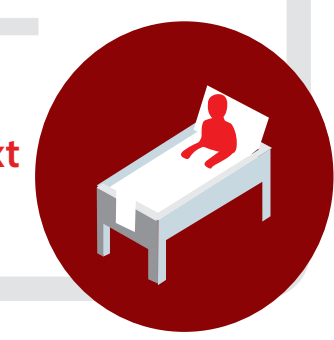

xxviii Inflated by $1.3 \%$ (Base Dec=100 January 2014)

xxix Data from 85,617 hospitalisations for acute decompensated heart failure recorded in the US Acute Decompensated Heart Failure National Registry indicated that approximately $80 \%$ of patients initially presented at the emergency department (Galvao M, 2005). 


\subsection{Outpatient Department visit}

\section{Hospitalised population}

Those hospitalised with an acute decompensation or WHF utilise OPD services more intensely, estimated at 3.5 visits per annum (12).

As HIPE entries are based on episodes of care rather than individual patients, a patient who has been admitted repeatedly will be represented several times in the database. Hence, it is necessary to adjust this figure to derive and estimate for patient numbers for this hospitalised population. To do this, the following steps are applied to HIPE data.

1. AHF admissions to a public hospitals $(5,642)$ minus inpatient mortalities $(445)$

2. Private AHF admission to a private hospital (921) minus inpatient mortality rates (74). Private inpatient mortalities were assumed to occur at the same rate as public inpatient mortalities.

3. Discharges are divided by a multiplier (1.29) in order to differentiate index and/or de novo admissions from readmissions, simultaneously approximating patient numbers. This multiplier is derived from one year hospitalisation among CHF and AHF patients, estimated at $22.7 \%$ and $30.7 \%$ respectively (155).

4. That is, representing all grades of hospitalised HF patients, the annual rehospitalisation rate is estimated at approximately $29 \%$.

(Total admissions $(5,642+921)$-mortalities

$(437+74)) / 1.29$

We have estimated an OPD visit at $€ 172$ per visit (not leading to an admission, tested by a consultant or non-consultant, with or without multidisciplinary approach not including patient treatment costs), parallel to that applied by the ESRI in 2010 when estimating the cost of stroke (€160) (156), inflating for the year 2012.

Following HSE communication, staff costs for OPD attendance were calculated using the HSE website with pension and PRSI included, estimating a per visit cost of $€ 155$ (131). This is included as a lower bound estimate for this cost category and presented in the sensitivity analysis in later sections. However the total cost is estimated based on $€ 172$ per OPD attendance.

$7 \%$ of all HSE inpatient bed days are Heart Failure related ${ }^{a}$

\section{1,042 \\ Total hospital bed days $^{a}$}

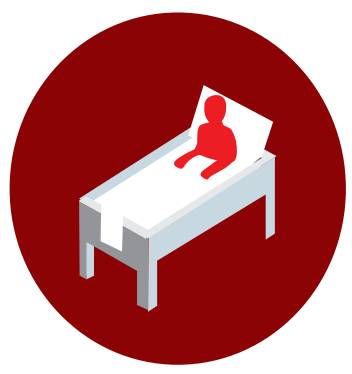

11 days

The average length of hospital stay ${ }^{\mathrm{a}}$ 
The estimated cost of Out Patient Department (OPD) visitations for this cohort is estimated as follows:

$4,691 \times € 172 \times 3.5=$ Total cost of OPD visits for hospitalised population

In addition, approximately 5\% $\%^{\mathrm{xx}}$ of HF hospital admissions are monitored with BNP (or NT-proBNP) testing. Per patient monitoring involves 4 to 9 tests (157-160). Additional drug costs per patient associated with BNP monitoring are an estimated $£ 16$ pounds (158). The associated costs of the latter care components are not applied, as these costs are included in the total cost per HF admission according to the national DRG average cost.

However it is estimated that, on average, there is an additional 0.6 outpatient visits for BNP (or NTproBNP) monitoring (159). This cost is estimated below:

$235 \times 0.6 \times € 172=$ additional $O P D$ cost due to $B N P$ monitoring

\section{Prevalence/community population}

There are limited data concerning GP referral to specialist out-patient clinics. Based on study estimates, approximately one third of the community based HF population require on average, 2 OPD visits per annum $(28,130)$.

90,071-(hospital admissions (5642+921)+mortalities)

3

$=$ total number of community HF population requiring 2 OPD visits

Final estimations equal:

$29,805 \times 172 \times 2=$ total cost of OPD care for community population

\subsection{Incidence Population (suspected HF)}

\section{Rates of Referral}

There is little information surrounding GP referral rates, both nationally and internationally. Study estimates suggest that 33 to $40 \%$ of patients with suspected HF have the diagnosis confirmed (161-163). The current annual detection rate for HF in Ireland is approximately $1 \%$ (the incidence of newly diagnosed congestive HF equalling 10,000 cases of HF diagnosed annually.

Thus, the incidence is multiplied by 3 to give an estimated 30,000 patients with suspected HF each year, all susceptible to referrals and diagnostic investigation. Recent Irish estimates indicate that up to $60 \%$ of patients with suspected HF are referred for further investigation (132). This population estimate has not been monetised.

\section{Diagnostics}

Unit costs applied for diagnostic investigation are presented below. A cost range is explored with the following lower and upper bound unit cost below. 
1. Estimated according to the hospital cost of providing such a service (including staff costs)

2. Estimated according to the economic cost of providing this service ${ }^{\mathrm{xxx} i}$. These costs are derived from the hospital finance department (i.e. Chest X-ray), St James's laboratory (BNP test) or micro costed excluding staff time \& overhead costs (i.e. ECG.)

\section{Cost of care}

The cost of a specialist assessment has been taken from the Payment by Results mandatory tariff 2010/11, 320 Cardiology, first outpatient attendance with single professional, converted to euro, and inflated to the current year using the Purchasing Power Parity Index (2012). The unit cost is estimated at $€ 266$ per patient.

$(12,420) \times € 266=$ cost of specialist assessment in incidence HF population

\section{Cardiac Rehabilitation (tertiary care)}

There is a paucity of data on referrals and discharges to cardiac rehabilitation facilities in Ireland, both from an acute and community setting.

\section{Quantity of care}

The national clinical programme examined 2 methods of rehabilitation delivery to HF patients in Ireland:

1. HF patients could access the existing cardiac rehabilitation programme. The education component of this is ischaemic based so it would require support from the HF nurse specialists in HF.

2. A HF specific rehabilitation programme managed by a HF team.

St Vincent's University Hospital (SVUH) is currently the only HF specific cardiac rehabilitation programme in Ireland accommodating 48 patients per year. Wexford, Tallaght and Cork are co-horting groups using cardiac rehabilitative staff and facilities. Most commonly, other facilities add HF patients to the main cardiac rehabilitation sessions, accommodating only 1-2 per group amounting to 1-2 per year.

Since 2011, the advanced skills programme for physiotherapists in HF was completed and now there are pilot programmes running in Sligo, Clonmel and St James's Hospital. However "access to this service for heart failure patients remains extremely poor" (133).

Data on referrals from the National Audit of Cardiac Rehabilitation Report 2008 ( $95 \%$ response rate) estimate $0.67 \%$ of hospital admissions are referred to cardiac rehabilitation services. Applying this estimate to Irish admissions, it is estimated that $44 \mathrm{HF}$ patients are admitted to cardiac rehabilitation in Ireland per annum. Thus, the comparability of results (44 and 48) suggests an analogue of the referral system for HF patients in both the UK and Ireland, where some $0.85 \%$ of hospital admissions are referred.

\section{Cost of care}

The unit cost of rehabilitation is not easily ascertained given the level of services available differs between regions. Practice may also differ within individual cardiac centres/networks; some offering specific combined exercise, diet and lifestyle advice, others offering rehabilitation as part of an existing cardiac programme, and others offering no rehabilitation services to HF patients at all.

The NICE Cardiac rehabilitation Commissioning Guide estimate cardiac rehabilitation costs at $£ 500$ per patient, adjusted using the PPP. The National Audit of Cardiac Rehabilitation estimate a median cost of $£ 461$ per patient and mean cost of $£ 625$ per person. Hence a median cost of $£ 500$ (€619) per patient is chosen. 
referred admissions $(48) \times$ cost $(€ 619)=$ total cost of rehabilitation

\section{Nursing Home Care}

\section{Quantity of care}

After hospitalisation, patients with AHF may require a transfer to long-term care units or nursing homes. In this report, the total number of days spent in a nursing-home following a hospitalisation (associated with a principal diagnosis of HF) was based on the HIPE system (2012) which reports the number of admissions directly discharged to such care per annum.

Based on the total number of admissions for HF $(5,642)$ in the year 2012 , it is possible to estimate that $9 \%$ of such admissions were discharged to nursing home care facilities in the Irish public hospital system ${ }^{\mathrm{xx} \times \mathrm{i}}$. In total,

- $97 \%$ of discharges to long term care are attributable to Congestive HF (475 discharges), Left Ventricular Failure (38 discharges) and Heart Failure, Unspecified (12).

The remaining $3 \%(6)$ of discharges to long term care are attributable to Ischemic Cardiomyopathy.

\section{Cost of Care}

The cost of nursing home care is based on the percentage of patients discharged to nursing home care each month, and their respective duration of stay, with adjustment for subsequent days of hospitalisation and HF mortalities. It is assumed that each discharge will experience at least one (re)hospitalisation (11.44 days) over the period of the year 2012, and is consequentially subtracted from the annual cost of nursing home care. Mortality rates are estimated at 1, 3 and 6 months at $6 \%, 11 \%$ and $14 \%$, respectively (136).

The unit cost (daily) was derived from both public and private nursing home care markets in Ireland (2012). On average, the HSE (137) report the gross cost of a nursing home bed at $€ 138$ per day (€966 weekly). This is comparable to the midpoint taken for low to medium dependency patients in private nursing home support, at $€ 975$ per week (range: $€ 650-1300$ ) although below the average reported cost of public nursing home support (range: $€ 430-€ 2,518$ ) estimated at $€ 1,474$. Current data suggests the hourly rate charged by the HSE and non-profits are $30 \%$ more expensive than the private sector (138). In this report, the private sector cost of $€ 975$ per week is applied (daily cost of $€ 138.90$ ).

Total nursing home costs are obtained by multiplying the total number of days spent in care (stratified by mortality rates and subsequent survival trends) by the number of HF patients, times the daily cost. It is assumed that each HF resident will experience, on average, one hospitalisation during the period of 2012 i.e. (11.44 days).

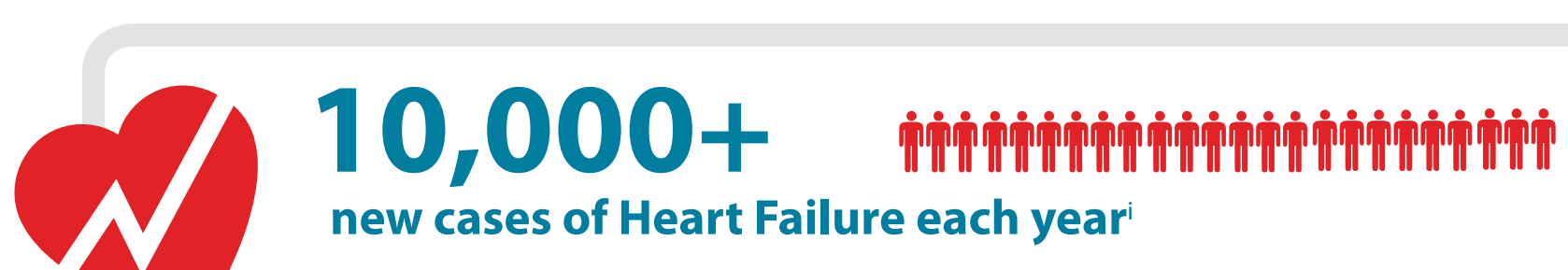

xxxii This figure does not include patients admitted and discharged to a nursing home; only those newly discharged according to HIPE. This was to ensure only those discharged in 2012 were captured in the cost. 


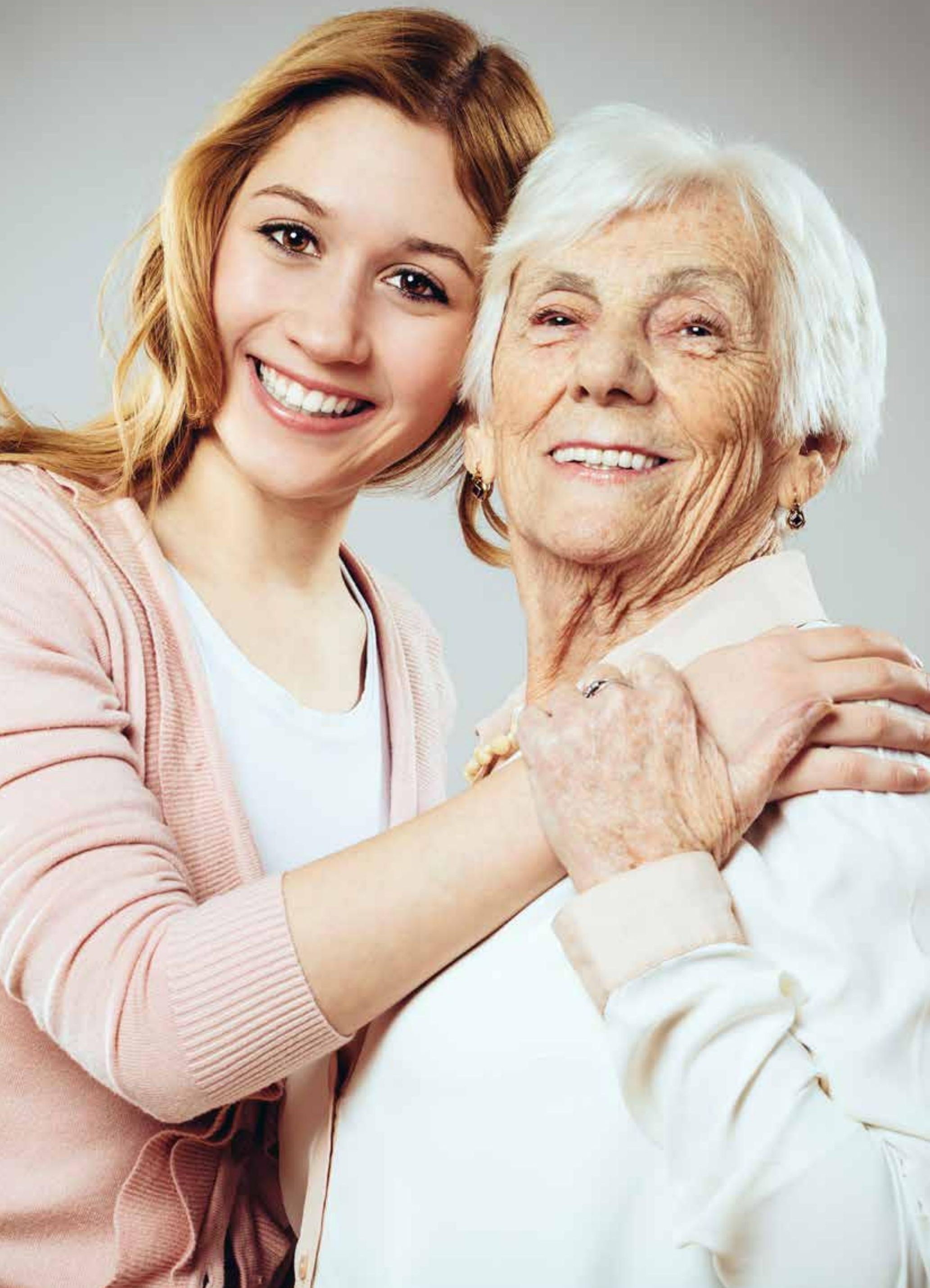




\section{Drug Treatment and prescriptions}

The mainstay treatment of HF is drug therapy which typically consists of diuretics, ACEls and beta blockers, in addition to various life-style measures, taking regular exercise and monitoring weight gain that might suggest fluid retention. Present drug therapy represents a small proportion of the costs associated with HF.

\section{Cost of HF medication}

Given high levels of co-morbidities in HF patients, and the multiple medications (listed below) used for treating a variety of conditions, we have applied a robust maintenance regime of three prescriptions (average cost of 113 ACEls + diuretics + betablockers) per HF patient, which are identified as key first line treatments in HF patients $(104,139)$. Approximately $20 \%$ of HF patients are intolerant to ACEls (164) and are separately calculated, simply replacing the ACEI with an ARB (weighted average of $\mathrm{ARBs}+$ diuretics + beta-blockers).

Although the pharmaceutical guidance relates to HF-rEF, the treatment of co-morbidities such as hypertension and atrial fibrillation means that most patients with HF-pEF are on similar medications $(132,165)$. Under the Medicines Management Programme (MMP), it is stipulated that some medications (e.g. ACEls) have dual indications and can thus be used to treat alternate conditions, such as hypertension. The therapeutic effects of essential drugs such as ACEls, beta blockers and diuretics do not, in general, significantly differ between ischemic and non-ischemic HF. Hence it is assumed that these pharmaceutical classes are used to primarily treat HF or secondary to another cardiovascular condition precipitated by HF, or simply developed over the course of their disease.

All available drug treatments within these therapeutic classes were further identified in the Monthly Index of Medical Specialities (MIMS) Ireland (166). From this, 113 brands (mainly generic drugs) were identified as possible first and second line treatments in CHF. Treatment costs for each drug were calculated via daily, monthly and annual dosage regimens under the headings of ACEIs, BBs, diuretics, ARBs, and aldosterone antagonists. Unit costs per tablet/ml per drug were obtained from the Primary Care Reimbursement Scheme (PCRS) or MIMS, and estimated by dividing the pack size (number of tablets/ml) by the cost. Monthly costs were then estimated by assuming an average of 30 days per month. Pharmacists receive a dispensing fee of $€ 4.54$ for GMS items dispensed to those over 70 years, which was additionally added to the monthly drug cost (167).

Annual costs per patient were simply obtained by multiplying the daily costs (plus additional fees per pack) by number days on medication, and applying this to the estimated prevalence population $(90,071)$. The wholesalers receive a $17.66 \%$ wholesale mark-up for delivery of drugs to community pharmacies. Drug taken from the Primary Care Reimbursement Scheme (PCRS) ${ }^{\text {xxiii }}$ reimbursable list were multiplied by 1.08 to account for this.

\section{Medication}

Drug costs account for $16 \%$ of total direct cost of Heart Failure ${ }^{a}$ 


\section{Quantity of drug doses}

Total annual drug costs were estimated for two populations.

\section{Prevalence/community based population}

\section{Hospitalised population}

For each, the annual number of drug doses are estimated, taking into account mortalities and subsequent days spent in hospital (where drug costs are inclusive in the DRG cost) and subtracting from annual drug doses (maximum 365 doses per annum). Total HF mortalities (537) in 2012 are based on the CSO, 2012 (102).

\section{Adherence to medication}

Mockler and colleagues (168) carried out a retrospective analysis of HF patients $(n=350)$ attending a 1 year follow up diseasemanagement programme (DMP) at St. Vincent's University Hospital, outpatient clinic ${ }^{x x x i v} 78 \%$ of patients reported that they were adherent to medication on a self-report questionnaire (4-item Morisky Medication Adherence Scale). Medication possession ratio $^{\mathrm{xxx}}$ (obtained and calculated from pharmacy records) was available in a subset of these patients $(n=106)$, of which $76 \%$ were considered adherent on this measure (MPR greater than $85 \%$ ). The author acknowledges that this population received specialist $\mathrm{HF}$ care and these figures may not reflect prescribing in other Irish HF populations. However, in the absence of alternative Irish specific data, the evidential dispersion of reported HF adherence levels personal communication with the study's co-authors ${ }^{\times x v i}$ a composite adherence level of $75 \%$ is applied to estimate the total annual cost of drug therapy in 2012.

\subsection{Non healthcare expenditure: Methodology}

\subsubsection{Informal care}

In addition to the cost to healthcare systems, HF can have a wider societal burden. HF patients require assistance with dayto-day living, particularly those with significantly reduced functional capacity in later stages of the condition. The negative consequences and functional decline after an AHF are not often temporary, so that the decline and subsequent care continues in the first year following diagnosis (169). High levels of co-morbidities associated with this population may also necessitate and/ or complicate care, especially in the AHF population (155). Despite this, most HF patients reside in their own home, but require effective management and ongoing home based care.

Necessitating a fine balance of 'gains' and 'strains' (170), the caregiver burden is a multidimensional construct encompassing the mental, physical, financial, and social impacts that informal care providers experience. In Ireland, as in most countries, the bulk of the care of older persons is provided by family caregivers, primarily spouses and adult children (171). However, there is little research examining the role of informal caregivers in the management of HF, despite the recognition that informal support has the potential to assist tertiary prevention in CHF. This is particularly in relation to compliance enhancement, facilitating self-care, and seeking treatment for worsening symptoms. Moreover, informal care is not explicitly captured by national datasets, nor subsequently examined in cost of illness studies, leading to a significant underestimation of the cost of illness (172).

A generalised census in the Republic of Ireland (173) indicated that a total of 6,287,510 hours of informal care was provided each week in 2011, giving an average of 33.6 hours per week per carer. A further review of this data by Care Alliance Ireland suggests that carers in Ireland provide an average of 35 hours per week of care. However, for those who reported providing full-time care (43+ hours or more), the average was 110 hours per week. According to a survey by O'Brien (142) including 10,000 family carers, $70.7 \%$ cared for more than 50 hours per week (95\% Confidence Interval; 68.6-72.8).

\footnotetext{
xxxiv HF Patients attending this HF programme were under the care of Professor McDonald (HSE national clinical lead for HF).

xxxv Number of days of medicine supplied within the refill interval divided by the total number of days in refill interval

xxxvi Professor McDonald, a key consultant at St Vincent's hospital and clinic- HSE national clinical lead in HF. Dr. Margaret Bermingham,

a clinical pharmacist based in the Heart Failure Unit, St Vincent's University Hospital and is a researcher in the Chronic Cardiovascular Disease Management Group
} 


\section{Cost of care}

The indirect cost of HF is estimated using the human capital approach (which is based on gross earnings), where the total value of income potentially lost by the worker due to absence from work is counted. Work and leisure time lost due to informally caring for HF patients (including both incident and prevalent cases) in 2012 is multiplied by the estimated earnings of the caregivers. These earnings are estimated as follows:

Using the human capital approach, the number of hours of informal care provided by caregivers in paid employment was multiplied by the productive value of paid work, proxied by the mid-point between CSO median wage of $€ 22$ per hour and the minimum wage of $€ 8.65$ in 2012 , equalling $€ 15.32$ and conservatively applied (140).

The number of hours of informal care provided by the economically inactive i.e. retired/unemployed is valued at leisure time; a hybrid or mark-up approach has been adopted and proxied leisure time at $1 / 3$ rd of the median industrial wage (€22) equalling $€ 7.33$.

The number of hours of informal care provided by those attending college or with similar academic commitments is estimated at $€ 8.65$.

\section{Quantity of care}

The number of hours required by CHF patients is calculated in accordance with the International Classification of Functioning, Disability and Health (ICF) (174). In accordance with this methodology, it is estimated that CHF patients receive, on average, 6.7 hours of informal care per week. The CHF population is estimated taking into account those hospitalised during the year 2012. Once these days are subtracted, an even dispersion of carers (and their economic status) among each NYHA classification is assumed, with each classification receiving, on average, 6.7 hours per week. The latter estimate is conservatively applied and calculated by multiplying the weekly cost by 52 weeks gives the total annual cost of chronic informal care.

\section{Hospitalised population (acute patients)}

The Irish Longitudinal Study on Ageing (TILDA) captures Activities of Daily Living (ADL) and Instrumental Activities of Daily Living (IADL) difficulties in the general 50+ population (not exclusive to HF patients); the mean IADL is 1.7 for age group 50-64, 1.6 for age group 65-79, and 2.0 for age 80 and over. The mean ADL is 1.6 for age group 50-64, 1.9 for age group 65-79, and 2.5 for age 80 and over (175). For those with IADL difficulties only, an average of 67 hours of informal care per month is given (15.6 hours per week), compared to those with ADL difficulties only. Those with difficulties in both ADL and IADL such as HF receive, on average, 118 hours of informal care per month (27.5 hours per week); this represents an intense level of care for this population.

Although Gure et al., (141) reports an average of 6.7 hours of informal care for CHF patients (following an adjustment for hospital admissions), there is a rationale for applying a higher rate of informal care to those previously hospitalised for $\mathrm{HF}$ in accordance with the ADL/IADL findings from TILDA (i.e. 27.5 hours per week). Given the low levels of follow up care (e.g. cardiac rehabilitation) and step down facilities (e.g. nursing home care) available to HF patients in Ireland, in particular those discharged from a hospital setting (AHF patients), it is assumed that this deficit is addressed by family and friends (informal care), and thus a higher rate of informal care was applied exclusively to the hospitalised for HF in 2012. An additional 1.3 hours of formal care is required for all HF patients (141) but was not considered in this report.

Hence, the number of care hours required by AHF patients is intensified to 27.5 hours per week per annum; approximately 4 hours per day ( 3.93 hours, rounded). Before applying this to the number of AHF patients, the following calculations are made.

The number of hospital admissions in 2012 with a primary diagnosis of $\mathrm{HF}$

Minus in-patient mortalities (445 public +74 private)

Minus all ${ }^{x x v i i}$ discharges to nursing/Long Term Care (LTC) (531 public +76 private; approx. 9\%) 
The number of patients discharged to their home is estimated by dividing the total by 1.29 (as done in previous sections).

The calculations are depicted in order of calculation below.

Figure 7. Patient calculations

\section{minus patients discharged to LTC}

This results in 4,215 Acutely AHF patients. Finally, the number of days spent in hospital for an index admission and subsequent readmissions was subtracted from the total numbers of days in the year to estimate the annual number of informal care hours required:

$(365-(11.44 \times 1.29) \times 4=$ annual number of informal care hours per patient

The annual cost for this cohort is then calculated as the annual number of informal care hours, multiplied by the hourly economic wage, multiplied by the number of patients (estimated above).

\section{1,376 hours annually $\times$ hourly economic wage of carer $\times 4,215=$ annual cost of informal acute care}

\subsubsection{Life years lost}

\section{Quantity}

Age and gender specific mortality rates were obtained from the national registry (102). The conservative estimate (for reasons previously detailed see section 5.3 ) of 537 mortalities is applied.

\section{Cost}

Although this population xxxviii may be involved in some form of non-market productive activities, either in a private, voluntary, or retired capacity, the monetary valuation of this activity is difficult. A series of values for the value of a life year (VOLY) lost are put forth in the literature, ranging from $€ 21,000$ to $€ 56,000$ for all age groups. In Canada, Krupnick et al., (176) found a value of a statistical life to be $C \$ 0.6$ million for people aged 70 and above (€460,000 unadjusted) and in the UK, Jackson et al., (177) found 
the value of life to be $£ 300,000$ ( $€ 450,000$ unadjusted). The latter estimates are valued using a technique based on willingnessto-pay (for reduction in current and future risk of death) rather than on market earnings. As the majority of these patients are economically inactive and non-participative in the labour market, the application of the VSLY was concluded an inaccurate application. However, the midpoint $(€ 455,000)$ of previously reported estimates (range from $€ 450,000$ to $€ 460,000$ ) is included for evaluation in the sensitivity analysis (see sensitivity analysis).

Ideally, in Ireland, the QALY (Quality Adjusted Life Year) measure represents society's willingness to pay (WTP) to avoid pain and suffering losses. The individual who becomes ill would have been in perfect health (QALY 1) if not for the illness. Applying Irish life tables to reported mortalities for the year 2012, variation in the certified age of death and the expected life expectancy at the time of death was quantified individually per mortality and subsequently multiplied by the QALY value to derive a monetary value for premature life loss. Given the societal approach of this report, it could be argued that the QALY value $(€ 45,000)$ should remain constant, expelling any adjustments for age, gender or levels of disutility caused by HF (143).

Whether this approach is consistent with welfare economics, however, depends on how, empirically, WTP for a reduction in risk of death varies with age. This procedure implies that each year of life is equally valuable, and the QALY is proportional to the remaining life expectancy. All values are discounted at 5\% in accordance with HIQA guidelines 2014, by applying the following formula to all Life Years Lost (LYL):

$P V=\frac{A \times 1-(1+r)-^{\top}}{r}$

Discounting health with time reflects the social preference of a healthy year now, rather than in the future.

Applying this methodology, the following equation is estimated:

number of premature life loss $\times Q A L Y$ value (unadjusted)-discount rate $5 \%$

$=$ cost of premature life loss due to heart failure

Although, to the authors knowledge, no previous cost of illness studies have attempted to monetise LYL in HF populations prior to this report, Stewart et al., (84) valued premature life loss in HF based on age and sex-dependent QALY values available in 5-year intervals: QALY values equalled 1 per year for ages up to 50 years, successively decline with age to 0.76 and 0.67 QALY per year for 85-year-old men and women, respectively (178). Applying this methodology, LYL in age categories 85 years and older are monetised with a revised QALY value. This QALY value is adjusted downwards to reflect a successive decline in health and, potentially, an equivalent WTP to avoid ill health.

number of premature life years lost $\times Q A L Y$ value (adjusted for age and gender) $-5 \%$ discount rate

$=$ cost of premature life lost due to heart failure

\subsubsection{Disability Adjusted Life Years (DALYS)}

The disability adjusted life year (DALY) is a measure combining the morbidity and mortality associated with a condition. According to the World Health Organisation (WHO),

"One DALY can be thought of as one lost year of "healthy" life. The sum of these DALYs across the population, or the burden of disease, can be thought of as a measurement of the gap between current health status and an ideal health situation where the entire population lives to an advanced age, free of disease and disability".... DALYs for a disease or health condition are calculated as the sum of the Years of Life Lost (YLL) due to premature mortality in the population and the Years Lost due to Disability (YLD) for people living with the health condition or its consequences" (179). 
The years if life years disabled (LYD) are estimated as follows:

$$
\operatorname{LYD}=\text { Incidence }(10,000) \times \text { Disability weight }(0.24-0.36) \times \text { disease duration }(7.7)
$$

The number of $L Y L$ is estimated as follows:

$\mathrm{LYL}=$ number of deaths $(537) \times$ age $\&$ gender specific life expectancy at time of death

Combined, these measures result in the DALY:

$D A L Y=L Y D(23,100)+\operatorname{LYL}(3,683)$

The mortality rate of 775 deaths in 2012 (when applying the extended codes) was not estimated. 


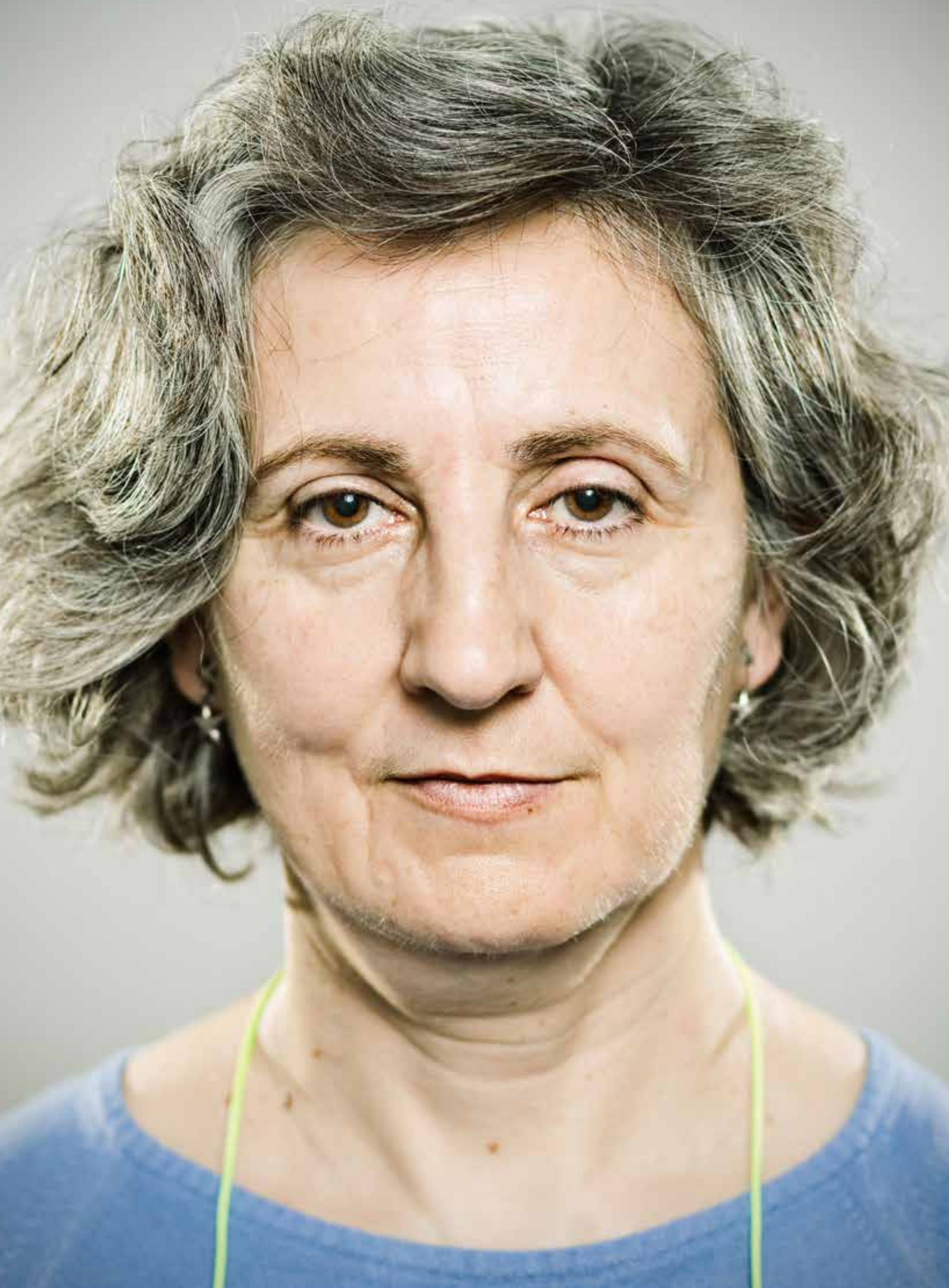




\section{Results}

This section of the report provides detailed cost estimates of HF in Ireland for the year 2012. The main costs estimated were those relating to inpatient hospital stays, ED visits, outpatient visits, GP visits, LTC, informal care, pharmacotherapy and premature mortality. HF expenditure has been estimated separately to include primary HF related costs only, the primary analysis of this report. In addition, a separate calculation of HF related costs has been estimated (for example including $\mathrm{HF}$ related hospital admissions and subsequent nursing home discharges, ambulance costs, and increased OPD visitations).

The current annual cost of HF in Ireland is estimated to be $€ 656,236,255$, increasing to $€ 778,607,367$. This report addressed seven pertinent costs of $\mathrm{HF}$ and their proportionate share of expenditure, depicted below.

Table 8. Total cost of Heart failure components

\begin{tabular}{|c|c|c|c|c|c|c|c|}
\hline \multicolumn{2}{|l|}{ Cost Groups } & \multicolumn{3}{|c|}{ Primary HF Costs } & \multicolumn{3}{|c|}{ HF related costs } \\
\hline Cost category & Description & $\begin{array}{c}€ \text { Cost } \\
\text { (primary HF } \\
\text { related costs) }\end{array}$ & \% Total Cost & $\%$ Direct Cost & $\begin{array}{l}\quad € \text { Cost } \\
\text { (including HF } \\
\text { related costs) }\end{array}$ & \% Total Cost & \% Direct Cost \\
\hline & Community care & & & & & & \\
\hline \multirow[t]{2}{*}{ Direct cost } & $G P$ & $€ 40,093,486$ & $6.1 \%$ & $24.8 \%$ & $€ 40,093,486$ & $5 \%$ & $14 \%$ \\
\hline & Hospital Costs & & & $\begin{array}{c}47 \% \text { total } \\
\text { hospital activity }\end{array}$ & & & \\
\hline \multirow[t]{7}{*}{$\begin{array}{l}\text { Hospital } \\
\text { activity }\end{array}$} & Hospitalisations & $\begin{array}{c}€ 42,943,087 \\
\text { (Public } \\
€ 36,916,791 \text { \& } \\
\text { Private } \\
€ 6,026,296)\end{array}$ & $6.5 \%$ & $27.2 \%$ & $\begin{array}{c}€ 138,172,965 \\
\text { (Public } \\
€ 132,146,669 \\
\text { \& Private } \\
€ 123,046)\end{array}$ & $17 \%$ & $47 \%$ \\
\hline & Ambulance & $\begin{array}{c}€ 876,817 \\
\text { (Public } \\
€ 753,771 \text { \& } \\
\text { Private } \\
€ 123,046)\end{array}$ & $0.1 \%$ & $0.6 \%$ & $\begin{array}{c}€ 2,852,761 \\
\text { (Public } \\
2,617,402 \& \\
\text { Private }\end{array}$ & $0 \%$ & $1 \%$ \\
\hline & $O P D$ & $€ 12,638,660$ & $1.9 \%$ & $8.0 \%$ & $€ 27,420,852$ & $4 \%$ & $10 \%$ \\
\hline & $\begin{array}{l}\text { Heart Transplant } \\
\text { Procedure }\end{array}$ & $€ 2,925,582$ & $0.4 \%$ & $1.9 \%$ & $€ 2,925,582$ & $0 \%$ & $1 \%$ \\
\hline & $\begin{array}{l}\text { Specialist } \\
\text { assessment }\end{array}$ & $€ 3,275,023$ & $0.5 \%$ & $2.1 \%$ & $€ 3,275,023$ & $0 \%$ & $1 \%$ \\
\hline & Cardiac Rehab & $€ 29,722$ & $0.005 \%$ & $0.02 \%$ & $€ 29,722$ & $0 \%$ & $0 \%$ \\
\hline & Diagnostics & $€ 11,161,663$ & $1.7 \%$ & $7.1 \%$ & $€ 11,161,663$ & $1 \%$ & $4 \%$ \\
\hline $\begin{array}{l}\text { Community } \\
\text { care }\end{array}$ & $\begin{array}{l}\text { Nursing home } \\
\text { care }\end{array}$ & $€ 17,925,376$ & $2.7 \%$ & $11.3 \%$ & $€ 34,334,770$ & $4 \%$ & $12 \%$ \\
\hline Drug costs & Pharmacotherapy & $€ 26,137,255$ & $4.0 \%$ & $16.5 \%$ & $€ 26,137,255$ & $3 \%$ & $9 \%$ \\
\hline \multirow[t]{2}{*}{ Indirect cost } & Informal care & $€ 364,188,083$ & $55.5 \%$ & N.A & $€ 364,188,083$ & $47 \%$ & N.A \\
\hline & Premature life loss & $€ 134,041,499$ & $20.4 \%$ & N.A & $€ 134,041,499$ & $17 \%$ & N.A \\
\hline Total & & $€ 656,236,255$ & N.A & N.A & $€ 778,607,367$ & N.A & N.A \\
\hline
\end{tabular}


This report examines the cost associated with HF in three specific categories. Firstly, the annual costs associated with the HF population living in the community $(90,071)$. Secondly, patients with suspected HF who incur diagnostic and specialist assessment costs $(30,000)$, and finally, the hospitalised HF population where resource utilisation is increased $(6,563)$. The aforementioned patient groups are not entirely independent or mutually exclusive, and cost overlap between groups is explored in the following section.

\subsection{Direct Costs}

\section{HF living in the community}

\section{GP cost}

Results indicate complex, intensive and predominantly physician driven care. The total expenditure for GP consultations in the year 2012 was estimated at $€ 40,093,486$. Clinic appointments accounted for $€ 36,448,624$ of the cost, while an additional $€ 3,644,862$ is attributable to home visits.

\section{OPD reviews}

This component of healthcare expenditure totalled $€ 12,638,660$ (applying the micro-unit costs totalled $€ 8,153,768$ ).

Assuming one third of HF patients (excluding those hospitalised), approximately 28,460 , attended an average of 2 OPD hospital outpatient visits (at a cost of $€ 172$ per visit) for further investigation/specialist management, costing $€ 9,790,186$.

Increased visitations experienced by those previously hospitalised in the year 2012 totals $€ 2,824,267(4,035$ hospitalised public patients costing $€ 2,429,000 ; 864$ hospitalised private patients $€ 519,909$ ).

Patients who received BNP monitoring in hospital subsequently receive, on average, 0.6 additional OPD visits costing $€ 24,208$.

\section{Drug therapy}

The cost of community based pharmacological management of HF patients in 2012 (according to the major classes of drugs used to treat this syndrome) is estimated to cost the HSE $€ 26,137,255$. The annual drug cost per patient averages at approximately $€ 194^{\text {xxxix }} € 290^{\times 1}$ per patient per annum.

\section{Diagnostics}

Assuming that,

One third of patients referred for further investigation of a chest $x$-ray and ECG $(€ 4,056,688)$.

- $5 \%$ of patients are monitored in hospital with, on average, 6.5 BNP tests $(€ 34,580)$ (already included on DRG cost, no separate calculation required).

Additional drug cost associated with BNP monitoring is approximately $€ 20.63(€ 5,488)$ (already included in DRG cost, no separate calculation is required).

The total cost of diagnostics for this patient population is estimated at $€ 4,056,688$. 


\section{Cardiac rehabilitation}

Referral to cardiac rehabilitation is both nationally and internationally low for HF. Based on previous (180) and recent UK findings (181), Irish research (104) and personal communication with the HSE cardiac services staff (HF), a limited provision and participation of HF patients among such programmes is evident. This equates to approximately $0.05 \%$ of the community $\mathrm{HF}$ population referred to cardiac rehabilitation services in 2012 , costing $€ 29,722$.

Total direct cost associated with the community HF population is an estimated $€ 82,955,811$. A diagram presenting the treatment pathway of this patient population is available in Appendix $K$.

\section{Suspected Heart failure/ Incidence Population}

There is limited data relating to the referral process of HF patients. The number of people presenting with suspected $\mathrm{HF}$ is based on UK findings $(30,163)$, and as part of discussions with health care practitioners $(12,132)$. Minimum (hospital) and maximum (economic) diagnostic unit costs were available and deliberated for this population. The impact of applying either unit cost was calculated and concluded negligible, given the minimal variance in unit costs and small patient numbers.

Following the patient algorithm for suspected HF patients (see Appendix $K$ ), the diagnostic costing and patient referrals are described in a summarised table format below. Applying minimum and maximum unit costs, the total ranges from $€ 5,058,374$ to $€ 7,104,974$ in 2012.

In total, the diagnostic cost of the communityxli (prevalence) and suspected HF (incidence) population is estimated at $€ 11,161,663$. Both cost applications are presented below with the assumption that,

- $30 \%$ of the suspected HF population will receive a BNP test

- $90 \%$ of the same population receive an ECG

- $46 \%$ of patient will have raised or high BNP, and a subsequent $46 \%$ will have an abnormal ECG

- $100 \%$ of these patients will be referred for specialist assessment and an echocardiogram

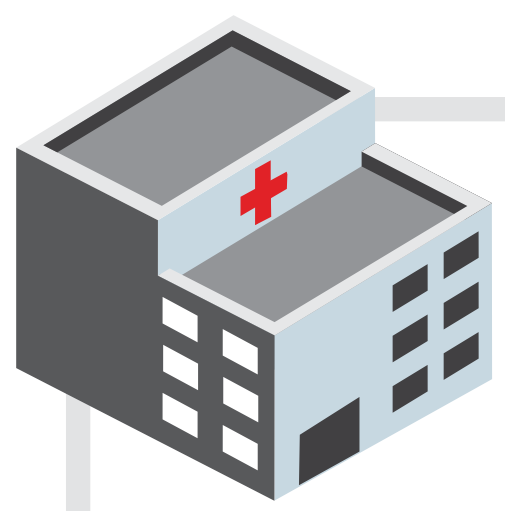

\section{Hospital related costs are}

\section{$47 \%$ of total direct cost of Heart Failure}


Table 9. Investigations- unit costs, quantities, and data sources

\begin{tabular}{|c|c|c|c|c|c|c|c|}
\hline Description & Quantity & Description & Total & $\begin{array}{l}\text { Unit } \\
\text { cost } €\end{array}$ & Cost Source & Patients (n) & $\begin{array}{c}\text { Total cost } \\
€\end{array}$ \\
\hline \multicolumn{8}{|c|}{ Diagnostic Procedures } \\
\hline BNP testing & 1 & $\begin{array}{l}30 \% \text { of population }(30,000) \\
\text { get BNP test }\end{array}$ & 9,000 & 20 & Roche figure & 9,000 & 180,000 \\
\hline ECG & 1 & $90 \%$ of the population $(30,000)$ get an ECG & 27,000 & $8.52-42$ & $\begin{array}{l}\text { NHS CHF costing } \\
\text { report (2010) }\end{array}$ & 27,000 & $\begin{array}{l}230,040- \\
1,134,000\end{array}$ \\
\hline $\begin{array}{l}\text { Echo- } \\
\text { cardiogram }\end{array}$ & 1 & $\begin{array}{l}100 \% \text { of Patients with abnormal ECG and } \\
\text { raised and/or High BNP ( } 46 \% \text { of patients) } \\
\text { levels sent for echo }(12,420)\end{array}$ & 12,420 & $108-200$ & $\begin{array}{l}\text { Expected hospital } \\
\text { cost } € 200 \\
\text { (Gallagher 2013) }\end{array}$ & 12,420 & $\begin{array}{l}1,341,360- \\
2,484,000\end{array}$ \\
\hline $\begin{array}{l}\text { Specialist } \\
\text { assessment }\end{array}$ & 1 & $\begin{array}{l}\text { Patient referred from ECG to echo with } \\
\text { abnormal rhythm found-approx. } 100 \% \\
\text { (of } 12,420 \text { ) sent for specialist assessment }\end{array}$ & 12,420 & 266 & $\begin{array}{l}\text { NHS CHF costing } \\
\text { report (2010) }\end{array}$ & 12,420 & $€ 3,306,974$ \\
\hline
\end{tabular}

A diagram presenting the treatment pathway of this patient population is similarly available in Appendix $K$.

\section{Hospitalised population}

The total cost of inpatients hospitalisations for the year 2012 is estimated at $€ 42,943,087$. This can be segregated into the public $€ 36,916,791$ and private $€ 6,026,296$ cost. In 2010 , Voluntary Health Insurance (VHI) paid over $€ 1$ billion in claims and over $€ 23$ million was paid out for patients with a diagnosis of HF (182). That is, over $23 \%$ of all VHI expenditure for the year 2010 was HF related.

\subsection{Indirect expenditure: Non healthcare}

\section{Informal care}

The total cost of informal care in Ireland for the year 2012 is estimated at $€ 364,188,083$. This includes $€ 59,865,219$ in acute informal care per annum and $€ 304,322,864$ in chronic informal care per annum.

Keeping a constant 6.7 hours for both acute and chronic care totals, acute HF patients receive the value of $€ 14,585,344$ in informal care, estimating a total cost of $€ 318,908,208$.

\section{Premature Life Years Lost (LYL)}

The monetary value derived from premature life lost due to HF in Ireland in 2012 is presented below in accordance with the applied methodologies. For the purpose of this report, equation 1 is estimated in the total cost.

1. $€ 134,041,499$ discounted at $5 \%$ (discounting at $3.5 \% € 142,013,119$ )

2. $€ 117,110,087$ discounted at $5 \%$ (discounting at $3.5 \% € 124,538,493$ ) 


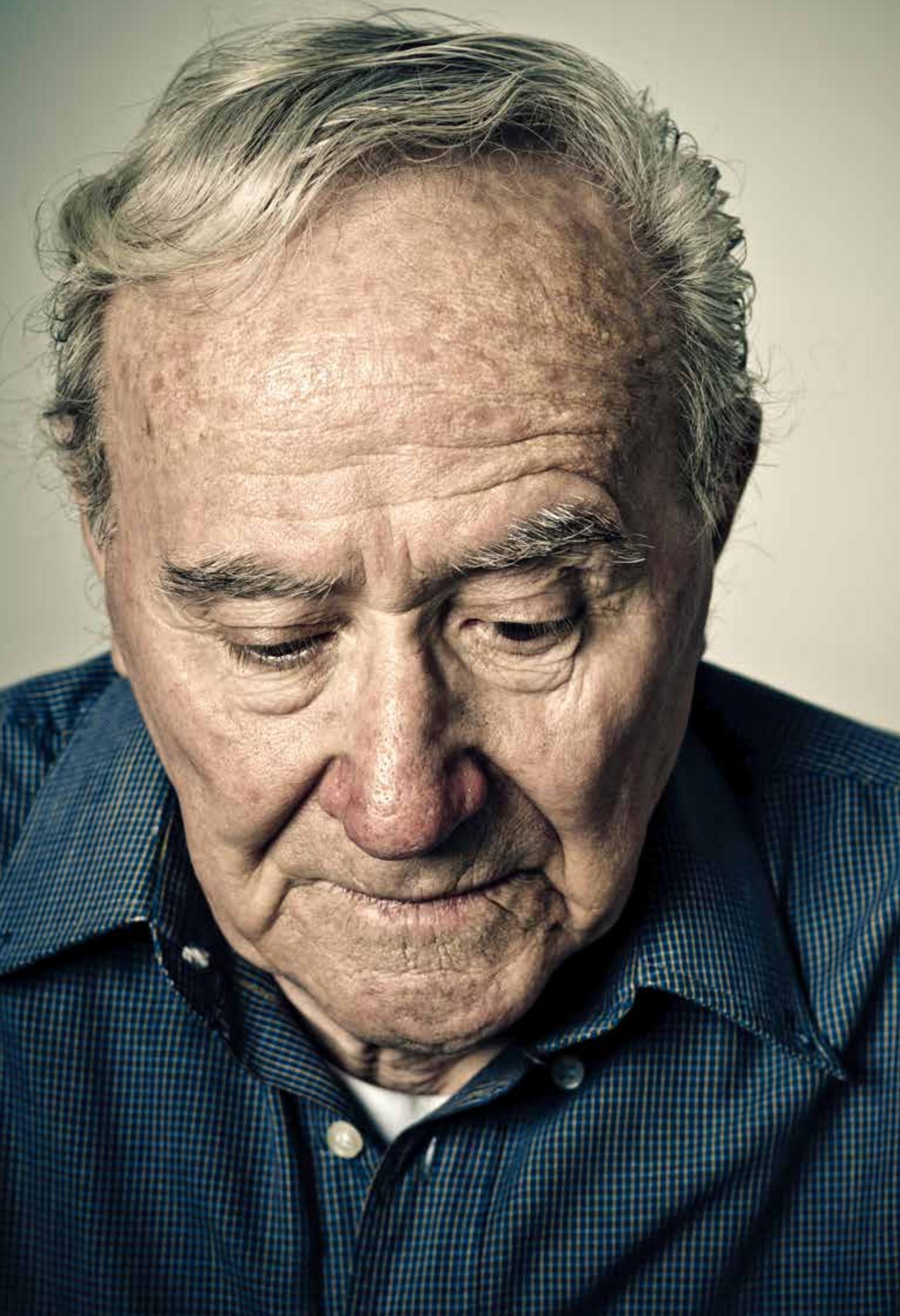




\section{Sensitivity analysis}

The impact of uncertainty in relation to both resource use and unit costs is explored using sensitivity analysis. A number of variables in our report were tested in order to ascertain how sensitive our results were to changes in these variables. The parameters analysed altered the baseline cost of HF positively and negatively, and is synthesised in the table below. Primary HF costs are applied as the baseline cost in this analysis.

Table 10. Sensitivity analysis variation

\begin{tabular}{|l|c|c|}
\hline Description & Upper Bound Variation ${ }^{3}$ & Lower Bound Variation \\
\hline Hospital Admissions & $€ 751,466,133$ & $€ 653,959,217$ \\
\hline Nursing home care & $€ 712,747,463$ & $€ 661,732,076$ \\
\hline GP Vists & $€ 678,399,328$ & $€ 641,536,515$ \\
\hline LYL & $€ 770,557,173$ & $€ 583,105,548$ \\
\hline Informal Care & $€ 726,266,356$ & $€ 582,770,850$ \\
\hline
\end{tabular}

\section{Premature life loss}

The variable with most uncertainty was the value of a life year, estimated at $€ 45,000$ per annum (without accounting for any QALY loses over time), totalling a baseline per annum cost of $€ 134,041,499$ (discounted at a rate of $5 \%$ ). The value of a life estimated at $€ 455,000$ represents an upper bound (183). Applying the PPP adjusted UK Cost Effectiveness (CE) threshold of $€ 19,196$ represents a lower bound (184). This results in an upper and lower bound for $L Y L$ of $€ 244,630,750$ and $€ 57,179,125$, respectively. This equates to a positive and negative increase and decrease from the baseline of $€ 110,589,251$ and $€ 76,862,374$, respectively, equating to an increase and decreases of $83 \%$ and $57 \%$ from the baseline

\section{GP clinic appointments}

Although primary care visits for HF patients are mainly HF related, it cannot be certain that all of these visits primarily relate to HF. That is, correlation does not imply causation. For this reason, the number of GP visits per patient per annum is adjusted downwards to reflect the national average in the ROI of 3.2 visits per annum (185), and that reported by TILDA which suggests a cumulative increase from 2.9 visits (50-54 years) to $5.7 \mathrm{GP}$ visits in those aged 80 years and above (186). A composite measure of 4.45 GP visits per annum captures an average baseline GP visitation rate in the adult and elderly Irish population.

Accounting for this, 4.45 is subtracted from the average visits associated HF patient in Ireland (i.e. 8.8 visits per annum). This estimates a lower and upper bound of 4.35 and 13.25, respectively. That equates to upper and lower bound estimates of $€ 54,880,031$ and $€ 18,017,218$, respectively, varying positively and negatively by $51 \%$ from the baseline $(€ 36,448,624)$.

\section{Hospitalisations/admissions}

Complexity surrounding HF diagnosis, availability of trained clinical coders to impute accurate diagnostic detail, and a reluctance to code the admissions and or death as HF (previously discussed) has led to some uncertainty in the public ${ }^{x l i}$ acute setting cost, currently estimated at $€ 36,916,791$ (excluding private admissions and $\mathrm{HF}$ related admissions other than primary coded cases).

There is little uncertainty surrounding the number of HF admissions with a primary and all case diagnosis, and subsequent number discharged to nursing home care in the same year. However, the large variation in the number of admissions with a primary and all case diagnoses (definite versus probable HF) and nursing home discharges should be explored. 
To explore this variation in hospitalisations/admissions, an upper bound estimate is derived through the inclusion of secondary and/or all case HF admissions (estimated at 20,432 admissions) whereby HF is listed further down ${ }^{\text {xliii }}$ on the medical chart. Similarly, the extension of HF related disease codes $^{\text {xliv }}$ in the baseline estimate equates to an additional 348 admissions. These are removed to create a lower bound estimate, leaving only pure primary HF related admissions $(5,294)$. This results in upper and lower bound thresholds of $€ 132,146,669$ and $€ 34,639,754$ respectively. The upper and lower bound increase and decrease from the baseline cost of $€ 36,916,791$ by approximately $258 \%$ and $6 \%$, respectively. The exploration of uncertainty in hospital costs is done independent of the private setting.

\section{Nursing home}

Calculating the cost of nursing home care based on all case HF discharges in the public setting $(1,704)$, excluding those admitted from (not just discharged to) a nursing home in the same year. This increases the total cost of nursing home care to $€ 74,436,584$, the upper bound estimate. Based on all primary HF discharges (536) to a nursing home, i.e. including those who were both admitted from and discharged to a nursing home in the same year increases the total cost to $€ 23,421,197$. That is, a $315 \%$ and $31 \%$ increase and decrease from the baseline cost of $€ 17,925,376$.

In tangency with the methodology applied by Stewart et al., (28), assessing both the increase in HF admissions due to the inclusion of secondary/all case coding of HF admissions and the subsequent cost of nursing home care, the total cost of $\mathrm{HF}$ for the year 2012 is increased to $€ 811,709,008$, an increase of $€ 151,741,086$ (24\%) from the baseline total cost, $€ 656,236,255$. The interpretation of this is dissimilar in that nursing home care costs have already been included in this report. However, it demonstrates that the overall direct cost of $\mathrm{HF}$ is sensitive to admission diagnoses as having probable or definite HF.

Applying the upper bound estimate increases the hospital activity cost attributable to HF within previous study findings (excluding indirect and economic costs), at approximately $70 \%$ of the total direct cost of care. These latter estimates demonstrate that the economic burden of $\mathrm{HF}$ is a function of the cost of hospitalisations.

\section{Informal care}

Finally, the cost of informal care was the largest cost driver of HF in 2012. A weighted average of care hours required between the chronic and acute stages of the condition is estimated ( 7.69 hours per week) and applied to the entire HF cohort, undifferentiated by severity, accounting for mortalities and patients residing in LTC, totalling $€ 358,738,764$. Increasing and decreasing the estimates by $20 \%$ as per HIQA (2012) guidelines calculates an upper and lower bound cost of $€ 430,486,517$ and $€ 286,991,011$. These changes are interpreted from variation in the baseline, estimated at $€ 364,188,083$. Similarly, keeping the CHF level of care constant (6.7 hours), a total cost of $€ 319,258,407$ is estimated, a $12 \%$ reduction from the baseline. 


\section{Limitations}

Several limitations of our report need to be acknowledged. These mainly relate to a lack of hard data available to inform a response to Ireland's growing HF and other cardiovascular related disease problems. As such, consideration of this fact should be given when interpreting results.

1. In addition to impacting the HSE budget, HF impacts other Government Agencies (e.g. Social Services) as well as patients and their families. No social service support has been included in this report, nor has the input from the voluntary sections been included.

2. Because sudden cardiac death and death from progressive HF are the two major modes of death in $\mathrm{HF}$, misclassification and underestimation of HF mortality rate are possible. For reasons previously discussed, HF deaths may be assigned to ill-defined cardiovascular codes because of insufficient clinical information at the time of death, local medical diagnostic practices or simply by error. Also, the analysis is based on mortality due to $\mathrm{HF}$ as a primary cause and this underestimates the total burden of death in all HF patients.

3. Similarly, the cost of hospitalisations due to HF is estimated in accordance with ICD-10 codes used to identify HF admissions in the primary instance. Although the range is presented for primary and all case diagnoses, the estimated cost in this report is for the primary diagnoses only. This may substantially underestimate both the cost and burden $\mathrm{HF}$ related admission put on the hospital sector in Ireland.

4. HF diagnosis can include ventricular dysrhythmias, generalised and ill-defined descriptions and complications of heart disease. To negate this limiation, additional ICD-10 codes are included to capture possible HF patients.

5. The complexity surrounding the DRG coding (and subsequent under coding) of HF may lead to an underestimate of $\mathrm{HF}$ related hospital admissions, and thus the hospitalisation costs. Although partially accounted for by the broader range of ICD-10 Codes used to capture heart failure admissions, there is no definitve way of knowing if these have, in fact, captured all HF admissions.

6. Nursing home care does not include all HF patients residing in nursing homes during the year 2012 but only those newly discharged during the period of this report, underestimating the total cost of nursing home care for all $\mathrm{HF}$ patients in 2012.

7. The application of mono-prescriptions may underestimate the cost of HF medication. It is acknowledged that a lot of pharmaceutical medicines are used in the treatment and management of HF; additional to those estimated in this report.

8. Lack of pharmaceutical guidance relating to the management of HF-pEF patients meant similar therapies were applied to all $\mathrm{HF}$ aetiologies.

9. The medication adherence level (75\%) was observed among Irish HF patients receiving specialist assessment and may not be representative of the entire HF population adherence.

10. Information on patients' New York Heart Association (NYHA) functional class was not accessible. As a result, the impact of disease severity cost could not be assessed in resource use, although substantial.

11. The quantity of informal care required by HF patients was kept constant for the full year of analysis, ie 2012. This may overestimate the cost of informal care as some patients condition may improve with symptom alleviation. 


\section{Limitations of HIPE data}

1. In the absence of HIPE differentiation of index and readmitted patients, a multiplier (1.29) is used to estimate the number of hospitalised patients for further cost differentiation (e.g. increased OPD visitations and informal care.

2. Missing observations were evident in some reporting. This meant that total number of admissions or mortalities per ICD-10 Code were not totalling the corresponding numbers when broken down for gender and private-public status. To account for this in mortalities, where symbols denoted $\sim$ to represent 5 or less admissions, the midpoint of 2.5 was taken and applied.

3. The private hospital market research quantified the number of acute HF admissions in 9 private hospitals. From this a weighted average of consultant-patient numbers was used (per hospital) to approximate the number of acute admissions in remaining hospitals. A total of ten private hospitals were included in this report based on service capacity (e.g. ED department. 


\section{Discussion}

To date, no economic evaluation has been done examining the economic impact of HF in Ireland. This report is distinctive through its broader cost inclusion and, more notably, the detailed segregation of patient populations. The differentiation of incidence from the wider prevalence (community) population allowed for detailed patient mapping and the use of both micro and macro costing approaches, making the overall analysis more robust to regional variation.

\section{International Comparability}

Comparisons across countries and studies are complicated by variations in methodologies, data sources and the range of costs included. In Ireland, the direct healthcare expenditure attributable to HF is currently estimated to range between 1.2-1.6\% of the total health budget for $2012^{\mathrm{xiv}}$. This is broadly consistent with the estimate in other developed countries, with the total direct expenditure on $\mathrm{HF}$ ranging from $1 \%$ to $2.5 \%$. This equates to a significant burden on primary and secondary care services, with the findings of this report suggesting an equivalent financial burden in both settings for HF treatment in Ireland ${ }^{\text {xivi. }}$.

The proportion of healthcare expenditure attributable to HF varies depending on the inclusion criteria, study population, and the amalgamation of cost categories (28). For example, HF related admissions based on primary diagnoses cost approximately $€ 37$ million in 2012 . This equates to approximately $27 \%$ of the total direct cost. Including secondary or all case diagnoses (i.e. HF related admissions) this figure increases to $68 \%$ of the total direct cost, totalling over $€ 132$ million, which is in line with international estimates and methodologies. Additionally, once patients are discharged from the hospital setting, the majority of follow up costs are considered community outlays (e.g. nursing home care and cardiac rehabilitation) unless resource use specifically increased for this cohort following an admission, such as outpatient department visits. Therefore, community outlays incurred by an AHF patient are assumed to be the cost associated with managing CHF, as these patients are not easily differentiated once discharged from hospital.

Patient morbidity and severity impacts greatly on resource utilisation, however, the aetiology and NYHA classification of HF patients is rarely explored and further research is needed in this area. Nevertheless, it has been observed that less severe patients dominate out-patient services and settings (130). Major cost drivers are a function of the study population and, given the wider HF population included in this report it can be expected that inpatient care (hospitalisations) would represent a smaller proportion of the overall cost among this study population. Approximately $95 \%$ of the HF patients were treated in the community without hospitalisation in 2012.

Despite this, the DoH (4) highlighted HF and stroke to account for the greatest bed use among all cardiovascular conditions in the Irish hospital setting ( $42.6 \%$ and $21.2 \%$ respectively). The report cautioned that since the proportion of the population in older age groups had not changed substantially from 1998 to this bed use will rise substantially in the coming decade, when the numbers of people aged 65 years and over are expected to increase by $41 \%$. These figures demonstrate that, in what is one of the youngest populations in Europe, the status quo in terms of hospitalisation resource use is "unsupportable" in the future, and "treatment developments must address the numbers of cardiovascular disease patients in hospital, but more particularly their length of stay" (4). The weighted average LoS in 2010 (and applied for the year 2012) further increased by 27\% (increase from 9 to 11.44 days) between the study periods, 2008 to 2010 (128). Hence, safely reducing the LoS for HF patients is still a pertinent goal of care, whilst the limited availability of step down facilities (i.e. nursing home care and cardiac rehabilitation capacity issues) over the study period may have reduced the likelihood of achieving this objective.

\section{Pharmaceutical management}

Expenditures on HF medicines accounts for approximately $11-18 \%$ of the direct costs of HF $(13,28)$ consistent with the $16 \%$ finding of this report. Similarly, the per patient per annum cost was comparable to previous Irish results (187), which suggested a cost of $€ 209$ in 2004 (using the Irish health CPI, this figure was inflated to $€ 258$ for 2012) compared to $€ 290$ in 2012 . Given that the pharmaceutical market for the treatment of $\mathrm{HF}$ remains relatively unchanged over the past two decades in terms of price and prescribing trends, the consistent trend of these figures suggest a robust estimate for pharmaceutical expenditure on HF in Ireland.

This variation can also be driven by the use of primary instead of all case heart failure diagnoses

In Ireland there are 14 million visits to GPs annually, compared to 6.3 million hospital visits (Teljeur, C., et al 2013) 
However, reviewing IMS prescribing trends more closely, some change is evident, and may correspond with the inception of the Medicines Management Programme (MMP) in 2013. In 2013, the total market sales for the ten most commonly prescribed HF drugs across all therapeutic areas was estimated at $€ 170,502,287$. HF prescribing accounted for approximately $16 \%(€ 26.7 \mathrm{~m})$, comparable to $€ 26.1 \mathrm{~m}$ estimated in this report. Of the total 2014 market, year to date (August 2014), the total market has reduced significantly to $€ 119,469,756$, although 4 months of prescribing remain ${ }^{x v i i}$. The MMP may be successfully influencing prescribing trends through the selection of a preferred ACEl and angiotensin II receptor blockers (ARBs) in HF and hypertension, while the small variance in HF estimates may be explained by the adherence level (medication) applied in this report or a natural increase in the number being treated. Similarly, a broader number of pharmaceuticals are captured and costed by the IMS database, but, as shown in Appendix $G$, these additional pharmaceuticals accounted for a very low percentage of the total prescribing market for $\mathrm{HF}$, and so incremental costs associated with these $\mathrm{HF}$ medications may be negligible.

A persistent challenge of pharmaceutical treatment is to apply therapeutic advances in the most effective manner to the general HF population. Recent prescribing data obtained from the GMS database suggest that ARB prescribing may not be not in accordance with drug licensing, and hence, sub- optimal for maximum therapeutic benefit ${ }^{x / v i i i}$ (188). Omitted in present-day pharmacological management of HF to help guide how much therapy to apply is an objective indicator of when enough therapy has been applied. Natriuretic peptides is being increasingly used to titrate therapy to more effective levels, and may in the future be used on its own or in combination with other markers to show when sufficient therapy has been applied.

Aside from this, one of the main reasons for decompensation of HF is not only physician non-adherence to treatment guidelines, but also non-adherence from patients (63). This represents a substantial cause of concern and cost, both nationally and internationally. High levels of non-adherence to dietary and medication recommendations is recognised as a "worldwide problem of striking magnitude" (189) and a precursor of events leading to $64 \%$ of HF hospitalisations (190). The prevalence of non-adherence is difficult to estimate with some studies suggesting adherence as high as $70 \%$ (191) in HF patients, while another estimated non-adherence rates between 4 and $54 \%$ (192).

\section{Diagnosis and management}

The complexity of HF diagnosis in primary care in Ireland and elsewhere remains problematic, resource driven, and leads to high referral rates. Long waiting times for diagnostics and specialist assessment are a deterring factor of referral in both suspected and existing HF patients, creating deficiencies in the collaborative link required to manage and treat patients effectively. Access to the most basic diagnostic tests (such as NP) at primary care level is worryingly low; more than $80 \%$ of HF diagnoses occur in hospital following an acute episode of an underlying condition and less than $20 \%$ in the community (193). Echocardiography is suggested as a suitable reference standard for reduced ejection fraction HF but not for preserved ejection fraction HF. The definitive tests to diagnose normal ejection fraction HF (cardiac catheterisation with calculation of pressure-volume loops) are often not carried out. Therefore, the diagnosis often relies upon clinical judgement and supportive evidence, such as may be obtained from BNP or NT-proBNP, reflecting a potential value (and affordability) of these tests over and above their use as a tool to determine who should undergo echocardiography (218). It is therefore unsurprising that studies exploring the validity of a clinical diagnosis of HF in primary care report high rates of misdiagnosis when patients are assessed against objective criteria (rates of $25-50 \%$ accuracy reported in different series) $(161,194,195)$.

Consequentially, $\mathrm{HF}$ is known to be under-diagnosis in primary care, and despite the high risk associated with asymptomatic $\mathrm{HF}$, these patients remain undetected ${ }^{\mathrm{xli}}$. Under diagnosis is evident across chronic diseases, with recent TILDA findings (171) advocating a substantial under diagnosis of hypertension in the 60 years and plus age group in Ireland. Preventative measures and subsequent patient outcomes improvements have been evidenced in both areas $(196,197)$.

Most GPs report 'fundamental changes' are needed to make chronic disease management (CDM) effective (198), with increased workloads and a lack of funding as the greatest barriers to delivering chronic care. Ireland's current GP system accounts for $3.6 \%$ of

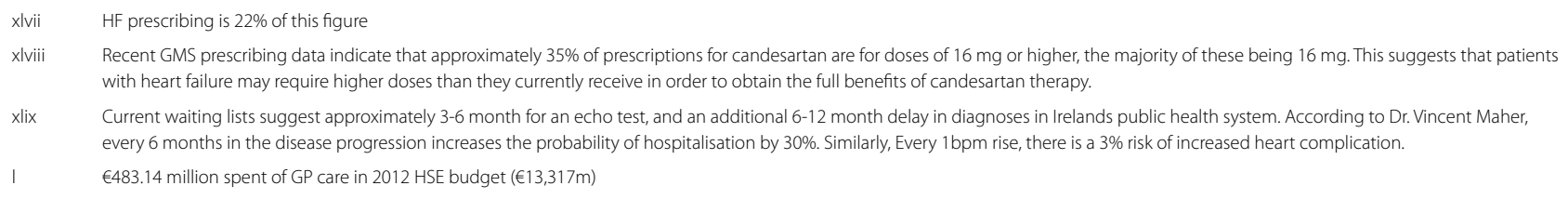


total health spend, with fees and practice support payments to GPs falling $(1,5)$. Since the introduction of new Financial Emergency Measures in the Public Interest (FEMPI) cuts, GP payments are down by 33\% per patient since the year 2008. At the same time, the number of patients with full medical card and GP visit cards is up 37\%. This translates into 2,001,195 patients (199). These primary care practices create demand spill over in secondary care services, most evidently hospitalisations, with a $45 \%$ increase in hospitalisation for chronic obstructive pulmonary disease (COPD) and a 112\% rise in hospitalisation for Type 2 diabetes in recent years (25). However, following a recent report, the lack of availability of information technology (IT) for assisting with the routine tasks considered essential for good chronic disease management in the public hospital system is striking (200). Without the development of nationally comprehensive and compatible cardiovascular information systems, including patient registers, comprehensive service provision data and patient care pathways cannot be achieved.

Additionally, the need for more primary care teams in the management, and more importantly the prevention of cardiovascular and other chronic conditions is palpable. The HSE Strategy provided for between 400-600 PCTs by 2011 - the most recent HSE data suggests there were 426 teams in place at the end of 2012 (148). However, there has been substantial debate surrounding HSE criteria for what constitutes a fully functioning PCT, and if indeed, the majority of teams exist functionally or merely by name, as suggested by the ICGP chief executive, Kieran Ryan (148). This may further diminish existing low levels of public confidence to manage and treat heart failure effectively in the Irish population (33).

Primary care represents the second largest direct cost, estimated at $€ 40,093,486$, with a mean 8.8 visits per HF patient per annum (126). Primary care has previously been shown to account for approximately one quarter of all expenditure (108), similar to the findings of this report. The inclusion of home visits ( 1 for every $10 \mathrm{GP}$ visits) was conservatively estimated in comparison to previous findings of 4 home visits per post myocardial infarction heart failure patient annually (201). Irish findings suggest an overall decrease in GP utilisation with increasing age (171), although this may be explained by increasing illness becoming a barrier to visiting GPs (33).

The findings of this report suggest that, although the burden on healthcare services is substantial, that bestowed on families and informal carers is equivalent. The cost of informal care was identified as a substantial hidden cost in the HF, accounting for $55 \%$ of total cost, estimated at $€ 364,188,083$. To the author's knowledge, the cost of informal care and its burden on family and friends has not been explored in previous studies. Similarly, the rare extension of studies to capture the long term care costs (28) should be highlighted for future research, given its identification as a substantial cost parameter in this report ( $11 \%$ of direct cost). Although a strong assumption underpins each HF patient receiving some informal care, it is important to make some observations regarding the rational of this.

\section{Regional Variation}

Most pertinently, there are important national variations in the services provided to HF patients. The report identified clear evidence of national disparity in the provision, activity and planning of cardiac and outpatient follow up services between counties, that were not related to differences in need. This extends to improving the QoL for patients and their families through a holistic approach that addresses psychological, social and spiritual needs. This type of approach can play an important role in facilitating emotionally difficult discussions between patients and healthcare professionals. However, at present only a minority of patients with HF are referred to palliative care services (202). Palliative care in both patients with HF and those with cancer demonstrate that both patient populations have similar needs for palliative care as assessed by symptom burden, depression, and spiritual well-being (203). However, these observations are not novel, particularly in the Irish context $(4,33)$.

In spite of this, most local services remain patchy, inequitable and chronically underfunded. Many patients are not therefore offered rehabilitation services. Similar dichotomies exist between hospital facilities, as the dramatic variance in readmission and subsequent mortality rates continue to portray an inconsistency in service provision nationally (104). Over a 2 year period (2010-2012), HF units have been established in at least 10 hospitals in Ireland, with plans for additional units. However, in many hospitals scarce resources still remain a key barrier to delivering efficient, effective and equitable care.

\section{Future demographics}

This is heightened by the current and future demographics of Ireland. Best case scenario of sustained prevalence at $2 \%$, would result in an increase of approximately $8.5 \%$ in the number of people with HF over the next 10 years. A more likely scenario of 
prevalence increasing by $1 \%$ to $3 \%$ would result in a $63 \%$ increase in HF by 2019 (4). In Ireland, the projected prevalence of these conditions is expected to inexorably rise by the year $2020^{\mathrm{li}}$. It has been suggested that diabetes plays a greater role than hypertension or other risk factors in the HF incidence ratelii.

In Ireland, 'normal weight' is no longer considered the norm, as 37\% of adults are currently identified as being overweight and a further $24 \%$ are estimated to be obese (204). More recent TILDA findings (2014) suggest $35 \%$ of older Irish adultsliii are classified as obese according to their body mass index; a further $44 \%$ are overweight (186). Ireland has demonstrated one of the highest increases in obesity prevalence in the last decade (205). However, even small decreases in average cholesterol levels can impact dramatically- $30 \%$ of the fall in CHD mortality was attributed to just a $4.6 \%$ reduction in cholesterol levels (217).

Estimates used in this evaluation were derived from international observation which reports a $2 \%$ prevalence in the adult population ( 25 years and older), and $10 \%$ in those aged 70 years and above (23); this identified 90,071 HF patients in Ireland, which is similar to the 90,000 reported by the Irish Heart Foundation (24). Stated incidence of CHF is estimated at 10,000 (4) and is comparable to 9,327 patients estimated with age and gender specific incidence rates' spanning over four decades of $\mathrm{HF}$ observation. It is acknowledged that these are conservative figures; lack of epidemiological data is undermining efforts to drive change. For example, the numbers of people developing HF is not clear and sufficient evidence exists to suggest the prevalence $(90,000)$ is significantly underestimated. Professor Kenneth McDonald (78) recently estimated the HF population in Ireland to be closer to 120,000 . This figure is more than doubled $(300,000)$ when including those with impeding HF due to left ventricular dysfunction and those who are asymptomatic (24). However, the various definitions and investigative processes used to diagnose HF patients was revealed by a meta-analysis of asymptomatic Left Ventricular (LV) systolic dysfunction, where prevalence varied from $0.9 \%$ to $12.9 \%$ (206).

\section{Disease awareness}

Despite the burden that HF imposes on society, awareness of the disease is poor. As a result, many premature deaths occur. This is in spite of the fact that many types of HF are preventable and that a healthy lifestyle can reduce risk of developing the condition. Even after HF has developed, premature deaths could be prevented if people were taught to recognise the symptoms and seek immediate medical attention.

A recent survey carried out in Europe by Novartis Pharmaceuticals- including 1,000 Irish nationals found that fewer than 1 in 10 people in Ireland were able to identify 3 common symptoms of HF including shortness of breath, swollen ankles and tiredness. A further $90 \%$ mistook at least one of the common symptoms of HF for a normal sign of ageing. Similar studies, including the Heart failure Awareness and Perception in Europe (SHAPE) survey liv (207) carried out in in 9 EU Countries ${ }^{\mathrm{lv}}$ revealed that, 86\% of people have heard of HF, but more than $70 \%$ of people do not consider HF to be a serious condition. Only $3 \%$ could identify the signs and symptoms of HF, and $67 \%$ of people wrongly believed that HF patients have a better prognosis than cancer patients (207).

Delaying hospital treatment by as little as 4-6 hours after symptoms of HF appear can increase the chances of death (208-211), yet patients typically seek treatment hours or even days after developing symptoms (212). According to Professor McDonald,

"Early diagnosis and intervention is key to managing heart failure. People can have active and comfortable lives if it's caught promptly. However when symptoms go unrecognised, heart failure can have a huge impact on quality of life. The importance of heart health cannot be ignored. I would urge everyone to become more familiar with the signs of heart failure" (213)

The burden of $\mathrm{HF}$ is the greatest among the elderly, with several European countries showing that more than half of hospitalisations for HF occur in patients aged 80 years or above (214-216), and over $90 \%$ of mortalities (109).

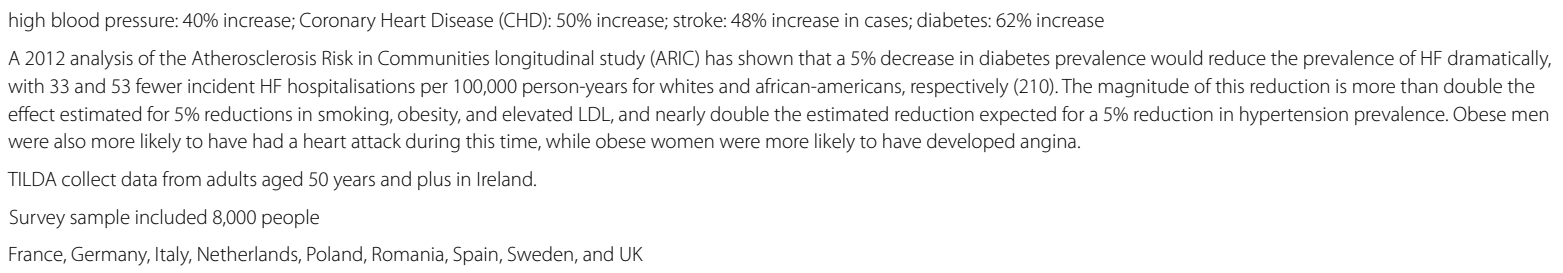


Small preventative changes to the way in which care is delivered can provide both economic opportunity and savings, while improving patient outcomes and freeing much needed hospital beds. The volatility of current service provision depends on the ability to identify and predict the current and future trends in cardiovascular prevalence and resource utilisation, as hospital admissions continue to rise, and the role of primary care physicians becomes more pertinent. Regular national audits assessing the impact of cardiovascular diseases on services at hospital and community level are needed to benchmark service development and future needs.

\section{Lack of awareness of signs and symptoms}

- $\mathbf{7 \%}$ people can identify the common symptoms of Heart Failure. ${ }^{j}$

- 1 in 4 people with symptoms would wait a week or more to seek medical advice, or not seek medical advice at all. ${ }^{j}$

- $\mathbf{8 4 \%}$ of people incorrectly thought patients with heart failure live longer than those with cancer, heart attack or stroke. ${ }^{j}$

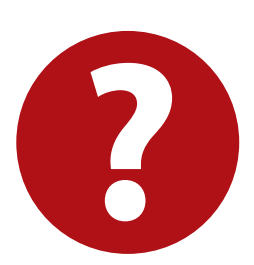




\section{Conclusion}

This report estimated the annual economic cost of HF in Ireland for the year 2012, including direct and indirect costs, at $€ 656,236,255^{\text {lvi. }}$. The annual cost per patient based on the (a) total direct costs only, (b) total direct and indirect costs (excluding intangible) and (c) total cost (all inclusive) is estimated a $€ 1,754, € 5,798$, and $€ 7,285$ respectively.

Findings of the report demonstrate a profound regional disparity in HF patient services and outcomes. Evidence for the existence of a post code lottery in both existing (mainly secondary care resources) and follow up services available to HF patients is strong. Present treatment decisions are mainly resource driven, and as the population ages and places increased pressure on already fraught health services, this is expected to intensify, as highlighted by the Department of Health and Children (4) and the findings of this report.

The substantial costs associated with primary care may reflect the limited availability of HF follow up clinics and rehabilitative programs nationally, similar to that highlighted by Irish Heart Foundation National Audit of Stroke Care, which concluded inadequate care facilities for future demographics. Similarly, this may partly explain the increased LoS for HF hospitalisations over the study period of 1998-2012. Policy shifting secondary care to community and primary care facilities will have a negligible impact without sufficient investment in primary care practices.

As chronic care is now the largest component of healthcare cost, integrated care is necessary and requires financial incentives to be aligned across providers and patients. Additionally, as the understanding and diagnosis of HF improve, patients may be treated at earlier stages of the disease, potentially delaying disease progression and thereby resulting in a decrease in the overall cost of disease management. Discussion and deliberation of policy directions adopted over the coming months surrounding chronic disease management will likely exert a major impact on the healthcare system. 


\section{Report Bibliography}

1. Health Service Executive. National Service Plan Dublin 8: Corporate Planning and Corporate Performance Directorate, 2012.

2. Health Service Executive (HSE). What is Heart Failure? 2013. Available from: http://www.hse.ie/eng/health/hl/living/ heartfailure/.

3. Health Service Executive, Irish Heart Foundation. Palliative care for all: Integrating Palliative Care into Disease Management Frameworks. HSE and IHF 2008.

4. Department of Health and Children. Changing Cardiovascular Health. National Cardiovascular Health Policy 2010-2019. Dublin: Government Publications, 2010.

5. Health Service Executive. Primary Care Reimbursement Service (statistical analysis of claims and payments 2012). 2012.

6. Balanda KP, Barron S, Fahy L, McLaughlin A. Making chronic conditions count: hypertension, stroke, coronary heart disease, diabetes. A systematic approach to estimating and forecasting population prevalence on the island of Ireland: Institute of Public Health in Ireland; 2010.

7. McGowan B, Heerey A, Ryan M, Barry M. Cost of treating heart failure in an Irish teaching hospital. Ir J Med Sci. 2000; 169(4):241-4.

8. World Health Organization. Diet, nutrition and the prevention of chronic diseases: report of a joint WHO/FAO expert consultation: Diamond Pocket Books (P) Ltd.; 2003.

9. Whelan J. WHO calls for countries to shift from acute to chronic care. British Medical Journal. 2002;324(7348):1237.

10. World Health Organization. Facing the Facts - The Impact of Chronic Disease in Europe. 2005.

11. World Health Organization. Global status report on non-communicable diseases 2010. . Geneva: WHO. 2011.

12. Professor Kenneth McDonald. National clinical lead in heart failure. In: Novartis, editor. 2013.

13. Lloyd-Jones D, Adams RJ, Brown TM, Carnethon M, Dai S, De Simone G, et al. Heart disease and stroke statistics-2010 update a report from the American Heart Association. Circulation. 2010;121(7):e46-e215.

14. Shah RU, Klein L, Lloyd-Jones DM. Heart failure in women: epidemiology, biology and treatment. Women's Health (Lond Engl). 2009;5(5):517-27.

15. Cowie MR, Anker SD, Cleland J, al e. Improving care for patients with acute heart failure: before, during and after hospitalization. . Oxford, UK: Oxford PharmaGenesis ${ }^{\mathrm{TM}} .2014$

16. Blair JE, Huffman M, Shah SJ. Heart failure in North America. Curr Cardiol Rev. 2013:9(2):128-46.
17. Al-Shamiri MQ. Heart failure in the Middle East. Current cardiology reviews. 2013;9(2):174.

18. Guo Y, Lip GY, Banerjee A. Heart Failure in East Asia. Current cardiology reviews. 2013;9(2):112-22.

19. Okura Y, Ramadan MM, Ohno Y, Mitsuma W, Tanaka K, Ito M, et al. Impending Epidemic. Circulation Journal. 2008;72:489-91.

20. Australian Institute of Health and Welfare. Cardiovascular disease: Australian facts. 2011.

21. Heidenreich PA, Albert NM, Allen LA, Bluemke DA, Butler J, Fonarow $\mathrm{GC}$, et al. Forecasting the impact of heart failure in the United States: a policy statement from the American Heart Association. Circ Heart Fail. 2013;6(3):606-19.

22. Bleumink GS, Knetsch AM, Sturkenboom MC, Straus SM, Hofman A, Deckers JW, et al. Quantifying the heart failure epidemic: prevalence, incidence rate, lifetime risk and prognosis of heart failure The Rotterdam Study. European heart journal. 2004;25(18):1614-9.

23. McMurray JJ, Adamopoulos S, Anker SD, Auricchio A, Bohm $M$, Dickstein $K$, et al. ESC Guidelines for the diagnosis and treatment of acute and chronic heart failure 2012: The Task Force for the Diagnosis and Treatment of Acute and Chronic Heart Failure 2012 of the European Society of Cardiology. Developed in collaboration with the Heart Failure Association (HFA) of the ESC. European heart journal. 2012;33(14):1787-847.

24. Irish Heart Foundation. From Crisis to Control: A cohesive strategy for hospital management of Heart Failure in Ireland. Irish Heart Foundation Council on Heart Failure. 2002.

25. Department of Health. Health in Ireland: key trends Information Unit, Hawkins Street, Dublin 2, Ireland.: 2013.

26. McMurray J, Stewart S. The burden of heart failure. European Heart Journal Supplements. 2002;4 (suppl D):D50-D8

27. WISLØFF U. Optimizing Exercise Training in Prevention and Treatment of Diastolic Heart Failure European Commission Health and Innovation Research2015. Available from: http://ec.europa.eu/research/health/medical-research/ cardiovascular-diseases/projects/optimex_en.html\#top.

28. Stewart S, Jenkins A, Buchan S, McGuire A, Capewell S, McMurray JJ. The current cost of heart failure to the National Health Service in the UK. European Journal of Heart Failure. 2002;4(3):361-71

29. Cook C, Cole G, Asaria P, Jabbour R, Francis DP. The annual global economic burden of heart failure. International journal of cardiology. 2014;171(3):368-76.

30. National Institute for Health and Clinical Excellence. National costing report: chronic heart failure London: National Health Services, 2010. 
31. Neumann T, Biermann J, Erbel R, Neumann A, Wasem J, Ertl $G$, et al. Heart failure: the commonest reason for hospital admission in Germany: medical and economic perspectives. Dtsch Arztebl Int. 2009;106(16):269-75.

32. Nieminen MS, Harjola VP. Definition and epidemiology of acute heart failure syndromes. Am J Cardiol. 2005;96(6a):5g-10g.

33. Tully NE, Morgan KM, Burke HM, Mcgee HM. Quality of Life and Quality of Care in Heart Failure: Perspectives of Irish Patients. 2009

34. Masoudi FA, Rumsfeld JS, Havranek EP, House JA, Peterson $E D$, Krumholz HM, et al. Age, functional capacity, and healthrelated quality of life in patients with heart failure. Journal of cardiac failure. 2004;10(5):368-73.

35. Hospital In-Patient Enquiry (HIPE) [Internet]. 2012. Available from: http://www.hiqa.ie/healthcare/health-information/datacollections/online-catalogue/hospital-patient-enquiry.

36. Cowie M, Wood D, Coats A, Thompson S, Suresh V, PooleWilson $\mathrm{P}$, et al. Survival of patients with a new diagnosis of heart failure: a population based study. Heart. 2000;83(5):505-10.

37. Hobbs FR, Roalfe AK, Davis RC, Davies MK, Hare R. Prognosis of all-cause heart failure and borderline left ventricular systolic dysfunction: 5 year mortality follow-up of the Echocardiographic Heart of England Screening Study (ECHOES). European heart journal. 2007.

38. Adams KF, Jr., Fonarow GC, Emerman CL, LeJemtel TH, Costanzo MR, Abraham WT, et al. Characteristics and outcomes of patients hospitalized for heart failure in the United States: rationale, design, and preliminary observations from the first 100,000 cases in the Acute Decompensated Heart Failure National Registry (ADHERE). Am Heart J. 2005;149(2):209-16.

39. Gheorghiade M, Abraham WT, Albert NM, Greenberg BH, O'Connor CM, She L, et al. Systolic blood pressure at admission, clinical characteristics, and outcomes in patients hospitalized with acute heart failure. Jama. 2006;296(18):2217-26

40. Goldberg RJ, Spencer FA, Farmer C, Meyer TE, Pezzella S. Incidence and hospital death rates associated with heart failure: a community-wide perspective. The American journal of medicine. 2005;118(7):728-34.

41. Rudiger A, Harjola VP, Müller A, Mattila E, Säila P, Nieminen $M$, et al. Acute heart failure: Clinical presentation, one-year mortality and prognostic factors. European journal of heart failure. $2005 ; 7(4): 662-70$

42. James S, Barton D, O'Connell E, Voon V, Murtagh G, Watson $C$, et al. Life expectancy for community-based patients with heart failure from time of diagnosis. International journal of cardiology. 2015;178:268-74.

43. Rutledge T, Reis VA, Linke SE, Greenberg BH, Mills PJ. Depression in heart failure: a meta-analytic review of prevalence, intervention effects, and associations with clinical outcomes. Journal of the American College of Cardiology. 2006;48(8):1527-37.

44. Bradley TD, Floras JS. Sleep apnea and heart failure part I: obstructive sleep apnea. Circulation. 2003;107(12):1671-8.

45. Jaarsma T, Dracup K, Walden J, Stevenson LW. Sexual function in patients with advanced heart failure. Heart \& Lung: The Journal of Acute and Critical Care. 1996;25(4):262-70.

46. Johansson P, Dahlström U, Broström A. Consequences and predictors of depression in patients with chronic heart failure: implications for nursing care and future research. Progress in cardiovascular nursing. 2006;21(4):202-11.

47. Jiang W, Alexander J, Christopher E, Kuchibhatla M, Gaulden LH, Cuffe MS, et al. Relationship of depression to increased risk of mortality and rehospitalization in patients with congestive heart failure. Archives of internal medicine. 2001;161(15):1849-56.

48. Moser DK, Dracup K, Evangelista LS, Zambroski CH, Lennie TA, Chung ML, et al. Comparison of prevalence of symptoms of depression, anxiety, and hostility in elderly patients with heart failure, myocardial infarction, and a coronary artery bypass graft. Heart \& Lung: The Journal of Acute and Critical Care. 2010;39(5):378-85.

49. Denollet J, Brutsaert DL. Personality, disease severity, and the risk of long-term cardiac events in patients with a decreased ejection fraction after myocardial infarction. Circulation. 1998;97(2):167-73.

50. Jeon Y-H, Kraus SG, Jowsey T, Glasgow NJ. The experience of living with chronic heart failure: a narrative review of qualitative studies. BMC health services research. 2010;10(1):77.

51. Schiff GD, Fung S, Speroff T, McNutt RA. Decompensated heart failure: symptoms, patterns of onset, and contributing factors. Am J Med. 2003;114(8):625-30.

52. Lainscak M, Keber I. Patient's view of heart failure: from the understanding to the quality of life. European Journal of Cardiovascular Nursing. 2003;2(4):275-81.

53. Hobbs FD, Kenkre JE, Roalfe AK, Davis RC, Hare R, Davies MK. Impact of heart failure and left ventricular systolic dysfunction on quality of life: a cross-sectional study comparing common chronic cardiac and medical disorders and a representative adult population. European heart journal. 2002;23(23):1867-76.

54. Zambroski CH, Moser DK, Bhat G, Ziegler C. Impact of symptom prevalence and symptom burden on quality of life in patients with heart failure. European Journal of Cardiovascular Nursing. 2005;4(3):198-206.

55. Gorkin L, Norvell NK, Rosen RC, Charles E, Shumaker SA Mclntyre KM, et al. Assessment of quality of life as observed from the baseline data of the Studies of Left Ventricular Dysfunction (SOLVD) trial quality-of-life substudy. The American journal of cardiology. 1993;71(12):1069-73. 
56. Heo S, Moser DK, Widener J. Gender differences in the effects of physical and emotional symptoms on health-related quality of life in patients with heart failure. European Journal of Cardiovascular Nursing. 2007;6(2):146-52

57. Heo S, Doering LV, Widener J, Moser DK. Predictors and effect of physical symptom status on health-related quality of life in patients with heart failure. American Journal of Critical Care. 2008;17(2):124-32

58. Pihl E, Jacobsson A, Fridlund B, Strömberg A, Måtensson J. Depression and health-related quality of life in elderly patients suffering from heart failure and their spouses: a comparative study. European journal of heart failure. 2005;7(4):583-9.

59. McDonald K. Prevalence of Heart Failure: A Reflection of the Good and the Bad of Modern Cardiovascular Care. Revista Española de Cardiología. 2008;61(10):1010-2.

60. Drummond MF, Sculpher MJ, Torrance GW, et al. Methods for the Economic Evaluation of Health Care Programmes. Oxford, UK: Oxford University Press; 2005.

61. Finkelstein E, Corso P. Cost-of-illness analyses for policy making: a cautionary tale of use and misuse. Expert Rev Pharmacoecon Outcomes Res. 2003;3(4):367-9.

62. Remme WJ, Swedberg K. Comprehensive guidelines for the diagnosis and treatment of chronic heart failure Task force for the diagnosis and treatment of chronic heart failure of the European Society of Cardiology. European Journal of Heart Failure. 2002;4(1):11-22.

63. Dickstein K, Cohen-Solal A, Filippatos G, McMurray JJ, Ponikowski P, Poole-Wilson PA, et al. ESC Guidelines for the diagnosis and treatment of acute and chronic heart failure 2008ł. European journal of heart failure. 2008;10(10):933-89.

64. Hunt SA, Abraham WT, Chin MH, Feldman AM, Francis GS, Ganiats TG, et al. 2009 Focused Update Incorporated Into the ACC/AHA 2005 Guidelines for the Diagnosis and Management of Heart Failure in Adults A Report of the American College of Cardiology Foundation/American Heart Association Task Force on Practice Guidelines: Developed in Collaboration With the International Society for Heart and Lung Transplantation. Circulation. 2009;119(14):e391-e479.

65. Swedberg K, Cleland J, Dargie H, Drexler H, Follath F, Komajda $M$, et al. Guidelines for the diagnosis and treatment of chronic heart failure: executive summary (update 2005) The Task Force for the Diagnosis and Treatment of Chronic Heart Failure of the European Society of Cardiology. European heart journal. 2005;26(11):1115-40.

66. Blanche C, Fumeaux T, Polikar R. Heart failure with normal ejection fraction (HFNEF): is it worth considering? Swiss Med Wkly. 2010;140(5-6):66-72.

67. Heart Failure. NHS Choices 2012. Available from: http://www. nhs.uk/conditions/Heart-failure/Pages/Introduction.aspx.
68. National Institute for Health and Clinical Excellence. New NICE guidance will improve diagnosis and treatment of chronic heart failure. 2010.

69. Kaila K, Haykowsky MJ, Thompson RB, Paterson DI. Heart failure with preserved ejection fraction in the elderly: scope of the problem. Heart failure reviews. 2012;17(4-5):555-62.

70. Caruana L, Petrie MC, Davie AP, McMurray JJ. Do patients with suspected heart failure and preserved left ventricular systolic function suffer from "diastolic heart failure" or from misdiagnosis? A prospective descriptive study. BMJ (Clinical research ed). 2000;321(7255):215-8

71. Cohn JN, Tognoni G. A randomized trial of the angiotensinreceptor blocker valsartan in chronic heart failure. The New England journal of medicine. 2001;345(23):1667-75.

72. Granger CB, McMurray JJ, Yusuf S, Held P, Michelson EL, Olofsson B, et al. Effects of candesartan in patients with chronic heart failure and reduced left-ventricular systolic function intolerant to angiotensin-converting-enzyme inhibitors: the CHARM-Alternative trial. Lancet (London, England). 2003;362(9386):772-6.

73. Massie BM, Carson PE, McMurray JJ, Komajda M, McKelvie $\mathrm{R}$, Zile $M R$, et al. Irbesartan in patients with heart failure and preserved ejection fraction. The New England journal of medicine. 2008;359(23):2456-67.

74. Yusuf S, Pfeffer MA, Swedberg K, Granger CB, Held P, McMurray $J$, et al. Effects of candesartan in patients with chronic heart failure and preserved left-ventricular ejection fraction: the CHARM-Preserved Trial. Lancet (London, England). 2003;362(9386):777-81.

75. Owan TE, Hodge DO, Herges RM, Jacobsen SJ, Roger VL Redfield MM. Trends in prevalence and outcome of heart failure with preserved ejection fraction. New England Journal of Medicine. 2006;355(3):251-9.

76. Yancy CW, Jessup M, Bozkurt B, Butler J, Casey DE, Jr., Drazner $\mathrm{MH}$, et al. 2013 ACCF/AHA guideline for the management of heart failure: executive summary: a report of the American College of Cardiology Foundation/American Heart Association Task Force on practice guidelines. Circulation. 2013;128(16):1810-52.

77. Yancy CW, Jessup M, Bozkurt B, Masoudi FA, Butler J, McBride PE, et al. 2013 ACCF/AHA Guideline for the Management of Heart Failure: A Report of the American College of Cardiology Foundation/American Heart Association Task Force on Practice Guidelines. J Am Coll Cardiol. 2013.

78. McDonald K. "Heart Failure Quality \& Qlinical Care Programme” Royal College of Physicians Ireland; 2011.

79. Ho K, Anderson KM, Kannel WB, Grossman W, Levy D. Survival after the onset of congestive heart failure in Framingham Heart Study subjects. Circulation. 1993;88(1):107-15. 
80. Fonarow GC, Albert NM, Curtis AB, Stough WG, Gheorghiade $M$, Heywood JT, et al. Improving evidence-based care for heart failure in outpatient cardiology practices: primary results of the Registry to Improve the Use of Evidence-Based Heart Failure Therapies in the Outpatient Setting (IMPROVE HF). Circulation. 2010;122(6):585-96.

81. Daley A, Matthews C, Williams A. Heart failure and palliative care services working in partnership: report of a new model of care. Palliat Med. 2006;20(6):593-601.

82. Jaarsma T. Are women different than men? Aspects of heart failure in special populations: elderly women. European journal of cardiovascular nursing : journal of the Working Group on Cardiovascular Nursing of the European Society of Cardiology. 2002;1(1):29-31.

83. Juenger J, Schellberg D, Kraemer S, Haunstetter A, Zugck $C$, Herzog W, et al. Health related quality of life in patients with congestive heart failure: comparison with other chronic diseases and relation to functional variables. Heart. 2002;87(3):235-41.

84. Stewart S, Ekman I, Ekman T, Odén A, Rosengren A. Population impact of heart failure and the most common forms of cancer a study of 1162309 hospital cases in Sweden (1988 to 2004). Circulation: Cardiovascular Quality and Outcomes. 2010;3(6):573-80.

85. Stewart AL, Greenfield S, Hays RD, Wells K, Rogers WH, Berry $\mathrm{SD}$, et al. Functional status and well-being of patients with chronic conditions: results from the Medical Outcomes Study. Jama. 1989;262(7):907-13.

86. Krum H, Abraham WT. Heart failure. Lancet (London, England). 2009;373(9667):941-55.

87. Gwaltney CJ, al. e, editors. Heart Failure Patient Insights Reflected in the Kansas City Cardiomyopathy Questionnaire. American Heart Association Quality of Care and Outcomes Research in Cardiovascular Disease and Stroke 2010 Scientific Sessions; 2010; Washington, D.C., .

88. Murray SA, Boyd K, Kendall M, Worth A, Benton TF, Clausen H. Dying of lung cancer or cardiac failure: prospective qualitative interview study of patients and their carers in the community. BMJ (Clinical research ed). 2002;325(7370):929.

89. Stewart S, Maclntyre K, Capewell S, McMurray J. Heart failure and the ageing population: an increasing burden in the $21 \mathrm{st}$ century? Heart. 2003;89(1):49-53.

90. Reisfield GM, Wilson GR. Prognostication in heart failure\# 143. Journal of palliative medicine. 2005;10(1):245-6.

91. Luttik ML, Jaarsma T, Veeger NJ, van Veldhuisen DJ. For better and for worse: Quality of life impaired in HF patients as well as in their partners. European journal of cardiovascular nursing : journal of the Working Group on Cardiovascular Nursing of the European Society of Cardiology. 2005;4(1):11-4.

92. Martensson J, Dracup K, Canary C, Fridlund B. Living with heart failure: depression and quality of life in patients and spouses. The Journal of heart and lung transplantation : the official publication of the International Society for Heart Transplantation. 2003;22(4):460-7.

93. lqbal J, Francis L, Reid J, Murray S, Denvir M. Quality of life in patients with chronic heart failure and their carers: a 3-year follow-up study assessing hospitalization and mortality. Eur J Heart Fail. 2010;12(9):1002-8.

94. Miettinen KH, Lassus J, Harjola VP, Siirilä-Waris K, Melin J, Punnonen KR, et al. Prognostic role of pro-and antiinflammatory cytokines and their polymorphisms in acute decompensated heart failure. European journal of heart failure. 2008;10(4):396-403.

95. Stewart S, MacIntyre K, Hole DJ, Capewell S, McMurray JJ. More'malignant'than cancer? Five-year survival following a first admission for heart failure. European Journal of Heart Failure. 2001;3(3):315-22.

96. McMurray JJ, Stewart S. Epidemiology, aetiology, and prognosis of heart failure. Heart. 2000;83(5):596-602.

97. McMurray JJ, Pfeffer MA. Heart failure. Lancet (London, England). 2005;365(9474):1877-89.

98. Engelfriet PM, Hoogenveen RT, Boshuizen HC, Baal PH. To die with or from heart failure: a difference that counts. European journal of heart failure. 2011;13(4):377-83.

99. Organization WH. Mortality 2015. Available from: http://www. who.int/topics/mortality/en/.

100. Personal communication with treating cardiologist in $\mathrm{St}$ James's Hospital. In: Novartis, editor. 2012.

101. Personal communication with specialist registrar in cardiology, St James's hospital. In: Novartis, editor. 2012.

102. Central Statistics Office. Heart failure mortalities. 2012.

103. Central Statistics office. Deaths due to Heart Failure and associated conditions in Ireland 2012. 2012.

104. Alison Lewis, Sandra Grant. Acute Heart Failure: Patient pathway and management. 2012-2013.

105. Taylor CJ, Roalfe AK, lles R, Hobbs F. Ten-year prognosis of heart failure in the community: follow-up data from the Echocardiographic Heart of England Screening (ECHOES) study. European journal of heart failure. 2012;14(2):176-84.

106. Berry C, Murdoch DR, McMurray JJ. Economics of chronic heart failure. European Journal of Heart Failure. 2001;3(3):283-91

107. Antonanzas Villar F, Anton Botella F, Juarez Castello CA, Echevarria Echarri L. [Costs of chronic heart failure in spain]. An Med Interna. 1997;14(1):9-14. 
108. Agvall B, Borgquist L, Foldevi M, Dahlstrom U. Cost of heart failure in Swedish primary healthcare. Scand J Prim Health Care. 2005;23(4):227-32.

109. Rosamond W, Flegal K, Friday G, Furie K, Go A, Greenlund K, et al. Heart disease and stroke statistics--2007 update: a report from the American Heart Association Statistics Committee and Stroke Statistics Subcommittee. Circulation. 2007;115(5):e69-171.

110. Davey PG, Clarkson PB, McMahon A, MacDonald TM. Costs associated with symptomatic systolic heart failure. Pharmacoeconomics. 1999;16(4):399-407.

111. Healthcare Cost and Utilization Project [Internet]. 2008. Available from: http://www.ahrq.gov/data/hcup/.

112. Hospital Episode Statistics. [Internet]. 2008. Available from: http://www.hesonline.nhs.uk.

113. Diagnostic data of the hospitals. [Internet]. 2008. Available from: www.gbe-bund.de.

114. Statistiques PMSI [Internet]. 2008. Available from: http://www. atih.sante.fr/index.php.

115. Kociol RD, Hammill BG, Fonarow GC, Klaskala W, Mills RM, Hernandez AF, et al. Generalizability and longitudinal outcomes of a national heart failure clinical registry: Comparison of Acute Decompensated Heart Failure National Registry (ADHERE) and non-ADHERE Medicare beneficiaries. American heart journal. 2010;160(5):885-92.

116. Tavazzi L, Senni M, Metra M, Gorini M, Cacciatore G, Chinaglia $\mathrm{A}$, et al. Multicenter prospective observational study on acute and chronic heart failure: one-year follow-up results of IN-HF (Italian Network on Heart Failure) outcome registry. Circ Heart Fail. 2013;6(3):473-81.

117. Tavazzi L, Maggioni AP, Lucci D, Cacciatore G, Ansalone G, Oliva F, et al. Nationwide survey on acute heart failure in cardiology ward services in Italy. European heart journal. 2006;27(10):1207-15.

118. Curtis LH, Greiner MA, Hammill BG, Kramer JM, Whellan DJ, Schulman KA, et al. Early and long-term outcomes of heart failure in elderly persons, 2001-2005. Arch Intern Med. 2008;168(22):2481-8.

119. Maggioni AP, Dahlstrom U, Filippatos G, Chioncel O, Crespo Leiro M, Drozdz J, et al. EURObservational Research Programme: regional differences and 1-year follow-up results of the Heart Failure Pilot Survey (ESC-HF Pilot). Eur J Heart Fail. 2013;15(7):808-17.

120. Aranda JM, Jr., Johnson JW, Conti JB. Current trends in heart failure readmission rates: analysis of Medicare data. Clin Cardiol. 2009;32(1):47-52.

121. Nieminen MS, Harjola VP, Hochadel M, Drexler $\mathrm{H}$, Komajda $M$, Brutsaert $D$, et al. Gender related differences in patients presenting with acute heart failure. Results from EuroHeart Failure Survey II. Eur J Heart Fail. 2008;10(2):140-8.
122. Dharmarajan $\mathrm{K}$, Hsieh AF, Lin Z, Bueno H, Ross JS, Horwitz $\mathrm{LI}$, et al. Diagnoses and timing of 30-day readmissions after hospitalization for heart failure, acute myocardial infarction, or pneumonia. JAMA. 2013;309(4):355-63.

123. Jencks SF, Williams MV, Coleman EA. Rehospitalizations among patients in the Medicare fee-for-service program. The New England journal of medicine. 2009;360(14):1418-28.

124. Cleland J, Swedberg K, Follath F, Komajda M,

Cohen-Solal A, Aguilar JC, et al. The EuroHeart Failure survey programme - a survey on the quality of care among patients with heart failure in Europe Part 1: patient characteristics and diagnosis. European heart journal. 2003;24(5):442-63.

125. Mji G. International Classification of Functioning, Disability \& Health. 2001.

126. Irish Primary Care Research Network.

127. 'GP fees in Dublin are the most expensive in the country'. The Journal. August 31, 2013.

128. Health Services Executive. Ready reckoner of acute hospital inpatient and daycase activity \& costs (Summarised by DRG) relating to 2010 costs \& activities. 2012.

129. Health Service Executive. Naas General Hospital A Guide to Patient Charges. October 2012.

130. Biermann J, Neumann T, Angermann CE, Erbel R, Maisch B, Pittrow $D$, et al. Economic burden of patients with various etiologies of chronic systolic heart failure analyzed by resource use and costs. International journal of cardiology. 2012;156(3):323-5.

131. Morgan. R. heart failure micro care costs in St James's Hospital. In: Novartis, editor. 2013.

132. Dr. Joe Gallagher. HSE primary care lead in Heart Failure. In: Novartis, editor. 2013.

133. Cradock K. National Heart Failure Care Programme - cardiac rehabilitative services. 2014.

134. Foundation. BH. National Audit of Cardiac Rehabilitation: Annual Statistical Report 2008.

135. National Institute for Clinical Excellence. Cardiac rehabilitation service commissioning guide: assumptions used in estimating a population benchmark.

136. Mehta PA, Cowie MR. Gender and heart failure: a population perspective. Heart. 2006;92 Suppl 3:iii14-8.

137. Buckley J. Health Service Executive Emergency Departments Comptroller and Auditor General, 2009.

138. EPS CONSULTANCY. The Business Case for the Outsourcing of Home Care Provision and a More Efficient Use of Fair Deal Funds. 2013. 
139. National Medicines Information Centre. Chronic Heart Failure. Dublin: National Medicines Information Centre, 2012

140. Earnings and Labour Costs [Internet]. 2012.

141. Gure TR, Kabeto MU, Blaum CS, Langa KM. Degree of disability and patterns of caregiving among older Americans with congestive heart failure. Journal of general internal medicine. 2008;23(1):70-6.

142. O'Brien F. Family Carers Health Survey. Tullamore:: Carers Association, 2009.

143. Health Information and Quality Authority. Guidelines for the Economic Evaluation of Health Technologies in Ireland. Dublin: HIQA, 2014.

144. Central Statisitics Office. Irish Life Tables 2005-2007. 2009;No. 15:4-7.

145. Tu K, Gong Y, Austin PC, Jaakimanian L, Tu JV. An overview of the types of physicians treating acute cardiac conditions in Canada. Can J Cardiol. 2004;20(3):282-91

146. Doughty R, Wright S, Pearl A, Walsh H, Muncaster S, Whalley G, et al. Randomized, controlled trial of integrated heart failure management. The Auckland Heart Failure Management Study. European heart journal. 2002;23(2):139-46.

147. Health Service Executive. 4.1 Chronic Illness Framework. 2008

148. Oireachtas Library \& Research Service. GPs and the Irish primary care system: towards Universal Primary Care? 2014

149. Nasrin S. Physician house calls - a solution for the elderly? Royal College of Surgeons in Ireland Student Medical Journal. 2012;5:81-3.

150. Lloyd-Jones D, Adams R, Carnethon M, De Simone G, Ferguson TB, Flegal K, et al. Heart disease and stroke statistics--2009 update: a report from the American Heart Association Statistics Committee and Stroke Statistics Subcommittee. Circulation. 2009;119(3):480-6.

151. Nieminen MS, Brutsaert D, Dickstein $K$, Drexler H, Follath F, Harjola VP, et al. EuroHeart Failure Survey II (EHFS II): a survey on hospitalized acute heart failure patients: description of population. European heart journal. 2006;27(22):2725-36.

152. Ambrosy AP, Fonarow GC, Butler J, Chioncel O, Greene SJ, Vaduganathan $\mathrm{M}$, et al. The global health and economic burden of hospitalizations for heart failure: lessons learned from hospitalized heart failure registries. J Am Coll Cardiol. 2014;63(12):1123-33.

153. Cavalcante JL, Khan S, Gheorghiade M. EVEREST study: Efficacy of Vasopressin Antagonism in Heart Failure Outcome Study with Tolvaptan. Expert Rev Cardiovasc Ther. 2008;6(10):1331-8.

154. National Clinical Guideline Centre. National Institute for Health and Clinical Excellence: Guidance. Chronic Heart Failure: National Clinical Guideline for Diagnosis and Management in Primary and Secondary Care: Partial Update. London: Royal College of Physicians (UK), National Clinical Guideline Centre.; 2010.
155. Tavazzi L, Maggioni AP, Lucci D, Cacciatore G, Ansalone G, Oliva $F$, et al. Nationwide survey on acute heart failure in cardiology ward services in Italy. Eur Heart J. 2006;27(10):1207-15.

156. Economic Social and Research Institute. Cost of Stroke in Ireland: Estimating the Annual Economic Cost of Stroke and TIA in Ireland. Dublin: The Irish Heart Foundation, 2010.

157. Lainchbury JG, Troughton RW, Strangman KM, Frampton CM, Pilbrow A, Yandle TG, et al. N-terminal pro-B-type natriuretic peptide-guided treatment for chronic heart failure: results from the BATTLESCARRED (NT-proBNP-Assisted Treatment To Lessen Serial Cardiac Readmissions and Death) trial. J Am Coll Cardiol. 2009;55(1):53-60.

158. Jourdain P, Jondeau G, Funck F, Gueffet P, Le Helloco A, Donal $E$, et al. Plasma brain natriuretic peptide-guided therapy to improve outcome in heart failure: the STARS-BNP Multicenter Study. J Am Coll Cardiol. 2007;49(16):1733-9.

159. Troughton RW, Frampton CM, Yandle TG, Espine EA, Nicholls MG, Richards AM. Treatment of heart failure guided by plasma aminoterminal brain natriuretic peptide (N-BNP) concentrations. The Lancet. 2000;355(9210):1126-30.

160. Pfisterer M, Buser P, Rickli H, Gutmann M, Erne P, Rickenbache $P$, et al. BNP-guided vs symptom-guided heart failure therapy: the Trial of Intensified vs Standard Medical Therapy in Elderly Patients With Congestive Heart Failure (TIME-CHF) randomized trial. Jama. 2009;301(4):383-92.

161. Wheeldon NM, MacDonald TM, Flucker CJ, McKendrick AD, McDevitt DG, Struthers AD. Echocardiography in chronic heart failure in the community. The Quarterly journal of medicine. 1993;86(1):17-23.

162. Clarke KW, Gray D, Hampton JR. Evidence of inadequate investigation and treatment of patients with heart failure. $\mathrm{Br}$ Heart J. 1994;71(6):584-7.

163. Zaphiriou A, Robb S, Murray-Thomas T, Mendez G, Fox K, McDonagh $\mathrm{T}$, et al. The diagnostic accuracy of plasma BNP and NTproBNP in patients referred from primary care with suspected heart failure: results of the UK natriuretic peptide study. Eur J Heart Fail. 2005;7(4):537-41.

164. Bart BA, Ertl G, Held P, Kuch J, Maggioni AP, McMurray J, et al. Contemporary management of patients with left ventricular systolic dysfunction. Results from the Study of Patients Intolerant of Converting Enzyme Inhibitors (SPICE) Registry. European heart journal. 1999;20(16):1182-90.

165. Stalhammar J, Stern L, Linder R, Sherman S, Parikh R, Ariely R, et al. The burden of preserved ejection fraction heart failure in a real-world Swedish patient population. Journal of medical economics. 2014;17(1):43-51.

166. Monthly Index of Medical Specialities (MIMS), July edition. Merchant Quay, Dublin 8: Kelly, D., 2013.

167. Kenneally M. Medical cards, the'over 70s' and all that...... out of the frying pan? 2009. 
168. Mockler M, O'Loughlin C, Murphy N, Ryder M, Conlon C, McDonald KM, et al. Causes and consequences of nonpersistence with heart failure medication. Am J Cardiol. 2009;103(6):834-8.

169. Van Jaarsveld CH, Sanderman R, Miedema I, Ranchor AV, Kempen Gl. Changes in Health-Related Quality of Life in Older Patients with Acute Myocardial Infarction or Congestive Heart Failure: A Prospective Study. Journal of the American Geriatrics Society. 2001;49(8):1052-8.

170. Harkness KI, Tranmer JE. Measurement of the caregiving experience in caregivers of persons living with heart failure: a review of current instruments. J Card Fail. 2007;13(7):577-87.

171. Barrett A, Burke H, Cronin H, Hickey A, Kamiya Y, Kenny RA, et al. Fifty plus in Ireland 2011: first results from the Irish longitudinal study on ageing (TILDA). 2011.

172. Segel JE. Cost-of-illness studies - A primer. RTI-UNC Center of Excellence in Health Promotion Economics. 2006:1-39.

173. Central Statistics Office. Census 2011 - Profile 8 Our Bill of Health Dublin: Stationary Office 2012.

174. World Health Organization. International Classification of Functioning, Disability, and Health: Children \& Youth Version: ICF-CY: World Health Organization; 2007.

175. Kamiya Y, Murphy C, Savva G, Timonen V. Profile of Community-Dwelling Older People with Disability and their Caregivers in Ireland. Lincoln Place, Trinity College Dublin Dublin 2.: Trinity College Dublin, 2012.

176. Krupnick A, Alberni A, Cropper M, Simon N, O'Brien B, Goeree $\mathrm{R}$, et al. "Age, Health, and the Willingness to Pay for Mortality Risk Reductions: A Contingent Valuation Survey of Ontario Residents,". Journal of Risk and Uncertainty. 2002;24:161-86.

177. Jackson D, Stone D, Butler G, McGlynn G, Jackson D, Stone D et al. A risk related value of spend for saving a statistical life. Radioprotection. 2005;40(S1):S973-S9.

178. P. K. The EuroQoL Instrument: An Index of HealthRelated Quality of Life. In: Spilker B, ed. Quality of Life and Pharmacoeconomics in Clinical Trials, Second Edition. Philadelphia, PA: Lippincott-Raven Publishers; 1996. 191-201. p.

179. World Health Organization. Metrics: Disability-Adjusted Life Year (DALY). Available from: http://www.who.int/healthinfo/ global_burden_disease/metrics_daly/en/.

180. British Heart Foundation. National Audit of Cardiac Rehabilitation: Annual Statistical Report 2008.

181. British Heart Foundation. The National Audit of Cardiac Rehabilitation: Annual Statistical Report 2010. Available from: http://www.cardiacrehabilitation.org.uk/docs/2010.pdf.

182. Culliton $\mathrm{G}$. New programme aims to cut readmissions by 30 per cent. Irish Medical Times. 2012.
183. Gannon B, O'Shea E, Hudson E. Economic consequences of falls and fractures among older people. Irish medical journal. 2008;101(6):170-3.

184. Claxton K, Martin S, Soares M, Rice N, Spackman E, Hinde S, et al. Methods for the estimation of the NICE cost effectiveness threshold. York: University of York. 2013.

185. McGregor P, McKee P, O Neill C. GP utilisation in Northern Ireland: exploiting the gatekeeper function. Economic and Social Review. 2006;37(1):71.

186. TILDA. The Over 50's in Ireland: Economic Circumstances, Health and Well-Being:. Trinity College Dublin. (2014)

187. Naughton C, Bennett K, Feely J. Prevalence of chronic disease in the elderly based on a national pharmacy claims database. Age and ageing. 2006;35(6):633-6.

188. Programme MM. Angiotensin-II receptor blockers 2013.

189. World Health Organization. Adherence to long-term therapies: evidence for action Switzerland: World Health Organization; 2003. Available from: http://www.who.int/chp/knowledge/ publications/adherence_full_report.pdf.

190. De Geest S, Sabaté E. Adherence to long-term therapies: evidence for action. European Journal of Cardiovascular Nursing. 2003;2(4):323-.

191. van der Wal MH, Jaarsma T. Adherence in heart failure in the elderly: problem and possible solutions. International journal of cardiology. 2008;125(2):203-8.

192. Wu JR, Moser DK, Lennie TA, Burkhart PV. Medication adherence in patients who have heart failure: a review of the literature. Nurs Clin North Am. 2008;43(1):133-53; vii-viii.

193. Cleland JG, Cohen-Solal A, Aguilar JC, Dietz R, Eastaugh $J$, Follath $\mathrm{F}$, et al. Management of heart failure in primary care (the IMPROVEMENT of Heart Failure Programme): an international survey. Lancet (London, England). 2002;360(9346):1631-9.

194. Davis RC, Hobbs FD, Kenkre JE, Roalfe AK, Hare R, Lancashire RJ et al. Prevalence of left ventricular systolic dysfunction and heart failure in high risk patients: community based epidemiological study. BMJ (Clinical research ed). 2002;325(7373):1156.

195. Remes J, Miettinen H, Reunanen A, Pyorala K. Validity of clinical diagnosis of heart failure in primary health care. European heart journal. 1991;12(3):315-21.

196. Beckett NS, Peters R, Fletcher AE, Staessen JA, Liu L, Dumitrascu $D$, et al. Treatment of hypertension in patients 80 years of age or older. The New England journal of medicine. 2008:358(18):1887-98.

197. Ledwidge M, Gallagher J, Conlon C, Tallon E, O'Connell E, Dawkins I, et al. Natriuretic peptide-based screening and collaborative care for heart failure: the STOP-HF randomized trial. Jama. 2013;310(1):66-74 
198. Darker C, Martin C, O'Dowd T, O'Kelly F, O'Shea B. Chronic disease management in general practice: results from a national study. 2012

199. Health Service Executive. Performance Report May 2013

200. Catherine Darker, Colm Bergin, Gillian Walsh, O'Shea B. A National Survey of Chronic Disease Management by Irish Hospital based Consultants. Dublin: Adelaide Health Policy Initiative, 2015.

201. Lacey L, Tabberer M. Economic burden of post-acute myocardial infarction heart failure in the United Kingdom. Eur J Heart Fail. 2005;7(4):677-83.

202. Jaarsma T, Beattie JM, Ryder M, Rutten FH, McDonagh T, Mohacsi $\mathrm{P}$, et al. Palliative care in heart failure: a position statement from the palliative care workshop of the Heart Failure Association of the European Society of Cardiology. European journal of heart failure. 2009;11(5):433-43.

203. Bekelman DB, Rumsfeld JS, Havranek EP, Yamashita TE, Hutt E, Gottlieb SH, et al. Symptom burden, depression, and spiritual well-being: a comparison of heart failure and advanced cancer patients. J Gen Intern Med. 2009;24(5):592-8.

204. Perry J, al. e. The cost of overweight and obesity on the island of Ireland. 2012

205. Sassi F, Devaux M. OECD obesity update 2012. Paris: Organisation for Economic Co-operation and Development; 2012.

206. Wang TJ, Levy D, Benjamin EJ, Vasan RS. The epidemiology of "asymptomatic" left ventricular systolic dysfunction: implications for screening. Ann Intern Med. 2003;138(11):907-16.

207. Remme WJ, McMurray JJ, Rauch B, Zannad F, Keukelaar K, Cohen-Solal A, et al. Public awareness of heart failure in Europe: first results from SHAPE. European heart journal. 2005;26(22):2413-21

208. Peacock WF, Emerman C, Costanzo MR, Diercks DB, Lopatin $M$, Fonarow GC. Early vasoactive drugs improve heart failure outcomes. Congest Heart Fail. 2009;15(6):256-64.

209. Peacock WFt, Fonarow GC, Emerman CL, Mills RM, Wynne J. Impact of early initiation of intravenous therapy for acute decompensated heart failure on outcomes in ADHERE. Cardiology. 2007;107(1):44-51.

210. Maisel AS, Peacock WF, McMullin N, Jessie R, Fonarow GC Wynne J, et al. Timing of immunoreactive B-type natriuretic peptide levels and treatment delay in acute decompensated heart failure: an ADHERE (Acute Decompensated Heart Failure National Registry) analysis. J Am Coll Cardiol. 2008;52(7):534-40.

211. Peacock WF, Costanzo MR, De Marco T, Lopatin M, Wynne J, Mills RM, et al. Impact of intravenous loop diuretics on outcomes of patients hospitalized with acute decompensated heart failure: insights from the ADHERE registry. Cardiology. 2009;113(1):12-9.

212. Gravely-Witte S, Jurgens CY, Tamim H, Grace SL. Length of delay in seeking medical care by patients with heart failure symptoms and the role of symptom-related factors: a narrative review. Eur J Heart Fail. 2010;12(10):1122-9.

213. Clinic HD. Heart failure awareness dangerously low 2014. Available from: http://www.irishhealth.com/clin/cholesterol/ newsstory.php?id=23598.

214. StatBank database [Internet]. 2013. Available from: http:// www.ssb.no/en/statistikkbanken.

215. Statistikdatabas for diagnoser i sluten vard 1998-2011. [Internet]. 2013. Available from: http://www.socialstyrelsen.se/ statistik/statistikdatabas/diagnoserislutenvard.

216. Statistique medicale des hopitaux 2011. [Internet]. 2013. Available from: http://www.bfs.admin.ch/bfs/portal/fr/index/ themen/14/04/01/data/01/05.html.

217. Bennett, K., Kabir, Z., Unal, B., Shelley, E., Critchley, J., Perry, I.,... \& Capewell, S. (2006). Explaining the recent decrease in coronary heart disease mortality rates in Ireland, 1985-2000. Journal of epidemiology and community health, 60(4), 322-327.

218. Mant, J., Doust, J., Roalfe, A., Barton, P., Cowie, M. R., Glasziou, P., ... \& Hobbs, F. D. R. (2009). Systematic review and individual patient data meta-analysis of diagnosis of heart failure, with modelling of implications of different diagnostic strategies in primary care. 


\section{Infographic Bibiography}

The Cost of Heart Failure in Ireland, Social, Economic and Health Implications.

Schiff GD, Fung S, Speroff T, McNutt RA. Decompensated heart failure: symptoms, patterns of onset, and contributing factors. Am J Med. 2003;114(8):625-30.

c. Calvert MJ, Freemantle N, Cleland JGF. The impact of chronic heart failure on health-related quality of life data required in the baseline phase of the CARE_HF study. Eur J Heart Fail. 2005;7(2):243-251

d. Health Service Executive, Irish Heart Foundation. Palliative care for all: Integrating Palliative Care into Disease Management Frameworks. HSE and IHF 2008.

e. National Institute for Health and Clinical Excellence. National costing report: chronic heart failure London: National Health Services, 2010.

f. Masoudi FA, Rumsfeld JS, Havranek EP, House JA, Peterson $E D$, Krumholz HM, et al. Age, functional capacity, and healthrelated quality of life in patients with heart failure. Journal of cardiac failure. 2004;10(5):368-73.

g. Maggioni AP, Dahlstrom U, Filippatos G, Chioncel O, Crespo Leiro M, Drozdz J, et al. EURObservational Research Programme: regional differences and 1-year follow-up results of the Heart Failure Pilot Survey (ESC-HF Pilot). Eur J Heart Fail. 2013;15(7):808-17.

h. Cleland J, Swedberg K, Follath F, Komajda M, Cohen-Solal A, Aguilar JC, et al. The EuroHeart Failure survey programme-a survey on the quality of care among patients with heart failure in Europe Part 1: patient characteristics and diagnosis. European heart journal. 2003;24(5):442-63.

i. Department of Health and Children. Changing Cardiovascular Health. National Cardiovascular Health Policy 2010-2019. Dublin: Government Publications, 2010.

RTNS UK Limited, March 2014. Survey of 11,000 members of the public aged $50+$ years old in Europe, funded by Novartis

k. The Irish Heart Failure Population and Future Resource Use

I. Balanda KP, Barron S, Fahy L, McLaughlin A. Making chronic conditions count: hypertension, stroke, coronary heart disease, diabetes. A systematic approach to estimating and forecasting population prevalence on the island of Ireland: Institute of Public Health in Ireland; 2010.

m. Stewart et al. More'malignant'than cancer? Five-year survival following a first admission for heart failure Eur J Heart Fail. 2001;3:315322. 6 


\section{Appendices}

\subsection{Appendix A: Disease overview}

\section{Forms of HF}

AHF populations can be identified from general observation of clinical and epidemiological trials, which suggest HF can present in three distinct forms:

1. Worsening of chronic HF associated with preserved or reduced ejection fraction- $70 \%$ of admissions $(65 \%$ of patients in Euro- HF, $66 \%$ EFICA, and $56 \%$ in AHFS. ADHF refers to worsening of symptoms in a patient with existing CHF (1-3).

2. De novo HF, occurring frequently after Ml; sudden increase in blood pressure on a non-compliant LV-25\% of admission (37\% in EURO-HF, 43\% EFICA and 44\% AHFS). De novo HF refers to new onset of AHF in a patient without previously known HF (1-3).

3. Advanced HF/refractory to therapy, with severe LV systolic or diastolic dysfunction associated with a continual low output state $-5 \%$ of admissions (6).

\section{HF-rEF \& HF-pEF}

In the normal heart, about $50 \%$ of the blood that enters the left ventricular chamber (LV) is ejected into the aorta and further on into the body during the process of chamber contraction; this is known as the ejection fraction. In HF-rEF (systolic HF, see illustration below), changes to the LV (enlargement of the chamber and impaired contractility) mean that a much smaller proportion of the blood in the LV before contraction (typically $<40 \%$ ) is ejected. That is, the ventricles are too weak to contract and do not pump sufficient blood to meet the requirements of the body, resulting in shortness of breath and other HF symptoms.

In HF-pEF (diastolic HF), the ventricles of the heart are too stiff to relax and expand and do not fill with sufficient volume of blood. This causes the heart to pump less blood, resulting in retention of fluid in the lungs and symptoms of HF. In this type of $\mathrm{HF}$, the volume of blood ejected from the LV is normal or near normal although the changes to the LV wall mean that the total volume of blood may be lower than normal and pressure inside the heart may be higher than normallvii. Hence, unlike most patients, those with HF-pEF have no obvious reduction in the volume of blood pumped out of the chamber of the heart that supplies blood to the body (the ejection fraction) (8) and many of them are elderly women with a history of high blood pressure (9). These patients usually have normal $\operatorname{LVEF}(>45 \%)(10)$.

While definite HF-pEF is generally considered to be LVEF $\geq 50 \%$, patients with an LVEF of $40-50 \%$ currently represent a 'grey area' in terms of HF classification. However, it is common that HF patients are likely to have evidence of both diastolic and systolic HF; they are not separate entities (11). In general, the ejection fraction for HF-pEF is $\geq 40-50 \%$, while the ejection fraction for HF-rEF is below $35-40 \%(11)$. 


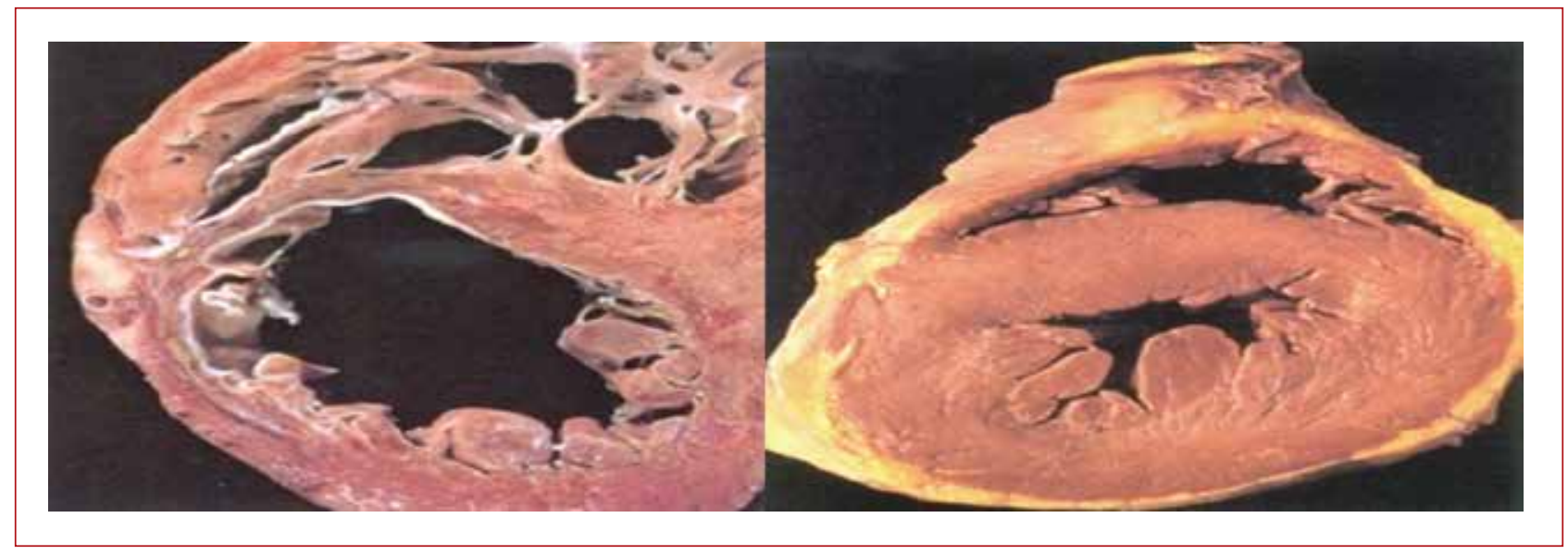

Source: Dickstein et al 2008 (11) \& Senni et al 2001 (12)

Below is a short description.

$H F-p E F(L V E F \geq 50 \%)$

- Normal sized LV cavity with thickened walls and preserved systolic function (with abnormalities in diastole, hence previously called 'diastolic HF'; diastolic dysfunction is also present in HF-rEF)

Older, predominantly female patients, more likely to have hypertension and atrial fibrillation, less likely to have coronary artery disease compared to patients with HF-rEF

Pathophysiology less well understood - no proven therapy exists

HF-rEF (LVEF of $\leq 35-\leq 40 \%)$

HF with reduced ejection fraction (HF-rEF, also called 'systolic dysfunction')

Globular heart with thinning of the LV walls, decrease in systolic function and enlarged left ventricular volume

Proven therapeutic options (e.g. ACEls, ARBs, ß-blockers, aldosterone antagonists), but mortality and morbidity remain high 


\section{NYHA Classification}

Table 11. Summary of international NYHA classifications

\begin{tabular}{|c|c|c|c|c|c|c|}
\hline Study & Study population & NYHA I & II & III & IV & Author (year) \\
\hline $\begin{array}{l}\text { Studies of left } \\
\text { ventricular function } \\
\text { SOLVD; US, Canada } \\
\text { and Belgium) }\end{array}$ & $\begin{array}{l}\mathrm{n}=2569 \\
20 \% \text { female } \\
80 \% \text { male } \\
\text { Mean age }=61\end{array}$ & $11 \%$ & $57 \%$ & $30 \%$ & $2 \%$ & $\begin{array}{l}\text { The SOLVD Investogators. } \\
1991 \text { (13) }\end{array}$ \\
\hline $\begin{array}{l}\text { Study of Patients } \\
\text { Intolerant of Converting } \\
\text { Enzyme Inhibitors } \\
\text { (SPICE; North America } \\
\text { and Europe) }\end{array}$ & $\begin{array}{l}\mathrm{n}=9580 \\
26 \% \text { female } \\
74 \% \text { male } \\
\text { Mean age }=66 \text { years }\end{array}$ & $10 \%$ & $38 \%$ & $34 \%$ & $9 \%$ & Bart et al. 1999 (14) \\
\hline $\begin{array}{l}\text { Euro Heart Failure } \\
\text { Survey (Europe) }\end{array}$ & $\begin{array}{l}n=3260 \text { hospitalized } \\
\text { HF patients } 39 \% \text { female } \\
\text { Mean age }=68 \text { years }\end{array}$ & $36 \%$ & $37 \%$ & $26 \%$ & & Cleland et al. 2003 (15) \\
\hline \multicolumn{7}{|l|}{ USA } \\
\hline $\begin{array}{l}\text { Acute decompensated } \\
\text { heart failure national } \\
\text { registry (ADHERE) }\end{array}$ & $\begin{array}{l}\mathrm{n}=105,388 \\
52 \% \text { female } \\
48 \% \text { male } \\
\text { Mean age }=72.4 \text { years }\end{array}$ & $4 \%$ & $20 \%$ & $44 \%$ & $32 \%$ & $\begin{array}{l}\text { Adams et al. } 2005 \text { (16) } \\
\text { ( } 89 \% \text { had unknown or } \\
\text { no mention of NYHA } \\
\text { classification) }\end{array}$ \\
\hline \multicolumn{7}{|l|}{ UK } \\
\hline $\begin{array}{l}\text { Euro Heart Failure } \\
\text { Study }\end{array}$ & $\begin{array}{l}\mathrm{n}=332 \text { hospitalised } \\
\text { HF patients } \\
43 \% \text { female } \\
\text { Mean age }=71 \text { years }\end{array}$ & $22 \%$ & $37 \%$ & $40 \%$ & & Cleland et al. 2003 (15) \\
\hline \multicolumn{7}{|l|}{ Germany } \\
\hline $\begin{array}{l}\text { Germany's disease } \\
\text { management } \\
\text { program }\end{array}$ & $\begin{array}{l}\mathrm{n}=185 \\
25.9 \% \text { female } \\
74.1 \% \text { male } \\
\text { Mean age } 65.6 \pm 10.2 \text { years }\end{array}$ & - & $51 \%$ & $37 \%$ & $12 \%$ & Kottmair et al. 2005 (17) \\
\hline $\begin{array}{l}\text { Euro Heart Failure } \\
\text { Survey }\end{array}$ & $\begin{array}{l}\mathrm{n}=342 \text { hospitalised } \\
\text { HF patients } \\
25 \% \text { female } \\
\text { Mean age }=64 \text { years }\end{array}$ & $25 \%$ & $52 \%$ & $24 \%$ & & Cleland et al. 2003 (15) \\
\hline \multicolumn{7}{|l|}{ France } \\
\hline $\begin{array}{l}\text { Euro Heart Failure } \\
\text { Survey }\end{array}$ & $\begin{array}{l}n=26 \text { hospitalised } \\
\text { HF patients } \\
27 \% \text { female } \\
\text { Mean age }=72 \text { years }\end{array}$ & $54 \%$ & $38 \%$ & $8 \%$ & & Cleland et al. 2003 (15) \\
\hline \multicolumn{7}{|l|}{ Spain } \\
\hline $\begin{array}{l}\text { Euro Heart Failure } \\
\text { Survey }\end{array}$ & $\begin{array}{l}n=168 \text { hospitalised } \\
\text { HF patients } \\
54 \% \text { female } \\
\text { Mean age }=69 \text { years }\end{array}$ & $35 \%$ & $36 \%$ & $28 \%$ & & Cleland et al. 2003 (15) \\
\hline \multicolumn{7}{|l|}{ Sweden } \\
\hline $\begin{array}{l}\text { Euro Heart Failure } \\
\text { Survey }\end{array}$ & $\begin{array}{l}n=136 \text { hospitalised } \\
\text { HF patients } \\
38 \% \text { female } \\
\text { Mean age }=73 \text { years }\end{array}$ & $31 \%$ & $35 \%$ & $34 \%$ & & Cleland et al. 2003 (15) \\
\hline \multicolumn{7}{|l|}{ Italy } \\
\hline $\begin{array}{l}\text { Euro Heart Failure } \\
\text { Survey }\end{array}$ & $\begin{array}{l}n=226 \text { hospitalised } \\
\text { HF patients } \\
39 \% \text { female } \\
\text { Mean age }=68 \text { years }\end{array}$ & $46 \%$ & $30 \%$ & $22 \%$ & & Cleland et al. 2003 (15) \\
\hline
\end{tabular}




\begin{tabular}{|c|c|c|c|c|c|c|}
\hline \multirow{3}{*}{$\begin{array}{l}\text { Author } \\
\text { (year) }\end{array}$} & \multirow{3}{*}{ Population } & \multicolumn{4}{|c|}{ Mortality (\%) } & \multirow{3}{*}{ Comments } \\
\hline & & \multicolumn{2}{|c|}{1 Year } & \multicolumn{2}{|c|}{5 Year } & \\
\hline & & Men & Women & Men & Women & \\
\hline $\begin{array}{l}\text { Roger et al. } \\
(2004)(18)\end{array}$ & $\begin{array}{l}\text { Olmsted County, MN, 1996-2000. } \\
\text { All ages mean age of HF patients at } \\
\text { diagnosis--75 years }\end{array}$ & 21 & 17 & 50 & 46 & \\
\hline $\begin{array}{l}\text { Levy et al. } \\
\text { (2002) (19) }\end{array}$ & $\begin{array}{l}\text { Framingham, MA, 1990-1999. } \\
\text { Original cohort plus offspring cohort. } \\
\text { Age } 65-74 \text { years at diagnosis of HF }\end{array}$ & 28 & 24 & 59 & 45 & $\begin{array}{l}\text { Outpatient only cases (i.e., } \\
\text { patients never admitted for HF } \\
\text { during } 5 \text {-year period) were not } \\
\text { counted }\end{array}$ \\
\hline $\begin{array}{l}\text { Owan et al, } \\
(2006)(20)\end{array}$ & $\begin{array}{l}\text { Olmsted County, MN, 1987-2001. } \\
\text { Persons hospitalised with decompen- } \\
\text { sated HF. } \\
\text { Mean age } 73 \text { years }\end{array}$ & \multicolumn{2}{|c|}{29 (HF-pEF) } & \multicolumn{2}{|c|}{65 (HF-pEF) } & $\begin{array}{l}\text { Separate rates for men and } \\
\text { women not reported }\end{array}$ \\
\hline $\begin{array}{l}\text { Barker et } \\
\text { al. (2006) } \\
(21)\end{array}$ & $\begin{array}{l}\text { Kaiser Northwest (Portland, OR), } \\
1990-1994 \text {. } \\
\text { Ages } \geq 65 \text { years. } \\
\text { Mean age at diagnosis of HF: } 75.5 \text { years }\end{array}$ & 32.5 & 27.8 & 68.8 & 64.8 & $\begin{array}{l}\text { Outpatient only cases } \\
\text { (i.e., patients never admitted for } \\
\text { HF during 5-year period) were } \\
\text { not counted }\end{array}$ \\
\hline $\begin{array}{l}\text { Parashar et } \\
\text { al. (2009) } \\
(22)\end{array}$ & $\begin{array}{l}\text { CHS, } 1989-1993 . \\
6,000 \text { white and African-American } \\
\text { subjects aged } \geq 65 \text { years. } \\
\text { Mean age at diagnosis of HF: } 81 \text { years }\end{array}$ & 37 & 27 & NR & NR & $\begin{array}{l}\text { Six-year mortality in the CHS } \\
\text { was } 45 \% \\
\text { (Gottdiener et al.,2002) }\end{array}$ \\
\hline
\end{tabular}

\section{Aetiology and pathophysiology}

HF progresses through chronic stages in which compensatory mechanisms and treatments initially allow the patient to function, but such long term compensatory responses to myocardial injury are harmful to cardiac function (23). When the function of the heart starts to fail, cardiac myocytes must adapt in order to maintain adequate cardiac output. This adaptation involves increased cardiac hypertrophy and ventricular remodelling. Patients develop symptomatic HF when the heart can no longer compensate for its failing function (24).

Both the Sympathetic Nervous System (SNS) and Renin-Angiotensin-Aldosterone System (RAAS) are stimulated in the failing heart and these systems have become key targets for pharmacological intervention (25). It can also be brought on by hypertension $^{\text {lvii }}$ (high blood pressure). Illnesses with no appreciable secondary diagnoses on the causal pathway are rare, and in particular for chronic conditions. HF is a complex condition encompassing several underlying aetiologies and co-morbidities (26). Certain pre-existing conditions can increase its risk. These vary between patients and are presented below:

Conditions that damage or weaken the heart over a prolonged period (e.g. hypertension)

Extrinsic factors that trigger an episode in a patient whose heart is already weakened by underlying conditions (e.g. serious illness in a patient with CAD) $(11,27)$.

- Coronary heart disease (CHD), cardiomyopathy (weakness of the heart muscle), arrhythmia (e.g. AF), heart valve disease/damage, anaemia (28). 
Acute coronary syndrome (ACS) is recognised in treatment guidelines (ACCF/AHA and ESC) as an important cause of worsening or new-onset HF $(5,27)$.

Pulmonary arterial hypertension is usually perceived as a complication of established HF rather than as a predictor or a marker of subclinical HF (29)

The structural abnormalities typically associated with HF are mainly caused by ischemic (e.g. myocardial infarction [MI], coronary artery disease $[C A D]$ ), or non-ischemic (e.g. hypertension- over $90 \%$ of the HF patients in the Framingham Heart study and the Framingham Offspring study had pre-existing hypertension) aetiologies, with $\mathrm{CHD}$ accounting for $\sim 70 \%$ of $\mathrm{CHF}(4,11)$. Other aetiologies include non-ischemic idiopathic cardiomyopathy, valvular heart disease \& myocarditis.

Additional contributing factors increasing the number of HF patients is the improvement in treating heart attacks ((Acute Coronary Syndrome (ACS) or myocardial infarction (MI)) lixand other cardiovascular diseases that damage or place an extra burden on the heart. More patients with these conditions are surviving now than did in the past, but those who survive are at a higher risk of developing HF. Hypertension and ischemic heart disease (IHD) were the most common contributory causes of HF (55\% and $47 \%$ respectively) among acute HF patients in the United Kingdom, whilst twenty-seven percent of patients had both conditions (30).

Several large registry studies ${ }^{\mid x}$ from Europe, Asia-Pacific and the US have reported baseline characteristics in patients admitted to hospital for HF (31-33). These studies report that, at admission to hospital, at least half of all patients had IHD/CAD, and more than $60 \%$ had hypertension $(31,32)$.

Nevertheless, some controversy exists over the relative contribution of hypertension and CAD/IHD disease (including $\mathrm{Ml}$ and angina) to the development of HF (34). Recent registries and clinical trial data suggest CAD plays a larger role in precipitating HF. However, the Framingham data suggest hypertension as a leading cause. This may be due to difference in patient populations studied, definitions used, and the fact that many patients have both CAD and hypertension present ${ }^{1 \times i}$. 


\subsection{Appendix B: Chronic and Acute Heart Failure treatment guidelines}

Figure 9. Initial assessment of a patient presenting with suspected AHF, based on ESC treatment guidelines

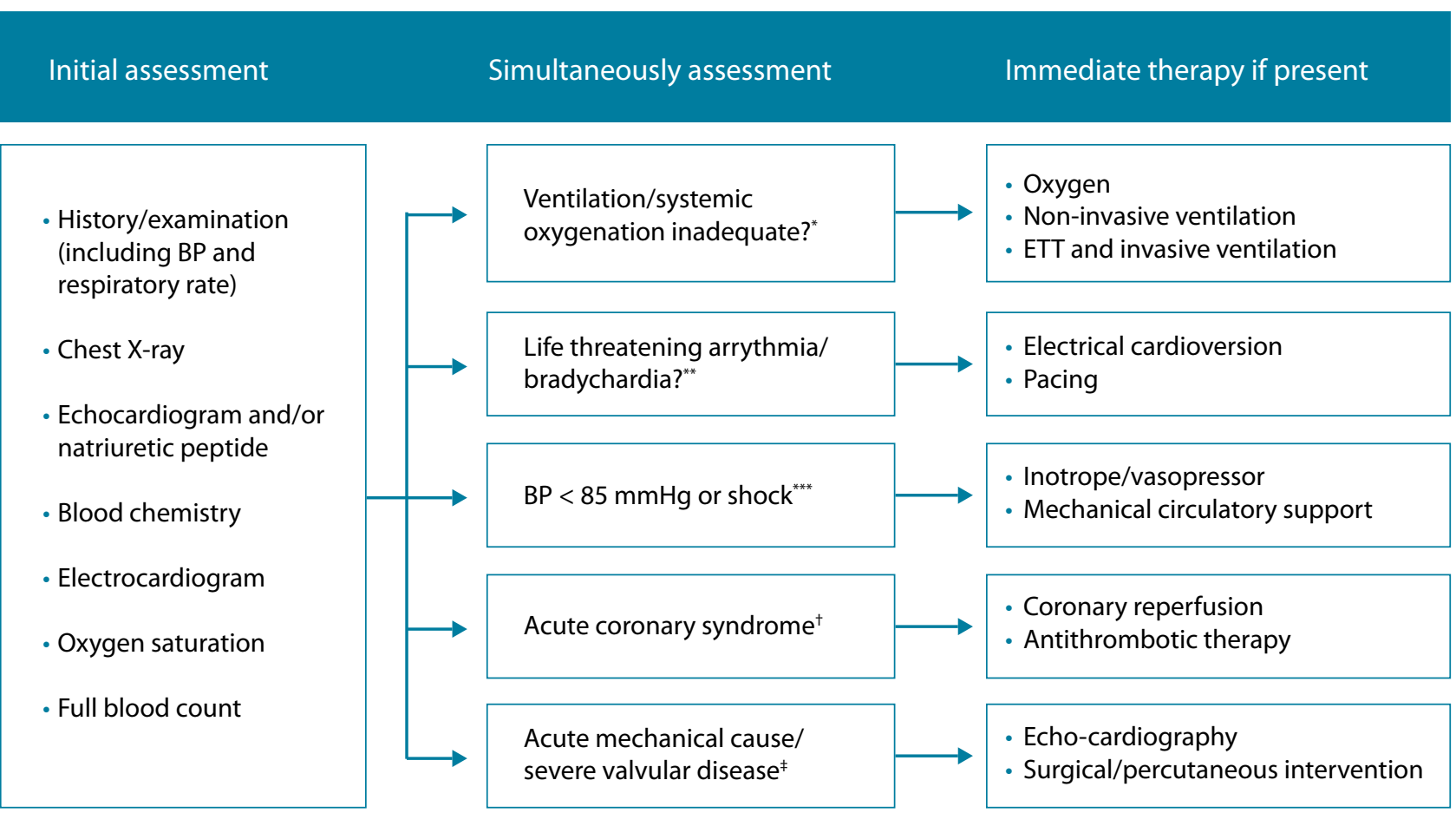

*For example, respiratory distress, confusion $\mathrm{SpO} 2<90 \%$, or $\mathrm{PaO} 2<60 \mathrm{mmHg}(8.0 \mathrm{kPa})$; **For example, ventricular tachycardia, third-degree atrioventricular block; ***Reduced peripheral and vital organ perfusion; patients often have cold skin and urine output $\leq 15 \mathrm{ml} / \mathrm{h}$ and/or disturbance of consciousness; +Percutaneous coronary revascularization (or thrombolysis) indicated if ST-segment elevation or new left bundle branch block; ¥Vasodilators should be used with great caution, and surgery should be considered for certain acute mechanical complications (e.g. inter-ventricular septal rupture, mitral valve papillary muscle rupture).

Adapted from McMurray JJ et al. 2012 (5) 
Figure 10. Algorithm for the treatment of AHF based on current ESC treatment guidelines

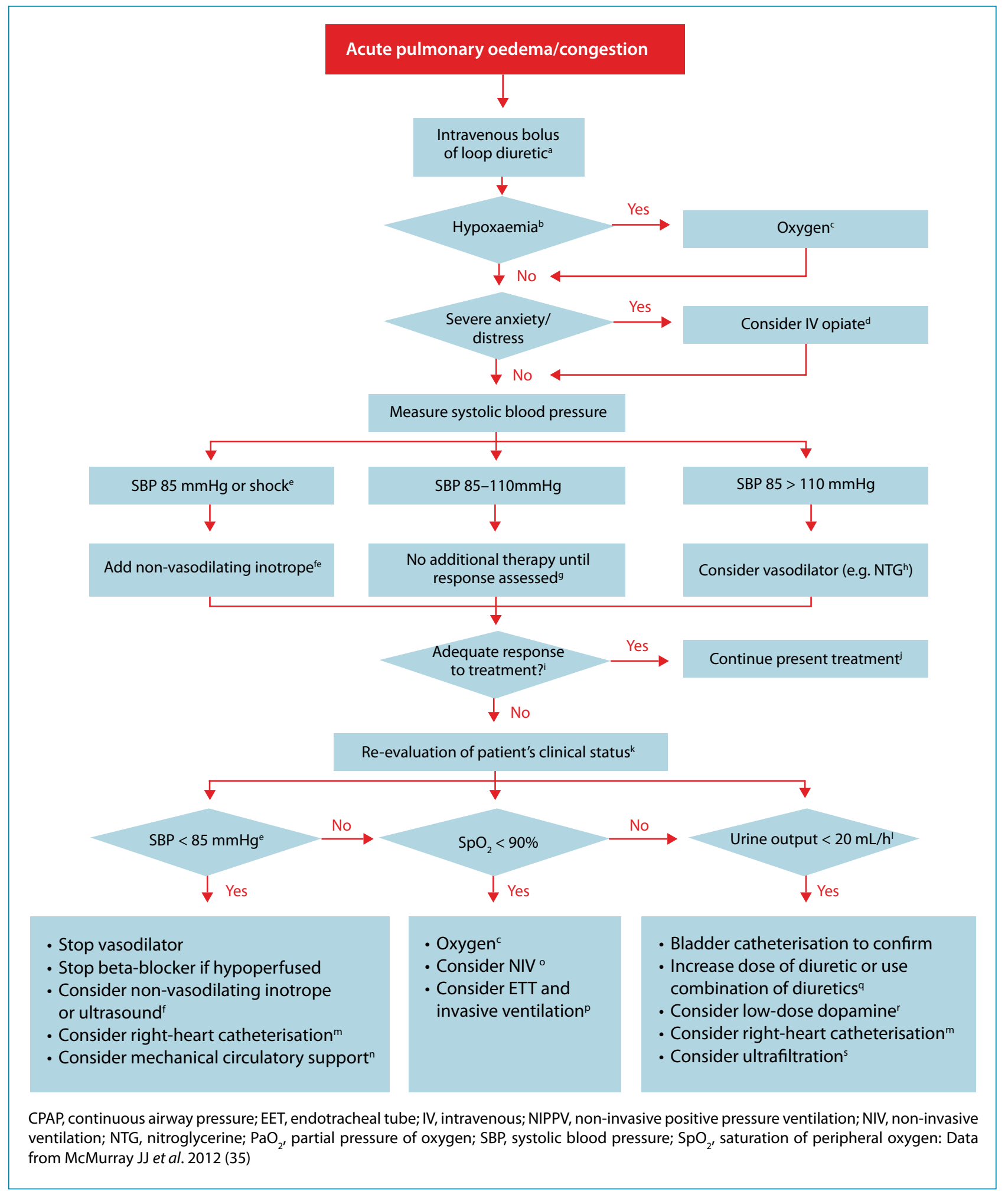


Figure 11. Treatment Pathway for patients with chronic systolic HF

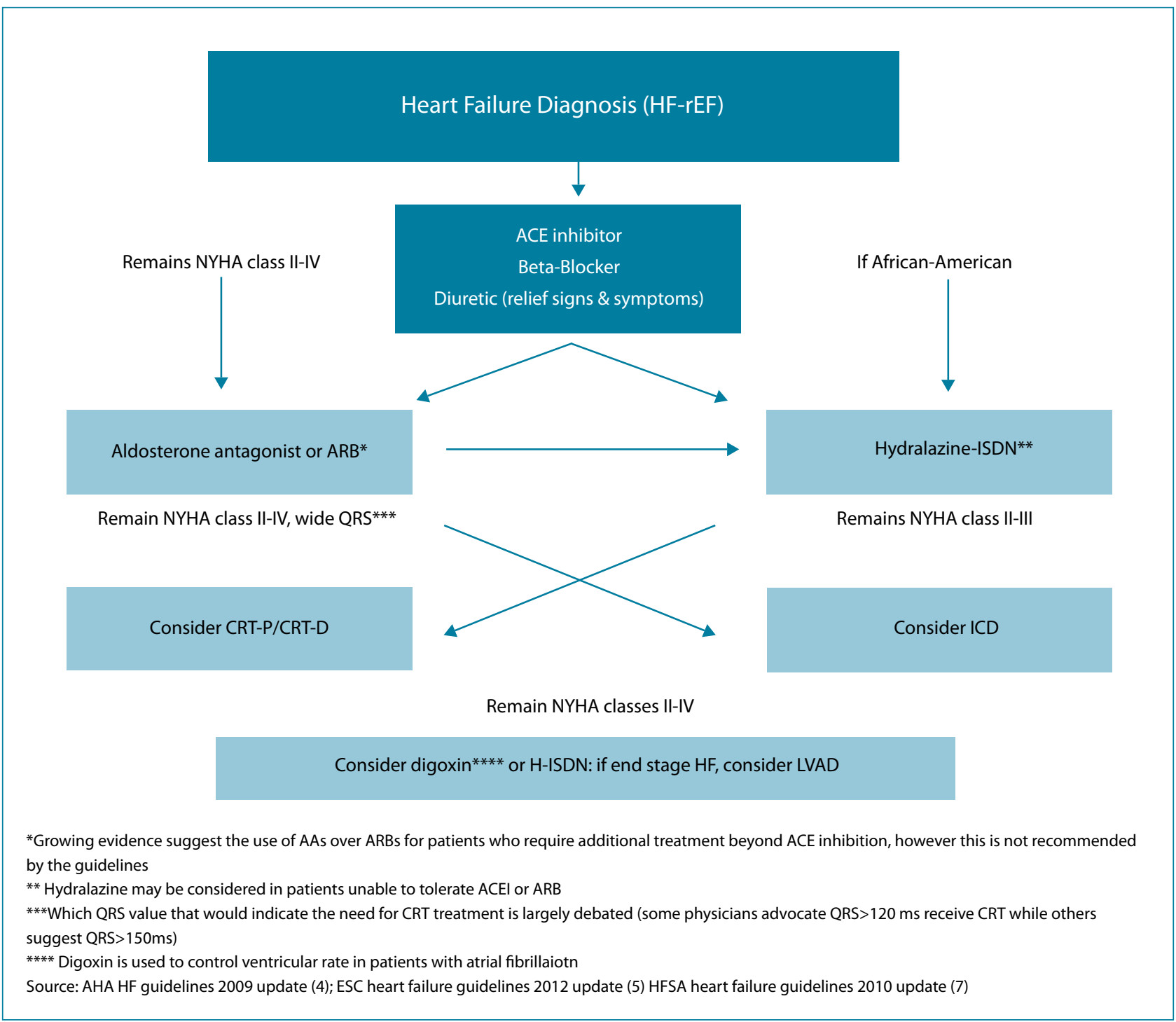

\section{Current treatment intervention}

The primary goals of the management of HF are to improve life expectancy and enhance QoL. The strategies employed to manage HF include pharmacological management, non-pharmacological management, implantation of devices, and surgical treatment, and are described in detail in the following sections.

There is currently a lack of consensus on the diagnostic criteria required to objectively define HF-pEF (11). LVSD is defined mainly on echocardiographic criteria (a semi-qualitative imaging assessment) where the main measure, left ventricular ejection fraction (LVEF), is a continuous variable, and the categorical cut-off that defines its presence, an LVEF below $40 \%$, is proposed to change to below $50 \%$ (36).

Chest X-rays are referred to as useful diagnostic tools, although symptoms and signs may indicate the possibility of HF, but are not reliable for establishing the diagnosis.

Cardiac catheterisation can be used to diagnose diastolic dysfunction (and thus HF-pEF), but is rarely used outside research protocols (37). Unfortunately, primary care physicians in both Europe \& Ireland have variable and often delayed access to the most appropriate objective test, namely echocardiography. 
Echocardiography is considered a useful method for evaluating systolic and diastolic dysfunction (5) but has some limitations in terms of sensitivity. This distinction has remarkable effect on choice and response to the treatment. For example, ARBs have been reported to provide benefit in patients with $\operatorname{HF}-r E F(38,39)$, but not in patients with $\operatorname{HF-pEF}(40,41)$. The sensitivity for detection of vegetation's (fibrinous clots) is lower on the right side of the heart ( $70 \%)$ than on the left (>95\%). Furthermore, prosthetic valves can reduce the sensitivity, but the findings are still considered informative ${ }^{\text {lxii. }}$ EF is expected to improve over the course of 3 to 6 months with pharmacotherapy. If it remains at 35\% or below, an Implantable Cardioverter Defibrillator (ICD) should be considered.

For this reason, the potential role of natriuretic peptides in diagnosing HF on the basis of a simple and inexpensive blood test has emerged. STOP-HF was a recent Irish trial (42) revealing the benefit of such preventative measures through use of BNP (or NTproBNP) screening. Over a four year follow up period, the primary endpoint of LV dysfunction with or without HF was monitored, as was the incidence of emergency hospitalisation, labelled the second end point. Overall there was a $40 \%$ reduction in the hospitalisation for cardiovascular events and a reduction of $42 \%$ relative risk reduction in the primary endpoint (that is, left ventricular dysfunction with or without HF).

Clinical trials have shown that treatment to reduce blood pressure can reduce the risk of developing HF. Moreover, NICE have recently updated their guideline on the management of CHF (37). This has taken account of the growing evidence base for the role of natriuretic peptides and the prognostic significance of very high natriuretic peptide levels in the diagnosis of HF. Its significance in the diagnosis of HF is clear, as many elderly patients that have HF do not have a significant reduction in LVSD as seen by imaging (43).

Foremost recent reports in the European Union and United States emphasise the difficulties in achieving adequate risk factor control and show present strategies may not reach a desired level of efficacy $(44,45)$. As $80 \%$ of HF diagnoses occur in hospital following an acute episode of an underlying condition, and a lesser $20 \%$ in the community (46) the need to engage in preventative and cost effective strategies is evident.

Despite recent advances in the treatment and relief of symptoms for $\mathrm{CHF}$, the prevailing pathology of HF requires constant treatment and care. Similarly, identification of those who already have some early structural and functional perturbation without advanced symptoms, are critically important.

\subsection{Appendix C: International prevalence and incidence}

\section{Prevalence}

UK: The British Heart Foundation estimates that 800,000 - 900,000 people in the UK live with definite or probable HF, and a further 60,000 to 80,000 people develop the condition each year $(47,48)$. Different studies give similar results on the prevalence of $\mathrm{HF}$ in the UK of around $1 \%$ of all men and women aged $<65$ years (47).

Using data from the Heart of England Screening Study, which collected data in the West Midlands between 1995 and 1999 , it is estimated that approximately 393,000 men and 314,000 women aged $\geq 45$ years are living in the UK with definite symptomatic $\mathrm{HF}$, giving a total of approximately 707,000 patients $(47,49)$. However, across England, the prevalence is recorded in QOF ${ }^{\mid x i i i}$ as $0.75 \%$, compared with the 1 to $2 \%$ reported in epidemiological studies (50). This means that, at best, there are 127,500 sufferers in England alone who do not appear in the QOF datasets.

Spain: The prevalence of HF in family practice was reported to be $6.9 \%$ in a cross-sectional observational study of 198,670 individuals $>14$ years in the Community of Madrid (51). Roger and colleagues (18) found prevalence rates in those aged 45 years and older at $6.8 \%$, rising to $19.1 \%$ in those aged 74 years and older.

Data from a well-structured demographic study (PRICE) of 15 healthcare centres in Spain emphasise the growing prevalence of $\mathrm{HF}$ in those above the age of 45 years, with an estimated prevalence of $6.8 \%$ for the total population, only modestly higher in women than men. As expected, prevalence increases with age, with an average $16.1 \%$ of those over 74 years with a diagnosis of 
HF (52). The accuracy of the diagnosis was confirmed by ensuring all suspected and confirmed HF patients were reviewed by a cardiologist, therefore diminishing the uncertainty of positive false diagnoses.

Additionally, Gomez-Soto et al., (53) found the prevalence of HF-rEF surpassed the prevalence of non-systolic HF. The prevalence of non-systolic HF among women surpassed the prevalence among men. In contrast, the prevalence of HF-rEF among men surpassed the prevalence among women. The prevalence of both non-systolic and HF-rEF increased over time, whilst the prevalence of HF among men surpassed the prevalence among women.

Overall, the prevalence of HF reported in Spanish studies is higher (by approximately 2 -fold) than prevalence figures described in other western countries. While the prevalence of $\mathrm{HF}$ in other European countries and the United States is approximately $2 \%$, Spanish studies report figures of $5 \%$ or higher. This difference is unlikely to reflect reality and is more likely due to methodological limitations of studies in Spain (54).

Italy: A community based study of 65-84 year olds in the Lazio Region Italy revealed the prevalence of undiagnosed HF is reported to be high. Compared to administrative data which captured a prevalence of $1.8 \%$, further clinical examination revealed a prevalence of $6.7 \%$ among those aged $64-84$ years and $4.2 \%$ among $65-74$ years (55). Clinical evaluation included blood test, echocardiography, electrocardiography, and clinical examination.

France: The prevalence of $\mathrm{HF}$ in individuals $\geq 65$ years in general practice is estimated to be $11.9 \%$ (56).

Germany: Prevalence of HF has risen substantially over the past few years. In 2002, prevalence of HF reached a ranking third in absolute numbers as the primary diagnosis in hospitals, after chronic IHD and mental and behavioural disorders (due to use of alcohol). A population based study from 2002-2006 in Halle Germany revealed the total prevalence of HF, both diagnosed and undiagnosed, is $9.7 \%$ of persons aged $45-83$ years (57). In 2006, HF had become the most common reason for hospital admission in Germany, with 317,000 primary diagnoses (58).

Belgium: The prevalence of ventricular diastolic dysfunction in a randomly recruited sample of 539 patients from August 1985 to December 2005 was found to be as high as $27.3 \%$ (59).

The Netherlands: The prevalence of HF was reported to be $7 \%$ in 1999 . Prevalence was higher in men than in women (e.g., 1998: men 8.0\%, women 6.0\%). There was a sharp rise of prevalence estimates with age (60).

Sweden: The overall prevalence of HF in Sweden is thought to be approximately $2 \%$ (61).

In economically developing areas, such as parts of Latin America and Asia, the numbers of patients with HF are also increasing (62-65). The increase is largely a result of the shift towards a Western-type lifestyle and its associated diseases, for example conditions such as diabetes increase the risk of developing $\mathrm{HF}^{\text {|xiv }}$. This is despite reductions in the number of cases caused by Chagas disease in urban areas of Latin America (66) as well as reductions in the number of cases of Davies disease (a disorder in which the heart muscle becomes rigid) in tropical areas ${ }^{\mathrm{kv}}$.

Infections remain a common cause of HF in many parts of the world and can strike at any age. HF is not a disease of the elderly in sub-Saharan Africa, where half of patients hospitalised with the disease are 55 years of age or under (67). Patients in the Asia Pacific region also tend to be younger than Western regions. Rheumatic fever due to preventable (treatable) bacterial infections is a prominent cause of heart failure in Africa, Asia, Australasia and Latin America (65). HIV infection is also a major contributor to heart-related disease across the world (68). 


\subsection{Appendix D: Co-morbidity Variation in the EU \& US registries}

A distinction is made between non-cardiac comorbidities and cardiac conditions that are directly related to the presence of CHF such as arrhythmias as well as the conditions that predate and contribute to its aetiology such as hypertension, diabetes mellitus and hyperlipidaemia.

Patients with HF commonly have other co-morbidities and cardiovascular risk factors, such as hypertension, diabetes, atrial fibrillation, coronary disease, COPD and renal dysfunction, which further complicate their clinical condition and medical management $(3,16)$. Comorbid conditions can exist as a precipitating cause of HF or which can be triggered by a decline in cardiac output. For example, hypertension, a common cause of HF, may also present as a secondary condition caused by physiological adaptations to a lowered circulating blood volume.

Non-cardiac comorbidities similarly complicate HF care and are prevalent in elderly patients with HF. This wide range of comorbidities, which includes respiratory comorbidities, renal dysfunction, anaemia, arthritis, cognitive dysfunction and depression, contributes to the progression of the disease and may alter the response to treatment.

Due to this, comorbidity care can play a role in the treatment of chronic HF. Patients with comorbidities may be taking a large number of medications that could limit use of HF medications (either due to compliance, reluctance of the physician to prescribe multiple medications, or reluctance of the patient to take multiple medications). Medications for comorbidities can have an adverse effect on $\mathrm{HF}$ progression (e.g., some medications for diabetes are detrimental for HF, and can be harmful in some comorbidities (e.g., beta blockers in lung disease and diabetes).

Data from ADHERE and EuroHeart Failure survey data reveal strikingly different characteristics in patients in these registries compared with those usually randomised in clinical trials. Associated conditions include evidence of prior ischemic heart disease in $68 \%$, myocardial infarction in $32 \%$, hypertension in up to $72 \%$, cardiac valvular disease in $23 \%$, atrial fibrillation in $31 \%$, peripheral vascular disease in $18 \%$, and chronic renal failure in up to $30 \%$ of patients and diabetes in approximately $45 \%$ of cases. These surveys established that patients requiring care are older, with a mean age between 70 and 75 years, are commonly female and have greater concomitant disease, making them more susceptible to decompensation, difficult to treat and prone to recurrent events. The prevalence of key morbidities is different between patients with HF-rEF and HF-pEF populations $(69,70)$. 
Table 13. Prevalence of co-morbidities amongst patients with HF in the US and Europe

\begin{tabular}{|c|c|c|c|c|c|c|c|c|}
\hline Description & $\begin{array}{l}\text { ADHERE } \\
(\mathrm{n}=110,000)\end{array}$ & $\begin{array}{l}\text { EURO-HF } \\
(n=11,000)\end{array}$ & $\begin{array}{l}\text { OPTIMIZE-HF } \\
(n=48,612)\end{array}$ & $\begin{array}{l}\text { Thomson } \\
\text { Reuters } \\
\text { Database } \\
(\mathrm{n}=7,814)\end{array}$ & $\begin{array}{l}\text { Euro HF } \\
\text { survey II } \\
(n=3,580)\end{array}$ & $\begin{array}{l}\text { ESC-HF } \\
\text { Pilot } \\
(n=3,226 \text { CHF) }\end{array}$ & $\begin{array}{l}\text { EPISERV } \\
(\mathrm{n}=2,249)\end{array}$ & $\begin{array}{l}\text { Shinken } \\
\text { Database } \\
(n=597)\end{array}$ \\
\hline $\begin{array}{l}\text { Country/ } \\
\text { region }\end{array}$ & USA & Europe & USA & USA & Europe & Europe & Spain & Japan \\
\hline CHD/IHD & 57 & 68 & 50 & - & 54 & - & - & 51 \\
\hline Hypertension & 72 & 53 & 71 & 37 & 64 & 58 treated & $65-81$ & 35 \\
\hline Diabetes & 44 & 27 & 42 & 26 & 34 & 29 & $31-46$ & 24 \\
\hline $\begin{array}{l}\text { Atrial } \\
\text { fibrillation }\end{array}$ & 31 & 43 & 31 & 18 & 39 & 39 & $32-38$ & 27 \\
\hline $\begin{array}{l}\text { Renal } \\
\text { insufficiency } \\
\text { (CKD) }\end{array}$ & 30 & 17 & 30 & 8 & 17 & 19 & $\begin{array}{l}\text { 6-12 } \\
\text { (renal } \\
\text { failure) }\end{array}$ & 36 \\
\hline COPD & 31 & - & 28 & 18 & 19 & - & $18-28$ & - \\
\hline PAD & - & - & - & 8 & - & - & $13-17$ & - \\
\hline
\end{tabular}

Trial data is subject to selection bias and is patient-based, as opposed to hospitalisation visit based, so patients that are frequently hospitalised in a given year are not captured in a Randomised Control Trial (RCT). An analysis of Medicare-linked ADHERE hospitalisations has shown that while some comorbidities are captured equally frequently in annual hospitalisation analyses versus patient comorbidity analyses, patients with some comorbidities (such as renal disease) seem to be hospitalised more frequently and thus may be under-represented in patient-level analysis (74).

Region specific registry data offer differentiating patterns of co-morbidities among AHF patients in the EU \& US (Table 14) In addition to further discussion surrounding the impact of concomitant and compounding diseases. 
Table 14. Co-morbidity Variation in the EU \& US registries

\begin{tabular}{|c|c|c|}
\hline Comorbidity & $\begin{array}{l}\text { US studies } \\
\text { (ADHERE and OPTIMIZE-HF) }\end{array}$ & $\begin{array}{l}\text { European studies } \\
\text { (EHFS I and II) }\end{array}$ \\
\hline CAD & $50-57^{*}$ & $54-68$ \\
\hline Hypertension (\%) & $64-73$ & $53-63$ \\
\hline Diabetes (\%) & $42-57$ & $27-33$ \\
\hline AF (\%) & $24-31$ & $39-43$ \\
\hline Chronic renal insufficiency** (\%) & $22-30$ & $17-18$ \\
\hline COPD (\%) & $28-31$ & 19 \\
\hline \multicolumn{3}{|c|}{$\begin{array}{l}\text { *In the ADHERE-US and International studies, medical history was reported as CAD/IHD ( } 54.1 \% \text { and } 42.4 \% \text {, respectively) } \\
\text { **Defined as patient with serum creatinine }>177 \mu \mathrm{mol} / \mathrm{L} \text { or on dialysis } \\
\text { ADHERE, Acute Decompensated Heart Failure National Registry; AF, atrial fibrillation; CAD, coronary artery disease; COPD, chronic obstructive } \\
\text { pulmonary disease; EHFS, European Heart Failure Survey }(\mathrm{n}=110,000) \text {; OPTIMIZE-HF, Organised Program to Initiate Lifesaving Treatment in } \\
\text { Hospitalised Patients With Heart Failure }(\mathrm{n}=48,612) \text {; EHFS I, EuroHeart Failure Survey I }(\mathrm{n}=11,327) \text {; EHFS II, EuroHeart Failure Survey II ( }= \\
\text { 3,580) } \\
\text { Data from Atherton JJ et al. } 2012 \text { (31): Gheorghiade M et al. } 2005 \text { (6) : Nieminen MS et al. 2005 (26): Nieminen MS et al. 2008 (75): West Ret al. 2011 (33) }\end{array}$} \\
\hline
\end{tabular}

\subsection{Appendix E: Primary and All case HF diagnoses}

Table 15. Ireland Primary \& All case diagnoses

\begin{tabular}{|c|c|c|c|}
\hline Code description & No. of Primary diagnoses & Secondary/all case diagnoses & $\begin{array}{l}\% \text { of primary diagnoses from } \\
\text { secondary / all case }\end{array}$ \\
\hline 150 & 4,690 & 16,092 & $29 \%$ \\
\hline 150.1 & 460 & 1,722 & $27 \%$ \\
\hline 150.9 & 144 & 544 & $26 \%$ \\
\hline R57 & 16 & 110 & $14 \%$ \\
\hline 125.5 & 210 & 944 & $22 \%$ \\
\hline 142.9 & 85 & 730 & $12 \%$ \\
\hline 110 & 39 & 290 & $71 \%$ \\
\hline Total Admissions & 5,642 & 20,432 & \\
\hline
\end{tabular}


Table 16. Primary and Secondary HF diagnoses

\begin{tabular}{|c|c|c|c|c|}
\hline Destination & $\begin{array}{l}\% \text { of primary diagnoses } \\
\text { out of total diagnoses }\end{array}$ & $\begin{array}{l}\text { Second-listed } \\
\text { diagnosis b }\end{array}$ & Other diagnosis C & Total AHF events, $n$ \\
\hline US & $26 \%$ & 1.3 million & 2.1 million & 4.6 million \\
\hline UK & $26 \%$ & 129,000 & 191,000 & 435,000 \\
\hline France & $26 \%$ & 185,000 & 299,000 & 648,000 \\
\hline Germany & $25 \%$ & 402,000 & 645,000 & 1.4 million \\
\hline \multicolumn{5}{|c|}{$\begin{array}{l}\text { aFirst-listed diagnosis = AHF diagnosis code in the first coding position of hospital discharge records. First-listed diagnosis captures patients whose presentation } \\
\text { to the hospital was most likely a result of an AHF event and is the most conservative estimate of the AHF population sizebSecond-listed diagnosis = AHF diagnosis } \\
\text { code in the second coding position of hospital discharge records. The second-listed diagnosis captures additional patients whose presentation to the hospital was } \\
\text { likely as a result of AHF. Data for second-listed diagnoses for European countries were based on ratios obtained from US data cOther diagnosis = AHF diagnosis } \\
\text { code in the third or later coding position of hospital discharge records. Other diagnosis captures additional patients who experienced an AHF event during their } \\
\text { hospitalisation and potentially overestimates the AHF population because the discharge code could reflect a previous diagnosis of AHF. Data for other diagnoses } \\
\text { for European countries were based on ratios obtained from US data } \\
\text { Agency for Healthcare Research and Quality (2008) (76) } \\
\text { National Health Service (2008) (77) } \\
\text { Programme de Médicalisation des Systèmes d'Information (2008) (78) } \\
\text { AHF, acute heart failure; UK, United Kingdom; US, United States }\end{array}$} \\
\hline
\end{tabular}

\subsection{Appendix F: Global Economic Burden of HF}

UK: In the UK, expenditure on CHF represents $10 \%$ of total expenditure on diseases of the circulatory system (79).

Cost of HF to the National Health Service (NHS) was evaluated in 1995 (80). The study estimated that there were 988,000 individuals requiring treatment for $\mathrm{HF}$ in the UK during 1995. The 'direct' cost of healthcare for these patients was estimated to be $£ 716$ million, or $1.83 \%$ of total NHS expenditure. Excluding secondary admissions and long-term nursing care, the principal hospital admissions, GP visits and drug treatment comprised $69 \%, 6 \%$ and $18 \%$ of healthcare expenditure related to HF in the UK. The additional costs associated with long-term nursing home care and secondary HF admissions accounted for a further $£ 751$ million (2.0\% of total NHS expenditure). It was projected from the 1995 data that the combined total direct cost of HF would rise to $£ 905$ million - equivalent to $1.91 \%$ of total NHS expenditure - by the year 2000 .

Further estimates relating to the cost of HF in the UK vary widely. In fact, a report from the British Heart Foundation estimated the overall cost of HF to the NHS in the year 2000 was $£ 629$ million, with hospital inpatient care representing the major expense (81). Recent estimates place the cost of HF in the UK at $€ 26$ million per million population (36), which would equate to $€ 1.7$ billion in 2012 prices (assuming a population of 62 million and a PPP of 1.238428). HF-related costs continue to increase dramatically due to population ageing and improved post-MI survival rates (82).

Germany: HF is responsible for $1.1 \%$ of direct health costs in Germany. In 2006, HF cost the German public health system $€ 2.9$ billion. The total figure includes costs for inpatient, outpatient and day care services, as well as drugs, devices and other medical products. In-patient hospital care accounts for $60 \%$ of the direct medical costs for HF in Germany, with the largest part related to hospital stays (€1.3 billion) (58).

The Netherlands: Cardiovascular diseases account for $10 \%$ of total healthcare expenditures in the Netherlands. Of the CV expenditures, $80 \%$ is due to HF (83). The expenditure on CHF has increased over and above the rate of inflation in the Netherlands since 1994. In a cost of illness study, healthcare expenditure in 1996 totalled NLG 654 million (€299.9 million), which represented $9.7 \%$ of Gross National Product (GNP). CHF accounted for $1.1 \%$ of this figure and ranked 29th when costs were compared with those of other chronic diseases (84).

Spain: It has been estimated that the cost of CHF in 1993 was between $€ 384.8$ and $€ 992.6$ million, equivalent to 1.8 and $3.1 \%$ of the overall budget for the Spanish National Health System $(85,86)$. The length of hospitalisation for an episode of HF from a regional hospital database was estimated to be 11.6 days with an associated cost of 350.8 Euros per day (86). 
Sweden: An economic evaluation of CHF on healthcare expenditure in Sweden assessed both direct treatment costs and those attributable to institutional care (87). The annual expenditure on CHF was $2000 \pm 2600$ million Swedish Kronor or $2 \%$ of the total healthcare budget. Institutional care (hospital and nursing home) represented $64-75 \%$ of this total expenditure. Patients aged 80 years and older represented $50 \%$ of all CHF hospital discharges and $75 \%$ of nursing home discharges. These figures demonstrate that the economic burden of $\mathrm{CHF}$ is a function of the cost of hospitalisations, which occur more frequently in elderly patients.

A more recent analysis suggests that the burden of HF may be greater, with total annual cost in the range of SEK 5.0-6.7 billion (88). The mean annual cost for a patient with HF is estimated to be approximately SEK 37,100, with hospital care, primary healthcare, medications, nursing home care and examinations comprising $47 \%, 22 \%, 18 \%, 5 \%$, and $6 \%$ of the costs, respectively (88).

France: HF accounts for more than 150,000 hospitalizations in France and the cost of HF is thought to represent 1-1.9\% of total health expenses $(79,89)$.

Italy: In 2003, HF was the primary medical cause of hospitalisation (1.6\%) in Italy (90). This estimate is based on analysis of national hospital discharge data for 2001, 2002 and 2003.

New Zealand: In New Zealand, HF is thought to cost NZ\$73 million, which is $1.4 \%$ of the total healthcare expenditure. A significant proportion of these costs are attributable to hospitalisations (79).

USA: The total (direct and indirect) costs of HF have increased steadily over the last decade (91). Approximately US\$39.2 billion ( $€ 29.4$ billion $^{1 \times v i}$ ) is spent annually on the care of patients with HF (92). Direct costs accounted for US\$35.1 billion, which included hospital costs of US\$20.9 billion, nursing costs of US\$4.7 billion, professional costs of US\$2.5 billion, medical costs of US\$3.2 billion, and home healthcare costs of US\$3.8 billion. Large portions of the associated costs of HF are related to insurance, wage replacement, and lost productivity (93). Indeed, the cost of lost productivity for HF in the USA is estimated to be US\$4.1 billion per year(40).

\subsection{Appendix G: IMS analysis}

Table 17. IMS Analysis (top ten)

\begin{tabular}{|l|l|l|}
\hline 125 CHR ISCHAEM HRT DIS & 150 HEART FAILURE & 151 COMPL/I/DEF DESC-HRT DIS \\
\hline B1C PLATELET AGGREG INHIBIT. & C3A DIURETICS & B1C PLATELET AGGREG INHIBIT. \\
\hline C10A CHOLEST\&TRIGLY.REGULATOR & C7A BETA BLOCKING AGENT PLAI & C7A BETA BLOCKING AGENT PLAI \\
\hline C7A BETA BLOCKING AGENT PLAI & C9A ACE INHIBITORS PLAIN & C10A CHOLEST\&TRIGLY. REGULATOR \\
\hline C9A ACE INHIBITORS PLAIN & B1C PLATELET AGGREG INHIBIT. & C9A ACE INHIBITORS PLAIN \\
\hline C3A DIURETICS & C1A CARDIAC GLYCOSIDES+COMB & C3A DIURETICS \\
\hline C8A CALCIUM ANTAGONIST PLAIN & C10A CHOLEST\&TRIGLY.REGULATOR & C8A CALCIUM ANTAGONIST PLAIN \\
\hline C1E NITRITES AND NITRATES & C9C ANGIOTEN-II ANTAG, PLAIN & C1E NITRITES AND NITRATES \\
\hline C9C ANGIOTEN-II ANTAG, PLAIN & C1E NITRITES AND NITRATES & C1A CARDIAC GLYCOSIDES+COMB \\
\hline C9D ANGIOTEN-II ANTAG COMB & A2B ANTIULCERANTS & C9D ANGIOTEN-II ANTAG, COMB \\
\hline B1A VITAMIN K ANTAGONISTS & B1A VITAMIN K ANTAGONISTS & B1F DIRECT FACTOR XA INHIBS \\
\hline C1D CORONRY THER EXC C AN+NI & C8A CALCIUM ANTAGONIST PLAIN & C1D CORONRY THER EXC C AN+NI \\
\hline
\end{tabular}


Table 18. Total top 10 sales across all therapeutic areas

\begin{tabular}{|l|l|}
\hline Description & Total Sales 2013 \\
\hline C10a Cholest\&Trigly.Regulator & $€ 77,543,344$ \\
\hline B01c Platelet Aggreg Inhibitrs & $€ 17,236,914$ \\
\hline C07a Beta Blocking Agent Plain & $€ 7,556,490$ \\
\hline C09a Ace Inhibitors Plain & $€ 12,065,614$ \\
\hline C08a Calcium Antagonists Plain & $€ 12,240,442$ \\
\hline C09c Angiotensn-li Antag,Plain & $€ 15,389,131$ \\
\hline C03a Diuretics & $€ 4,659,896$ \\
\hline C09d Angiotensin-li Antag,Comb & $€ 15,296,273$ \\
\hline C09b Ace Inhibitors Combinat & $€ 5,454,031$ \\
\hline B01a Vitamin K Antagonists & $€ 1,320,783$ \\
\hline C01e Nitrites And Nitrates & $€ 1,599,515$ \\
\hline C01a Cardiac Glycosides \& Comb & $€ 139,854$ \\
\hline Total & $€ 170,502,287$ \\
\hline
\end{tabular}

\subsection{Appendix H: Professional Curiosity (2013)}

Table 19. Readmission rates and HF services

\begin{tabular}{|l|l|l|}
\hline Description & Re-admission Rates & Follow up services \\
\hline Hospital 1 & $10-25 \%$ & None \\
\hline Hospital 2 & $20 \%$ (6months-1year) & Informal HF clinic \\
\hline Hospital 3 & $60-70 \%$ (3-6 months) & None \\
\hline Hospital 4 & $10-50 \%$ depending on follow up programme & HF clinic \\
\hline Hospital 5 & $10-90 \%$ depending on follow up programme & HF clinic \\
\hline Hospital 6 & $7-10 \%$ (3 months) & HF day unit \\
\hline Hospital 7 & $75 \%$ (3-4 months) NOTE: mainly elderly & HF clinic \\
\hline Hospital 8 & $75 \%$ (6 months) & HF clinic \\
\hline Hospital 9 & $70 \%$ (3-6 months) & HF clinic \\
\hline
\end{tabular}




\subsection{Appendix I: Estimated prevalence of HF in Ireland (2007)}

Figure 12. Estimated prevalence of heart failure (HF) in Ireland (2007)

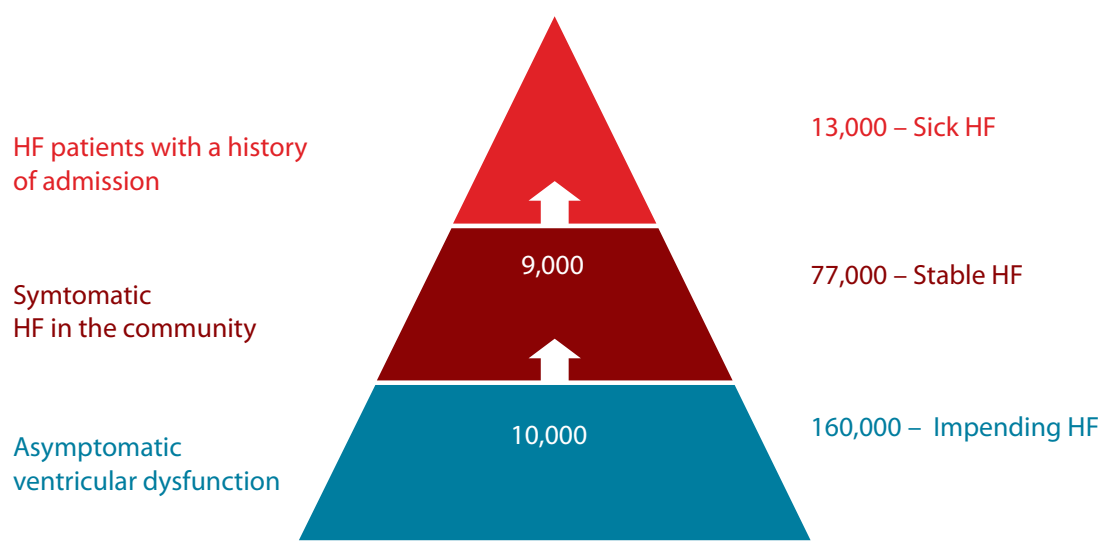

Source: Changing Cardiovascular Health 2010-2019 (94)

\subsection{Appendix J: Cost of IIIness Review}

This appendix briefly outlines the costs associated with other diseases and conditions in the Irish setting.

\section{Obesity}

The annual cost of obesity in Ireland is estimated at $€ 1.64$ billion. In the Republic of Ireland and Northern Ireland, the cost of obesity is approximately $€ 1.13$ billion and $€ 510$ million, respectively. In both jurisdictions, the expenditure is between 2.7 and $2.8 \%$ of total health expenditure. $56 \%$ of the economic costs were indirect. Reduced or lost productivity and absenteeism related to obesity or being overweight totals $€ 728$ million.

\section{Mental illness}

For the year 2006, O'Shea and Kennelly (95) estimated the cost of mental health problems in Ireland exceeded $€ 3$ billion. Just over $€ 1$ billion of this cost was attributed to healthcare expenditure, social care and other forms of direct care. The greater part of this $€ 3$ billion, however, stems from indirect cost of this condition. That is, lost economic output amounting to over $€ 2$ billion, and comprises $€ 1044.6$ million due to non-employment and under-employment, $€ 207$ million due to premature mortality, and $€ 751.1$ million due to unpaid work.

\section{Dementia}

For the year 2010, Connolly, S. et al. (96) estimated the total baseline annual cost for dementia at $€ 1.69$ billion, $48 \%$ of which was attributable to the opportunity cost of informal care provided by family and friends, and $43 \%$ to residential care. Only $16 \%$ of total costs (€807million) were attributable to dementia-related direct health care.

The combined formal health and social care costs came to $€ 148$ million. Of this figure, acute-hospital care accounted for $14 \%$, psychiatric care $26 \%$, and primary and community care accounted for $44 \%$ of the cost. Primary and community care for those with dementia was $€ 65$ million, of which $59 \%$ was spent on respite care. The total cost associated with dementia-related medication was almost $€ 16$ million, of which $85 \%$ was spent on anti-dementia drugs. 


\section{Schizophrenia}

For the year 2006, Behan et al. (97) estimated the economic cost of schizophrenia in Ireland at $€ 460.6$ million. This comprised of $€ 117.5$ million for direct costs of care and $€ 343$ million for indirect costs, including $€ 43.8$ million for informal care provided by families. Lost productivity due to absence from work, unemployment and premature mortality came to $€ 277$ million.

\section{Stroke and TIA}

For the year 2007, the IHF (in association with a research team and steering group) estimated the annual economic cost of stroke and Transient Ischaemic Attack (TIA) in Ireland (98) to be between $€ 489 \mathrm{~m}$ (low prevalence) and $€ 805 \mathrm{~m}$ (high prevalence). The direct expenditure on stroke accounted for $€ 557 \mathrm{~m}$, of this, $€ 414$ million- or almost $80 \%$ - is spent on nursing home accommodation, and less that $€ 7$ million is being spent on community based rehabilitation. This accounted for $2-4 \%$ of the total health care expenditure, and between 0.2 and $0.3 \%$ of GNP in Ireland, with an average direct cost per stroke patient estimated at $€ 18,751$. The total cost of TIA was estimated at $€ 11 \mathrm{~m}$, the majority of which was accounted for by the hospital costs. The total cost of TIA was valued between $€ 470 \mathrm{~m}$ and $€ 1,008 \mathrm{~m}$, with an average cost per TIA case estimated at $€ 4,925$.

\section{Type 2 Diabetes}

Employing a bottom-up, prevalence-based approach, the total annual direct cost was estimated at $€ 377.2$ million for diagnosed diabetes and $€ 580.2$ million for both diagnosed and undiagnosed diabetes over a 12-month period (1999/2000). Although the true prevalence of Type 2 diabetes in Ireland is unknown, conservative estimates of $3.9 \%$ for diagnosed diabetes and $6 \%$ for both diagnosed and undiagnosed diabetes are assumed. Using these figures, the corresponding total healthcare expenditure is estimated at $4.1 \%$ and $6.4 \%$, respectively. The annual cost per patient per annum was estimated at $€ 2,468$. Two thirds of the cost is spent on dealing with complications of the disease.

Hospitalisations were the main driver of costs, accounting for almost half of overall costs, while ambulatory and drug costs accounted for $27 \%$ and $25 \%$ respectively. $60 \%$ of patients had developed complications over the course of their condition, therefore increasing hospitalisation costs. The annual cost of care for patients with microvascular and macro vascular complications were 1.8 and 2.9 times the cost of treating those without clinical evidence of complications respectively. The figure for patients with both types of complications was 3.8 .

\section{Cancer}

Using data from 2009, UK researchers analysing the economic burden of cancer on Europe found that the disease cost Ireland $€ 1.447 \mathrm{~b}$ in just one year, which is $0.89 \%$ of GDP. The study found that Ireland was the fifth highest spender on cancer-related healthcare per capita in the EU. Healthcare costs, including primary care, outpatient care, accident \& emergency, inpatient care, and medication amounted to $€ 619 \mathrm{~m}$ of the total $€ 1.447 \mathrm{~b}$, or $€ 139$ per person. The remaining $€ 828 \mathrm{~m}$ was calculated by adding together other determinants, including productivity losses and informal care costs. That includes the loss of hours due to premature death or time off work due to illness, as well as the worth of care by family and relatives. Informal care costs totalled $€ 162$ million, while mortality and morbidity losses amounted to $€ 603 \mathrm{~m}$ and $€ 63 \mathrm{~m}$ respectively.

The economic burden of lung cancer in Ireland was estimated to cost $€ 209$ million, colorectal cancer cost $€ 158 \mathrm{~m}$, while the corresponding figure for breast and prostate cancer was $€ 137 \mathrm{~m}$ and $€ 81 \mathrm{~m}$, respectively. However, researchers have warned that these estimates are conservative as they do not include some aspects of healthcare such as screening.

\section{Suicide}

The total cost of suicide was estimated to cost over $€ 906 \mathrm{~m}$ in 2001, and over $€ 835 \mathrm{~m}$ in 2002 (in 2001 prices). This is equivalent to a little under $1 \%$ of the GNP in Ireland for those years.

\section{Chronic Pain}

For the year 2008, Raftery et al. (99) estimated the total cost of chronic non cancer pain (CNP) in Ireland at $€ 4.76 b$, representing $2.55 \%$ of Irish GDP in 2008. Across all grades of CNP, the mean costs per patient were $€ 5,665$. The costs increased with increasing 
pain severity; the most expensive $5 \%$ and $10 \%$ of patients accounted for $26 \%$ and $43 \%$ of the total cost, respectively. When the results were extrapolated to the national level, the total costs of CNP were $€ 5.34$ billion, which equated to $2.86 \%$ of the Irish Gross Domestic Product (GDP) in 2008. The authors also note that patients "with clinically significant depression had costs twice as high as those without depression."

\section{Falls and Fractures}

For the year 2004, Gannon et al. (100) estimated the annual baseline cost of falls and fractures at $€ 402 \mathrm{~m}$, equating to approximately $4.2 \%$ of all public health expenditure in Ireland. Overall, the direct and indirect cost of fractures amounts to $€ 225 \mathrm{~m}$. Inpatient costs and long-stay care costs account for almost two thirds of the total cost of care for fractures, excluding mortality. QoL costs account for one quarter of the total cost of care for fractures, again excluding mortality. Drug costs for both combines to $€ 25$ million. Mortality costs associated with falls and fractures accounts for $€ 135$ million, or one third of the total costs.

These enormous costs highlight the pervasive effects of the latter conditions, not only on individuals with the illness, but also their families and carers, and society as a whole. Indirect costs form approximately two thirds of total expenditures, indicating that, generally, the cost of the conditions mainly falls outside the direct cost of HSE. 


\subsection{Appendix K: Treatment pathways}

Figure 13. Treatment Pathway (Prevalence/Community population)

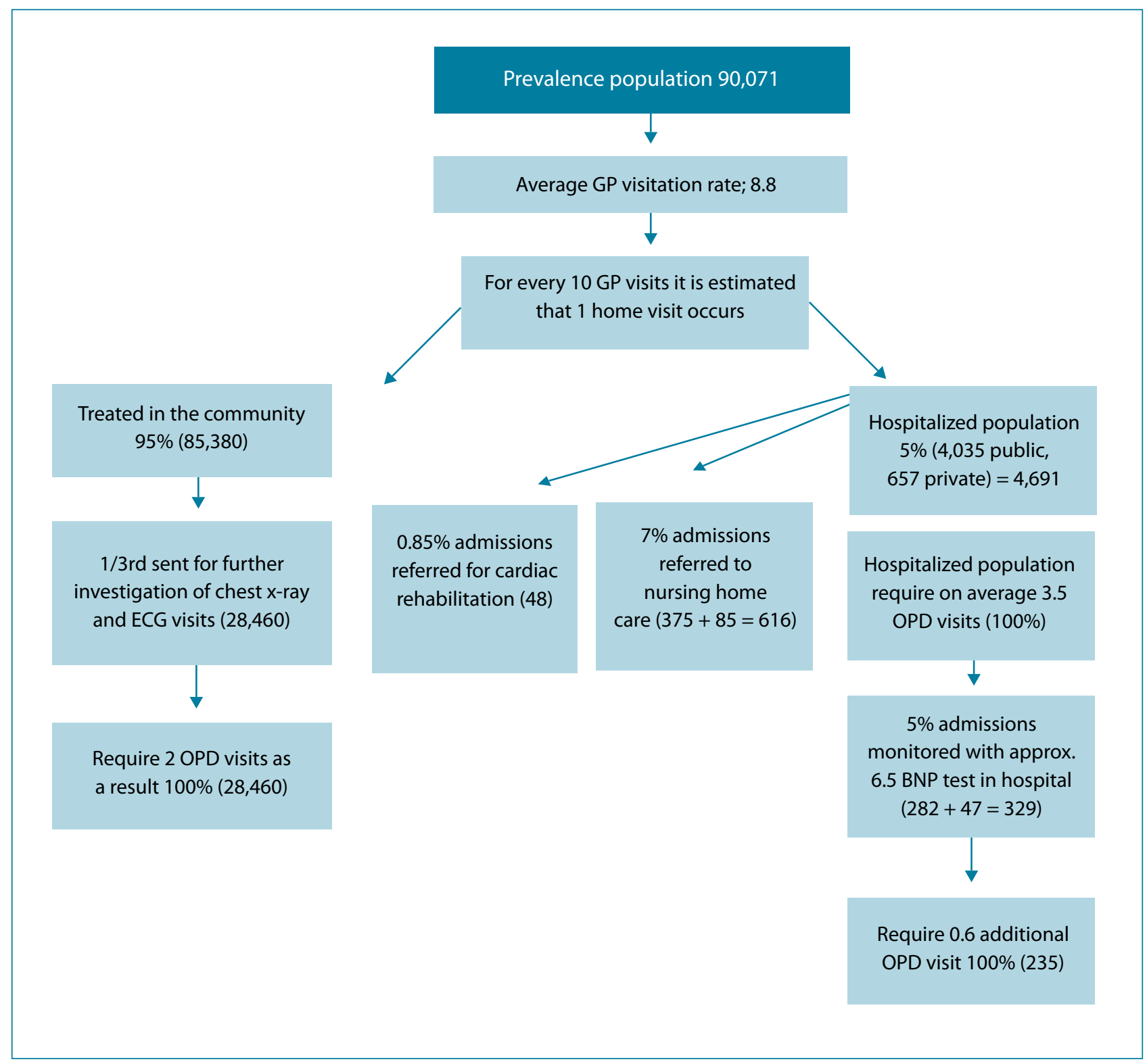


Figure 14. Diagnostic Pathway (Incidence)

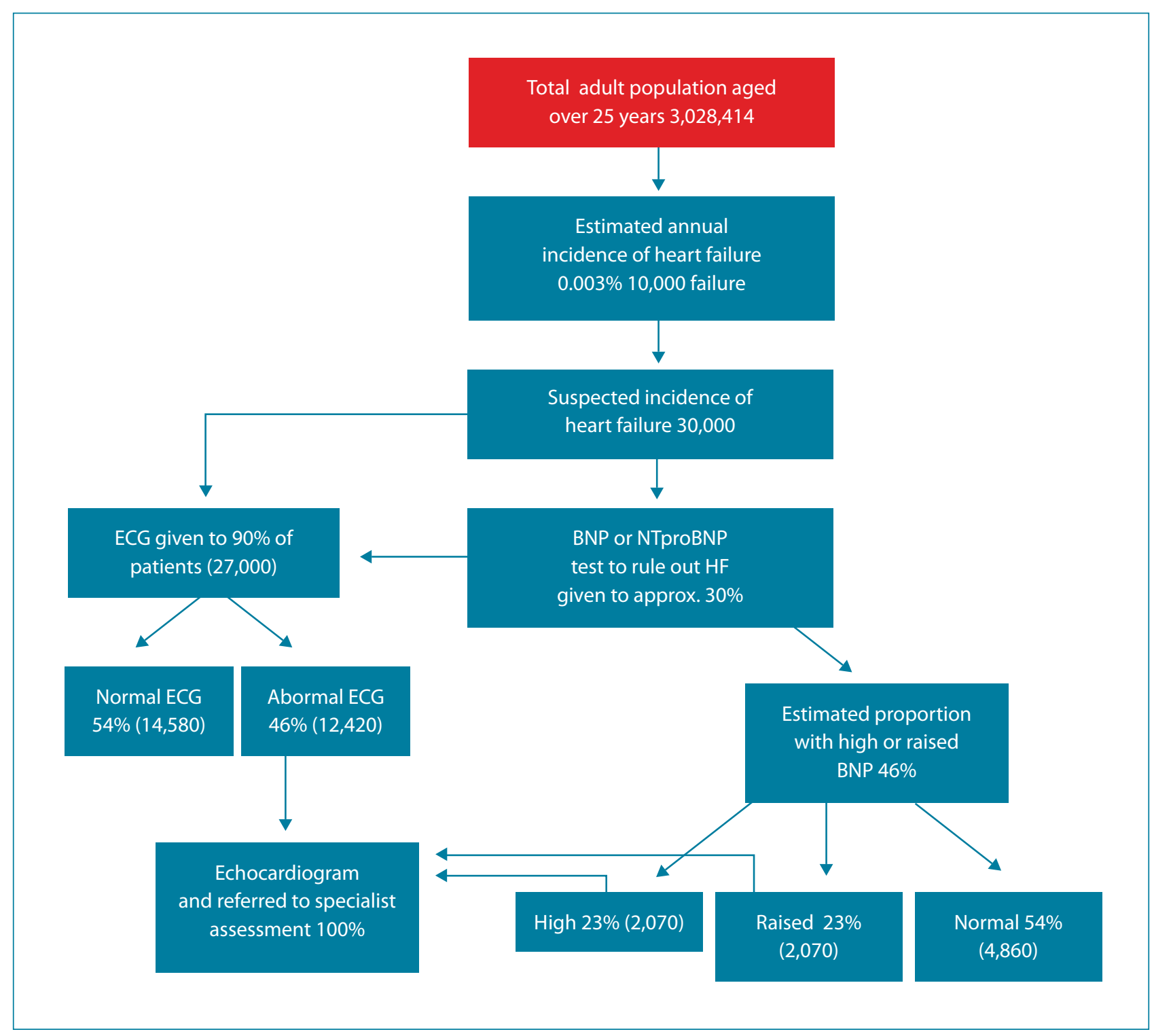




\section{Appendices Bibliography}

1. Zannad F, Mebazaa A, Juilliere Y, Cohen-Solal A, Guize L, Alla F, et al. Clinical profile, contemporary management and one-year mortality in patients with severe acute heart failure syndromes: The EFICA study. Eur J Heart Fail. 2006;8(7):697-705.

2. Tavazzi L, Maggioni AP, Lucci D, Cacciatore G, Ansalone G, Oliva F, et al. Nationwide survey on acute heart failure in cardiology ward services in Italy. European heart journal. 2006;27(10):1207-15.

3. Nieminen MS, Brutsaert D, Dickstein K, Drexler H, Follath F, Harjola VP, et al. EuroHeart Failure Survey II (EHFS II): a survey on hospitalized acute heart failure patients: description of population. Eur Heart J. 2006;27(22):2725-36.

4. Hunt SA, Abraham WT, Chin MH, Feldman AM, Francis GS, Ganiats TG, et al. 2009 Focused Update Incorporated Into the ACC/AHA 2005 Guidelines for the Diagnosis and Management of Heart Failure in Adults A Report of the American College of Cardiology Foundation/American Heart Association Task Force on Practice Guidelines: Developed in Collaboration With the International Society for Heart and Lung Transplantation. Circulation. 2009;119(14):e391-e479.

5. McMurray JJ, Adamopoulos S, Anker SD, Auricchio A, Bohm M, Dickstein K, et al. ESC Guidelines for the diagnosis and treatment of acute and chronic heart failure 2012: The Task Force for the Diagnosis and Treatment of Acute and Chronic Heart Failure 2012 of the European Society of Cardiology. Developed in collaboration with the Heart Failure Association (HFA) of the ESC. Eur Heart J. 2012;33(14):1787-847.

6. Gheorghiade M, Zannad F, Sopko G, Klein L, Pina IL, Konstam $M A$, et al. Acute heart failure syndromes: current state and framework for future research. Circulation. 2005;112(25):3958-68.

7. Lindenfeld J, Albert NM, Boehmer JP, Collins SP, Ezekowitz JA, Givertz MM, et al. HFSA 2010 Comprehensive Heart Failure Practice Guideline. J Card Fail. 2010;16(6):e1-194.

8. Beattie JM. Death by oxymoron? The enigma of heart failure with preserved ejection fraction. Current opinion in supportive and palliative care. 2014;8(1):1-3.

9. Rigolli $M$, Whalley $G A$. Heart failure with preserved ejection fraction. Journal of geriatric cardiology: JGC. 2013;10(4):369.

10. Jessup M, Brozena S. Heart failure. The New England journal of medicine. 2003;348(20):2007-18.

11. Dickstein K, Cohen-Solal A, Filippatos G, McMurray JJ, Ponikowski P, Poole-Wilson PA, et al. ESC Guidelines for the diagnosis and treatment of acute and chronic heart failure 2008ł. European journal of heart failure. 2008;10(10):933-89.

12. Senni M, Redfield MM. Heart failure with preserved systolic function. A different natural history? J Am Coll Cardiol. 2001;38(5):1277-82.
13. Effect of enalapril on survival in patients with reduced left ventricular ejection fractions and congestive heart failure. The SOLVD Investigators. The New England journal of medicine. 1991;325(5):293-302.

14. Bart BA, Ertl G, Held P, Kuch J, Maggioni AP, McMurray J, et al. Contemporary management of patients with left ventricular systolic dysfunction. Results from the Study of Patients Intolerant of Converting Enzyme Inhibitors (SPICE) Registry. Eur Heart J. 1999;20(16):1182-90.

15. Cleland J, Swedberg K, Follath F, Komajda M, Cohen-Solal A, Aguilar JC, et al. The EuroHeart Failure survey programme-a survey on the quality of care among patients with heart failure in Europe Part 1: patient characteristics and diagnosis. European heart journal. 2003;24(5):442-63.

16. Adams KF, Jr., Fonarow GC, Emerman CL, LeJemtel TH, Costanzo MR, Abraham WT, et al. Characteristics and outcomes of patients hospitalized for heart failure in the United States: rationale, design, and preliminary observations from the first 100,000 cases in the Acute Decompensated Heart Failure National Registry (ADHERE). Am Heart J. 2005;149(2):209-16.

17. Kottmair S, Frye C, Ziegenhagen DJ. Germany's disease management program: improving outcomes in congestive heart failure. Health Care Financ Rev. 2005;27(1):79-87.

18. Roger VL, Weston SA, Redfield MM, Hellermann-Homan JP, Killian J, Yawn BP, et al. Trends in heart failure incidence and survival in a community-based population. Jama. 2004;292(3):344-50.

19. Levy D, Kenchaiah S, Larson MG, Benjamin EJ, Kupka MJ, Ho $\mathrm{KK}$, et al. Long-term trends in the incidence of and survival with heart failure. The New England journal of medicine. 2002;347(18):1397-402.

20. Owan TE, Hodge DO, Herges RM, Jacobsen SJ, Roger VL, Redfield MM. Trends in prevalence and outcome of heart failure with preserved ejection fraction. New England Journal of Medicine. 2006;355(3):251-9.

21. Barker WH, Mullooly JP, Getchell W. Changing incidence and survival for heart failure in a well-defined older population, 1970-1974 and 1990-1994. Circulation. 2006;113(6):799-805.

22. Parashar S, Katz R, Smith NL, Arnold AM, Vaccarino V, Wenger $\mathrm{NK}$, et al. Race, gender, and mortality in adults $\geq 65$ years of age with incident heart failure (from the Cardiovascular Health Study). The American journal of cardiology. 2009;103(8):1120-7.

23. Palazzuoli A, Nuti R. Heart failure: pathophysiology and clinical picture. Contrib Nephrol. 2010;164:1-10.

24. Krum H, Abraham WT. Heart failure. Lancet. 2009;373(9667):941-55.

25. Lim S. Blockade of renin-angiotensin-aldosterone system in kidney and heart disease: how much do we need? Acta Med Indones. 2008;40(1):34-7. 
26. Nieminen MS, Harjola VP. Definition and epidemiology of acute heart failure syndromes. Am J Cardiol. 2005;96(6a):5g-10g.

27. Yancy CW, Jessup M, Bozkurt B, Butler J, Casey DE, Jr., Drazner $\mathrm{MH}$, et al. 2013 ACCF/AHA guideline for the management of heart failure: executive summary: a report of the American College of Cardiology Foundation/American Heart Association Task Force on practice guidelines. Circulation. 2013;128(16):1810-52.

28. Heart Failure. NHS Choices 2012. Available from: http://www. nhs.uk/conditions/Heart-failure/Pages/Introduction.aspx.

29. Mutlak D, Lessick J, Carasso S, Kapeliovich M, Dragu R, Hammerman $\mathrm{H}$, et al. Utility of pulmonary hypertension for the prediction of heart failure following acute myocardial infarction. The American journal of cardiology. 2012;109(9):1254-9.

30. Cleland J, Dargie H, Hardman S, al. e. National heart failure audit April 2012-March 2013. National Institute for Cardiovascular Outcomes Research. 2013.

31. Atherton JJ, Hayward CS, Wan Ahmad WA, Kwok B, Jorge J, Hernandez AF, et al. Patient characteristics from a regional multicenter database of acute decompensated heart failure in Asia Pacific (ADHERE International-Asia Pacific). Journal of cardiac failure. 2012;18(1):82-8.

32. Maggioni AP, Dahlstrom U, Filippatos G, Chioncel O, Crespo Leiro M, Drozdz J, et al. EURObservational Research Programme: regional differences and 1-year follow-up results of the Heart Failure Pilot Survey (ESC-HF Pilot). Eur J Heart Fail. 2013;15(7):808-17.

33. West R, Liang L, Fonarow GC, Kociol R, Mills RM, O'Connor $\mathrm{CM}$, et al. Characterization of heart failure patients with preserved ejection fraction: a comparison between ADHEREUS registry and ADHERE-International registry. Eur J Heart Fail. 2011;13(9):945-52.

34. Adams KF, Jr. Are angiotensin-converting enzyme inhibitors and beta-blockers making an impact on the epidemiology of heart failure? Curr Cardiol Rep. 2004;6(3):162-8.

35. McMurray JJ, Adamopoulos S, Anker SD, Auricchio A, Böhm $M$, Dickstein K, et al. ESC Guidelines for the diagnosis and treatment of acute and chronic heart failure 2012: The Task Force for the Diagnosis and Treatment of Acute and Chronic Heart Failure 2012 of the European Society of Cardiology. Developed in collaboration with the Heart Failure Association (HFA) of the ESC. European heart journal. 2012;33(14):1787847.

36. Hobbs FD, Doust J, Mant J, Cowie MR. Heart failure: Diagnosis of heart failure in primary care. Heart (British Cardiac Society). 2010;96(21):1773-7.

37. National Institute for Health and Clinical Excellence. New NICE guidance will improve diagnosis and treatment of chronic heart failure. 2010.
38. Cohn JN, Tognoni G. A randomized trial of the angiotensinreceptor blocker valsartan in chronic heart failure. The New England journal of medicine. 2001;345(23):1667-75.

39. Granger CB, McMurray JJ, Yusuf S, Held P, Michelson EL, Olofsson B, et al. Effects of candesartan in patients with chronic heart failure and reduced left-ventricular systolic function intolerant to angiotensin-convertingenzyme inhibitors: the CHARM-Alternative trial. Lancet. 2003;362(9386):772-6.

40. Massie BM, Carson PE, McMurray JJ, Komajda M, McKelvie $\mathrm{R}$, Zile MR, et al. Irbesartan in patients with heart failure and preserved ejection fraction. The New England journal of medicine. 2008;359(23):2456-67.

41. Yusuf S, Pfeffer MA, Swedberg K, Granger CB, Held P, McMurray $J$, et al. Effects of candesartan in patients with chronic heart failure and preserved left-ventricular ejection fraction: the CHARM-Preserved Trial. Lancet. 2003;362(9386):777-81.

42. Ledwidge M, Gallagher J, Conlon C, Tallon E, O'Connell E, Dawkins I, et al. Natriuretic peptide-based screening and collaborative care for heart failure: the STOP-HF randomized trial. Jama. 2013;310(1):66-74.

43. Gaasch WH. Diagnosis and treatment of heart failure based on left ventricular systolic or diastolic dysfunction. Jama. 1994;271(16):1276-80.

44. Kotseva K, Wood D, De Backer G, De Bacquer D, Pyorala K, Keil U. EUROASPIRE III: a survey on the lifestyle, risk factors and use of cardioprotective drug therapies in coronary patients from 22 European countries. Eur J Cardiovasc Prev Rehabil. 2009;16(2):121-37.

45. Huffman MD, Capewell S, Ning H, Shay CM, Ford ES, LloydJones DM. Cardiovascular health behavior and health factor changes (1988-2008) and projections to 2020: results from the National Health and Nutrition Examination Surveys. Circulation. 2012;125(21):2595-602.

46. Cleland JG, Cohen-Solal A, Aguilar JC, Dietz R, Eastaugh J, Follath $\mathrm{F}$, et al. Management of heart failure in primary care (the IMPROVEMENT of Heart Failure Programme): an international survey. Lancet. 2002;360(9346):1631-9.

47. Allender S, Peto V, Scarborough P, Kaur A, Rayner M. Coronary heart disease statistics. London: British Heart Foundation; 2008.

48. Mehta PA, Dubrey SW, Mclntyre HF, Walker DM, Hardman SM, Sutton GC, et al. Improving survival in the 6 months after diagnosis of heart failure in the past decade: populationbased data from the UK. Heart (British Cardiac Society). 2009;95(22):1851-6.

49. Davies M, Hobbs F, Davis R, Kenkre J, Roalfe AK, Hare R, et al. Prevalence of left-ventricular systolic dysfunction and heart failure in the Echocardiographic Heart of England Screening study: a population based study. Lancet. 2001;358(9280):439-44. 
50. Royal College of Physicians. Managing chronic heart failure: learning from best practice. . London.: Clinical Effectiveness and Evaluation Unit, Royal College of Physicians., 2005.

51. Carmona M, Garcia-Olmos LM, Alberquilla A, Munoz A Garcia-Sagredo P, Somolinos R, et al. Heart failure in the family practice: a study of the prevalence and co-morbidity. Fam Pract. 2011;28(2):128-33.

52. Anguita Sanchez M, Crespo Leiro MG, de Teresa Galvan E, Jimenez Navarro M, Alonso-Pulpon L, Muniz Garcia J. Prevalence of heart failure in the Spanish general population aged over 45 years. The PRICE Study. Rev Esp Cardiol. 2008;61(10):1041-9.

53. Gomez-Soto FM, Andrey JL, Garcia-Egido AA, Escobar MA, Romero SP, Garcia-Arjona R, et al. Incidence and mortality of heart failure: a community-based study. International journal of cardiology. 2011;151(1):40-5.

54. Sayago-Silva I, Garcia-Lopez F, Segovia-Cubero J. Epidemiology of heart failure in Spain over the last 20 years. Rev Esp Cardiol (Engl Ed). 2013;66(8):649-56.

55. Mureddu GF, Agabiti N, Rizzello V, Forastiere F, Latini R, Cesaroni $G$, et al. Prevalence of preclinical and clinical heart failure in the elderly. A population-based study in Central Italy. European journal of heart failure. 2012;14(7):718-29.

56. Saudubray T, Saudubray C, Viboud C, Jondeau G, Valleron AJ, Flahault $A$, et al. [Prevalence and management of heart failure in France: national study among general practitioners of the Sentinelles network]. Rev Med Interne. 2005;26(11):845-50.

57. Tiller D, Russ $\mathrm{M}$, Greiser $\mathrm{KH}$, Nuding $\mathrm{S}$, Ebelt $\mathrm{H}$, Kluttig $\mathrm{A}$, et al. Prevalence of symptomatic heart failure with reduced and with normal ejection fraction in an elderly general populationthe CARLA study. PLoS One. 2013;8(3):e59225.

58. Neumann T, Biermann J, Erbel R, Neumann A, Wasem J, Ertl $G$, et al. Heart failure: the commonest reason for hospital admission in Germany: medical and economic perspectives. Dtsch Arztebl Int. 2009;106(16):269-75.

59. Kuznetsova T, Herbots L, Lopez B, Jin Y, Richart T, Thijs L, et al. Prevalence of left ventricular diastolic dysfunction in a general population. Circ Heart Fail. 2009;2(2):105-12.

60. Bleumink GS, Knetsch AM, Sturkenboom MC, Straus SM Hofman A, Deckers JW, et al. Quantifying the heart failure epidemic: prevalence, incidence rate, lifetime risk and prognosis of heart failure The Rotterdam Study. Eur Heart J. 2004;25(18):1614-9.

61. Cline CM, Boman $\mathrm{K}$, Holst M, Erhardt LR. The management of heart failure in Sweden. Eur J Heart Fail. 2002;4(3):373-6.

62. Sakata Y, Shimokawa H. Epidemiology of heart failure in Asia. Circ J. 2013;77(9):2209-17.

63. Huffman MD, Prabhakaran D. Heart failure: epidemiology and prevention in India. Natl Med J India. 2010;23(5):283-8.
64. Sasayama S. Heart disease in Asia. Circulation 2008;118(25):2669-71.

65. Bocchi EA. Heart failure in South America. Curr Cardiol Rev. 2013;9(2):147-56

66. Bocchi EA, Braga FG, Ferreira SM, Rohde LE, Oliveira WA, Almeida DR, et al. [III Brazilian Guidelines on Chronic Heart Failure]. Arq Bras Cardiol. 2009;93(1 Suppl 1):3-70.

67. Damasceno A, Mayosi BM, Sani M, Ogah OS, Mondo C, Ojji $D$, et al. The causes, treatment, and outcome of acute heart failure in 1006 Africans from 9 countries. Arch Intern Med. 2012;172(18):1386-94.

68. Thienemann F, Sliwa K, Rockstroh JK. HIV and the heart: the impact of antiretroviral therapy: a global perspective. Eur Heart J. 2013;34(46):3538-46.

69. Fonarow GC, Heywood JT, Heidenreich PA, Lopatin M, Yancy $\mathrm{CW}$. Temporal trends in clinical characteristics, treatments, and outcomes for heart failure hospitalizations, 2002 to 2004: findings from Acute Decompensated Heart Failure National Registry (ADHERE). Am Heart J. 2007;153(6):1021-8.

70. Saczynski JS, Go AS, Magid DJ, Smith DH, McManus DD, Allen $\mathrm{L}$, et al. Patterns of comorbidity in older adults with heart failure: the Cardiovascular Research Network PRESERVE study. J Am Geriatr Soc. 2013;61(1):26-33.

71. Lassus JP, Siirila-Waris K, Nieminen MS, Tolonen J, Tarvasmaki T, Peuhkurinen $\mathrm{K}$, et al. Long-term survival after hospitalization for acute heart failure - differences in prognosis of acutely decompensated chronic and new-onset acute heart failure. Int J Cardiol. 2013;168(1):458-62.

72. Maggioni AP, Dahlstrom U, Filippatos G, Chioncel O, Leiro MC, Drozdz J, et al. EURObservational Research Programme: the Heart Failure Pilot Survey (ESC-HF Pilot). Eur J Heart Fail. 2010;12(10):1076-84

73. Korves C, Mchale J, Lafeuille M, Ariely R, M. SD. Hospitalization due to heart failure is associated with significant medical resource utilization and costs. In: AHA-QCOR Ppa, editor. 2010.

74. Kociol RD, Hammill BG, Fonarow GC, Klaskala W, Mills RM Hernandez AF, et al. Generalizability and longitudinal outcomes of a national heart failure clinical registry: Comparison of Acute Decompensated Heart Failure National Registry (ADHERE) and non-ADHERE Medicare beneficiaries. American heart journal. 2010;160(5):885-92.

75. Nieminen MS, Harjola VP, Hochadel $\mathrm{M}$, Drexler $\mathrm{H}$, Komajda $M$, Brutsaert $D$, et al. Gender related differences in patients presenting with acute heart failure. Results from EuroHeart Failure Survey II. Eur J Heart Fail. 2008;10(2):140-8.

76. Healthcare Cost and Utilization Project [Internet]. 2008 Available from: http://www.ahrq.gov/data/hcup/.

77. Hospital Episode Statistics. [Internet]. 2008. Available from: http://www.hesonline.nhs.uk. 
78. Statistiques PMSI [Internet]. 2008. Available from: http://www. atih.sante.fr/index.php. .

79. Berry C, Murdoch DR, McMurray JJ. Economics of chronic heart failure. European Journal of Heart Failure. 2001;3(3):283-91.

80. Stewart S, Jenkins A, Buchan S, McGuire A, Capewell S, McMurray JJ. The current cost of heart failure to the National Health Service in the UK. European Journal of Heart Failure. 2002;4(3):361-71.

81. Sutherland KB. Bridging the quality gap: heart failure. London The Health Foundation, 2010.

82. National Health Service. National Heart Failure Audit - Second report for the audit period between July 2007 and March 2008. (2007-2008)

83. Jaarsma T, Haaijer-Ruskamp FM, Sturm H, Van Veldhuisen DJ. Management of heart failure in The Netherlands. Eur J Heart Fail. 2005;7(3):371-5.

84. Meerding WJ, Bonneux L, Polder JJ, Koopmanschap MA, van der Maas PJ. Demographic and epidemiological determinants of healthcare costs in Netherlands: cost of illness study. Bmj. 1998;317(7151):111-5.

85. Antonanzas Villar F, Anton Botella F, Juarez Castello CA, Echevarria Echarri L. [Costs of chronic heart failure in spain]. An Med Interna. 1997;14(1):9-14.

86. Hart WM, Rubio-Terres C, Pajuelo F, Gonzalez Juanatey JR. Cost-effectiveness of the treatment of heart failure with ramipril: a Spanish analysis of the AIRE study. Eur $J$ Heart Fail. 2002:4(4):553-8.

87. Ryden-Bergsten T, Andersson F. The health care costs of heart failure in Sweden. J Intern Med. 1999;246(3):275-84.

88. Agvall B, Borgquist L, Foldevi M, Dahlstrom U. Cost of heart failure in Swedish primary healthcare. Scand J Prim Health Care. 2005;23(4):227-32.

89. Malaquin D, Tribouilloy C. [Epidemiology of heart failure]. Rev Prat. 2010;60(7):911-5.

90. Gigli G, Lispi L, Donati C, Orlandi S, Vallebona A, Gigli L, et al. Trends in hospitalization for heart failure in Italy 2001-2003. $J$ Cardiovasc Med (Hagerstown). 2009;10(5):367-71.

91. Braunschweig F, Cowie MR, Auricchio A. What are the costs of heart failure? Europace. 2011;13 Suppl 2:ii13-7.

92. Lloyd-Jones D, Adams RJ, Brown TM, Carnethon M, Dai S, De Simone G, et al. Heart disease and stroke statistics-2010 update $A$ report from the American Heart Association. Circulation. 2010;121(7):e46-e215.
93. Mital A, Shrey D, Govindaraju M, Broderick T, Colon-Brown K, Gustin B. Job-simulated phase II cardiac rehabilitation training program: Part A. A comparison with conventional phase II cardiac rehabilitation training program. International journal of industrial ergonomics. 1999;24(5):515-29.

94. Department of Health and Children. Changing Cardiovascular Health. National Cardiovascular Health Policy 2010-2019. Dublin: Government Publications, 2010.

95. O'Shea E, Kennelly B. The economics of mental health care in Ireland. 2008

96. Connolly S, Gillespie P, O'Shea E, Cahill S, Pierce M. Estimating the economic and social costs of dementia in Ireland. Dementia. 2014;13(1):5-22.

97. Behan C, Kennelly B, O'Callaghan E. The economic cost of schizophrenia in Ireland: a cost of illness study. Irish Journal of Psychological Medicine. 2008;25(3):80-7.

98. Economic Social and Research Institute. Cost of Stroke in Ireland: Estimating the Annual Economic Cost of Stroke and TIA in Ireland. Dublin: The Irish Heart Foundation, 2010

99. Raftery MN, Ryan P, Normand C, Murphy AW, de la Harpe $D, M c G u i r e$ BE. The economic cost of chronic noncancer pain in Ireland: results from the PRIME study, part 2. J Pain. 2012;13(2):139-45.

100. Gannon B, O'Shea E, Hudson E. Economic consequences of falls and fractures among older people. Irish medical journal. 2008;101(6):170-3. 


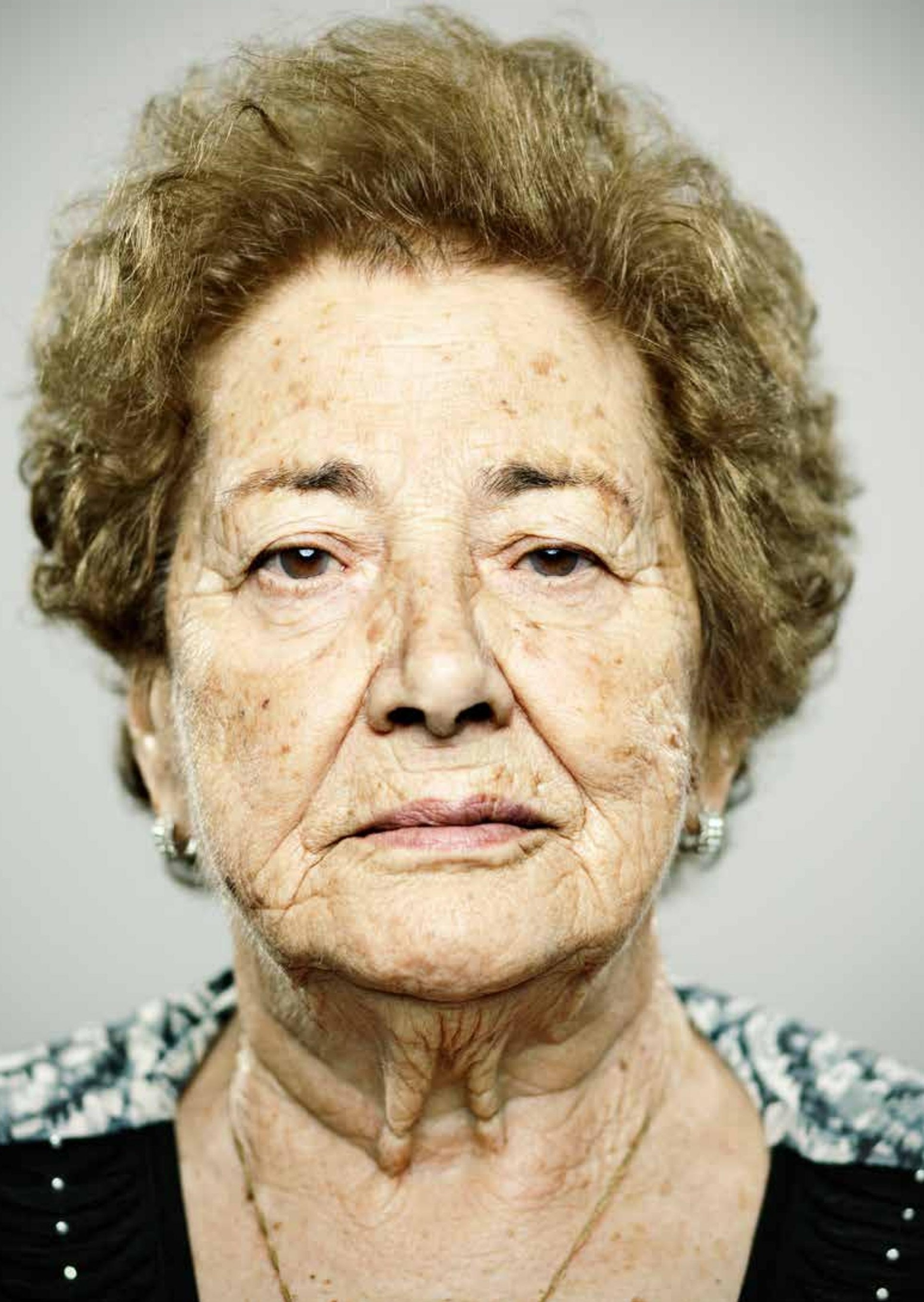


Heartbeat Trust 